\title{
Composição de fluxos de controle de frameworks java
}

\author{
Bruno Martins Moutinho
}

\author{
DISSERTAÇÃO APRESENTADA \\ AO \\ INSTITUTO DE MATEMÁTICA E ESTATÍSTICA \\ DA \\ UNIVERSIDADE DE SÃO PAULO \\ PARA \\ OBTENÇÃO DO TÍTULO DE MESTRE \\ $\mathrm{EM}$ \\ CIÊNCIA DA COMPUTAÇÃO
}

Área de concentração: Ciëncia da Computação

Orientadora: Profa. Dra. Ana Cristina Vieira de Melo

Durante parte da elaboração deste trabalho o autor recebeu apoio financeiro da CAPES

- São Paulo, Outubro de 2001 - 


\title{
Composição de fluxos de controle de frameworks java
}

\author{
Bruno Martins Moutinho
}

Este exemplar corresponde à redação final da dissertação devidamente corrigida e defendida por Bruno Martins Moutinho e aprovada pela comissão julgadora.

São Paulo, 23 de Outubro de 2001

\section{Banca Examinadora}

- Prof. Dra Ana Cristina Veira de Melo (Orientadora) IME-USP

- Francisco Carlos Rocha Reverbel

- Augusto Cezar Alves Sampaio

IME-USP

UFPE 


\section{RESUMO}

Um dos principais motivos para se utilizar frameworks é a reutilização de software, alcançando com isso reutilização de código e design. Hoje, o desenvolvimento de aplicação baseado em frameworks está mudando de baseado em um único framework para baseado em múltiplos frameworks. Contudo, a maioria dos frameworks não foi projetada para ser composta com outros frameworks ou componentes (biblioteca de classes, componentes legados ou design patterns), mas para ser reutilizado individualmente. Então, quando frameworks são compostos, surgem problemas tais como: composição de fluxo de controle; composição com sistemas legados; frameworks gap; sobreposição de entidades e composição de funcionalidade de entidade [1].

Este trabalho trata dos problemas que podem acontecer durante a composição de fluxo de controle de frameworks construídos utilizando a linguagem Java. A forma de comunicação entre os frameworks está limitada à troca de mensagens. Foram definidas quatro formas de composições: sem composição; seqüencial, unidirecional e bidirecional. Para cada forma de composição foram levantados os problemas que podem acontecer durante a composição do fluxo de controle.

Para cada problema foram analisados: suas causas; conseqüências; forma de deteç̧ão e algumas sugestões. Baseado nessas informações, foi desenvolvida uma ferramenta de diagnóstico. Tal ferramenta verifica, a partir de dois frameworks e da forma de composição desejada, que tipos de problemas podem acontecer, onde eles podem acontecer e uma possível sugestão para o problema.

Palavras Chaves: Frameworks; Reutilização de Frameworks; Composição de Frameworks; Composição de Fluxo de Controle de Frameworks e Frameworks Java. 


\section{ABSTRACT}

One of the main reasons to use frameworks is software reuse, obtaining with this code and design reuse. Today, the framework-based application development is changing from based on single framework to based on multiple frameworks. However, most of the frameworks were not designed to be composed with other frameworks or components (class library, legacy components or design patterns), but to be reused individually. Then, when frameworks are composed, several problems appear, related to: compositions of framework control, composition with legacy components, framework gap, overlap of framework entities and composition of entity functionality.

This work treats the problems that can happen during the composition of flow of control of frameworks using the Java language. The communication form among the frameworks is limited to message passing. It was defined four forms of compositions based on message passing: without composition; sequential, unidirectional and bidirectional. For each composition form the problems that can happen during the composition of the control flow were raised.

For each problem it was analyzed: its causes; consequences; detection form and some suggestions. Based on that information, a diagnosis tool was developed. Such tool verifies, starting from two frameworks and from the desired form of composition, the types of problems that can happen, where they can happen and a possible suggestion for the problem.

Keywords: Frameworks; Frameworks Reuse; Frameworks Composition; Çomposition of frameworks control, and Java Frameworks. 


\section{Sumário}

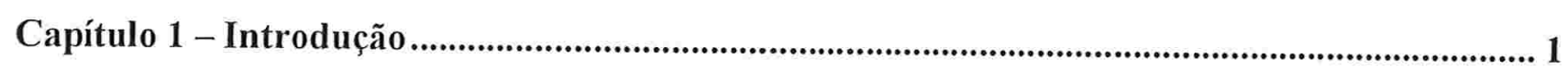

1.1 - Relação de Frameworks com Outras Formas de Reutilização .......................................... 2

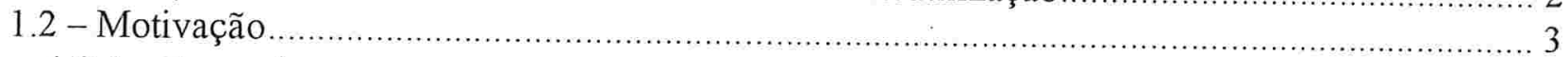

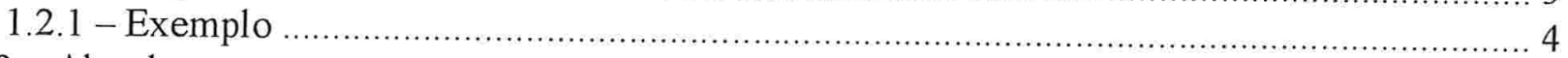

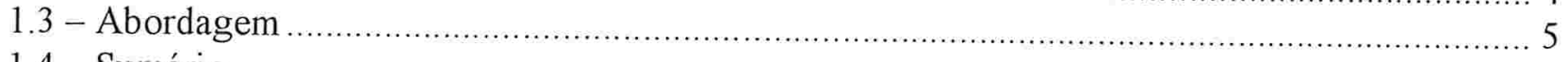

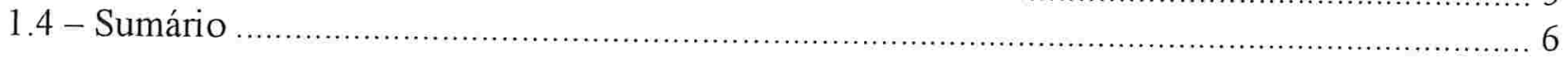

Capítulo 2 - Reutilização de Frameworks .................................................................................... 8

2.1 - Reutilização de Design OO ............................................................................... 8

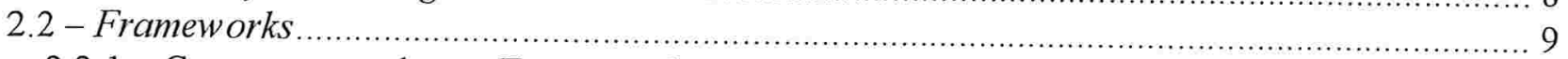

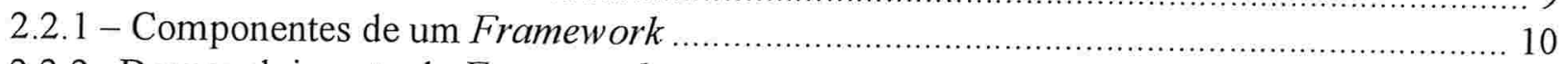

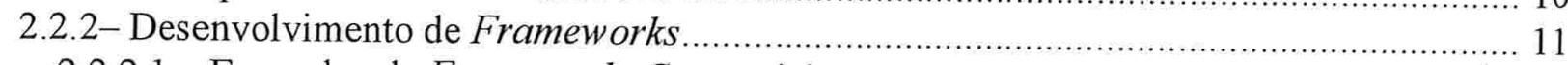

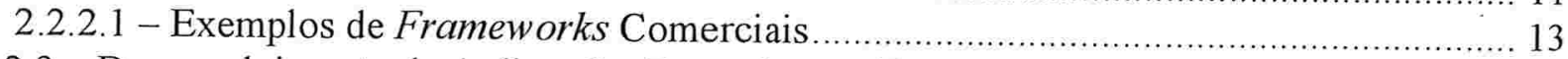

2.2.3 - Desenvolvimento de Aplicações Baseadas em Frameworks .............................................. 14

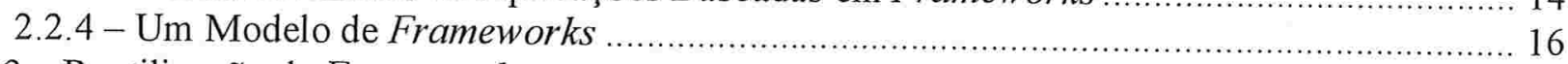

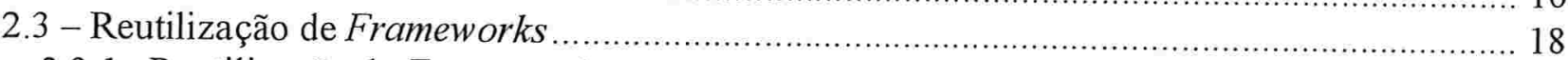

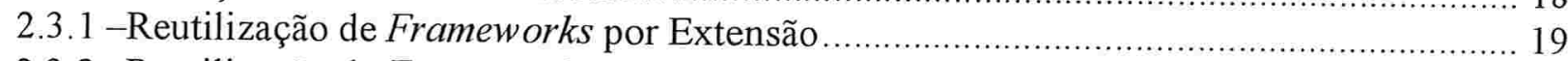

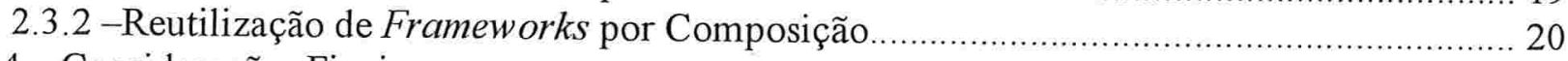

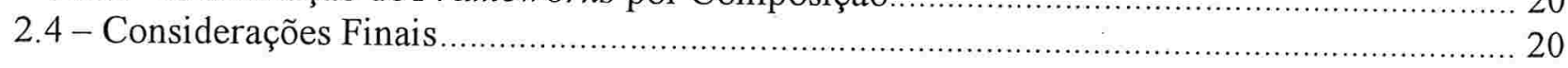

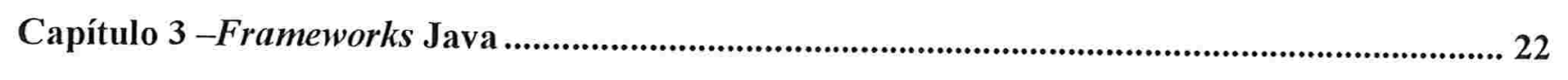

3.1 - Java Como uma Linguagem para Construção de Frameworks .......................................... 22

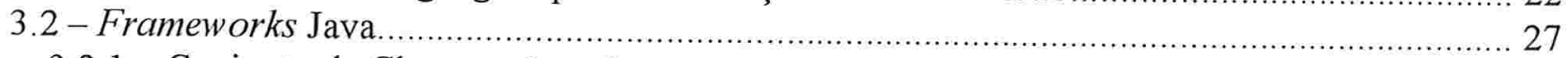

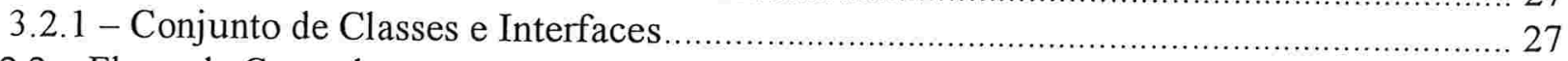

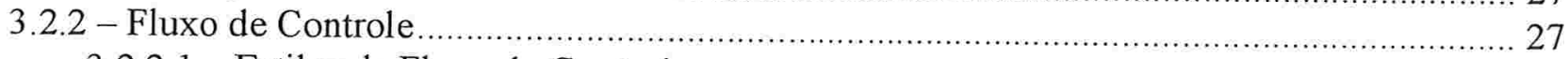

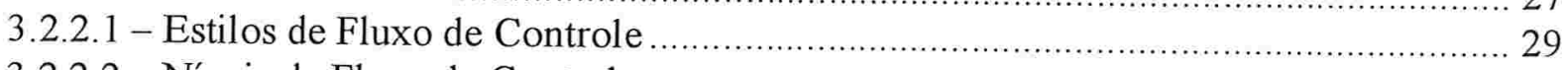

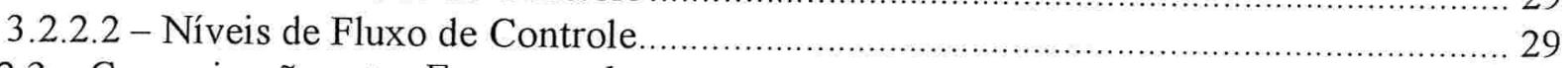

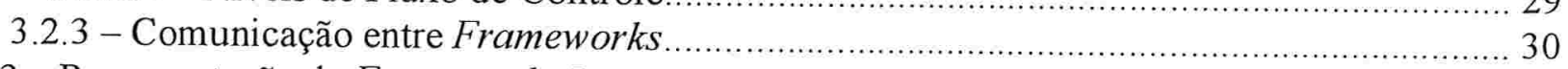

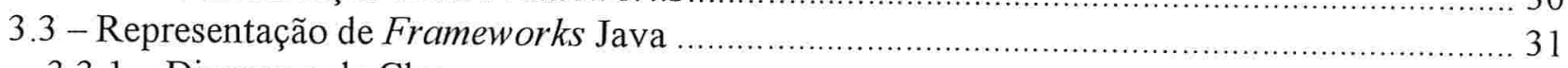

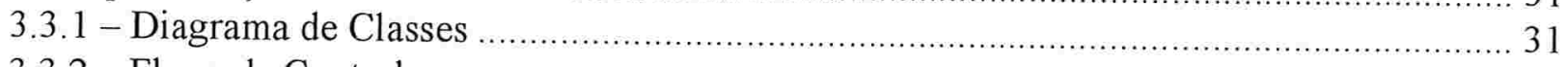

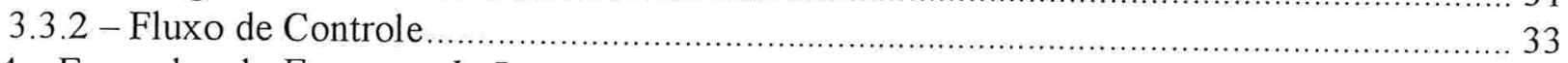

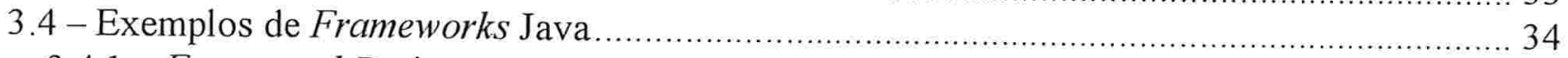

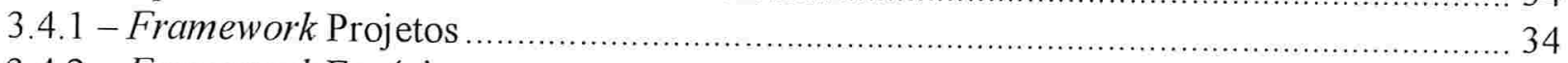

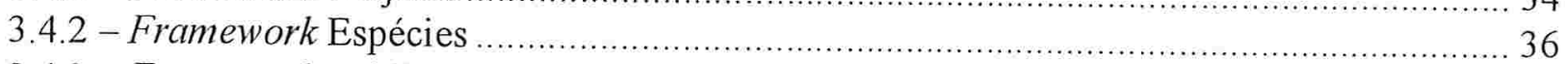

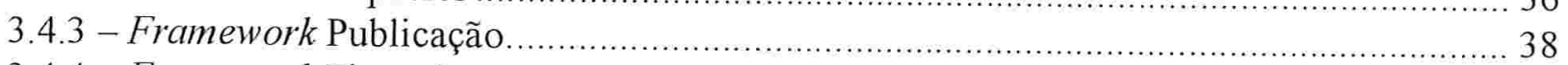

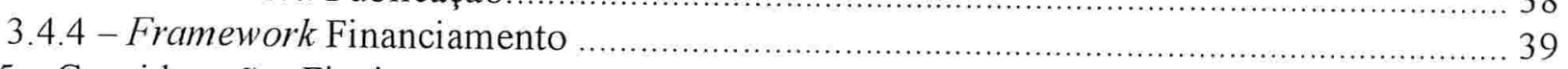

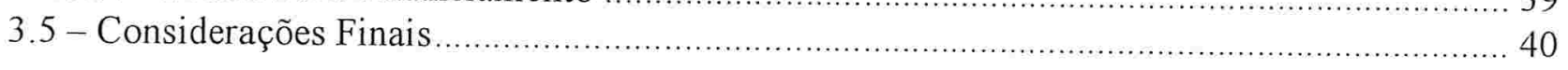

Capítulo 4 - Composição de Fluxos de Controle de Frameworks............................................... 42

4.1 - Composição de Software OO ................................................................................ 42

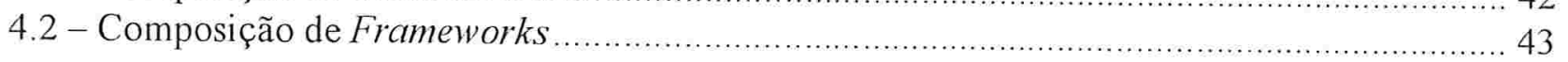


4.2.1 - Problemas e Causas

4.3 - Composição de Fluxos de Controle de Frameworks ..................................................... 48

4.3.1 - Tipos de Composição de Fluxo de Controle ............................................................. 49

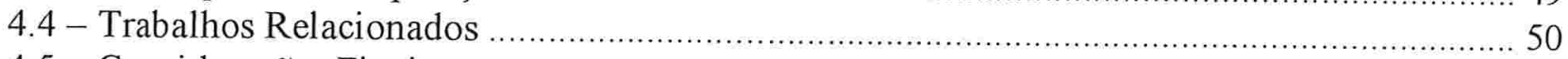

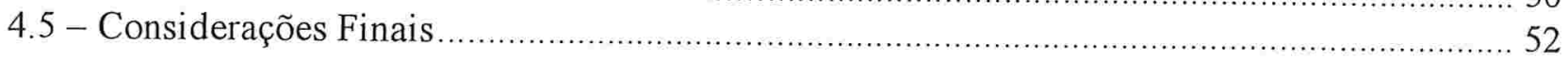

\section{Capítulo 5 - Composição de Fluxos de Controle de Frameworks Java Baseada em Troca de}

\section{Mensagens}

5.1 - Escopo do Trabalho.

5.2 - Composição de Frameworks Java.

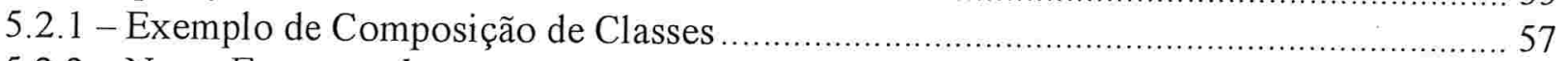

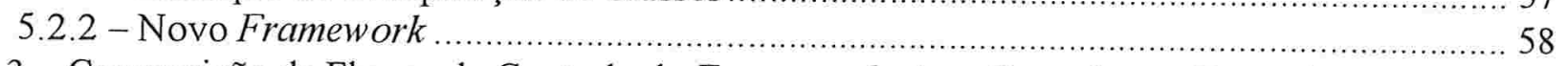

5.3 - Composição de Fluxos de Controle de Frameworks Java Baseada em Troca de Mensagens

5.3.1 - Novos Elementos.

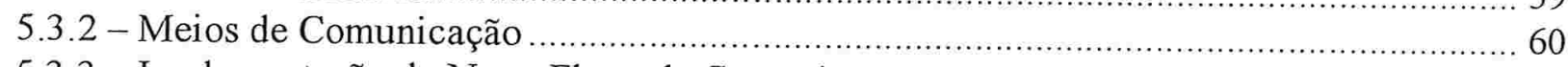

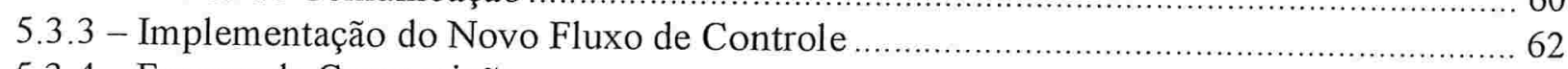

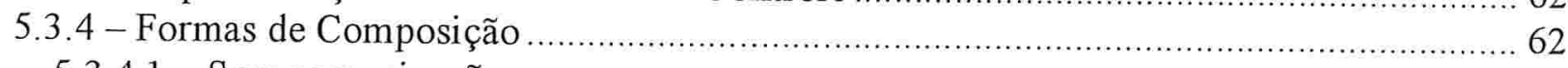

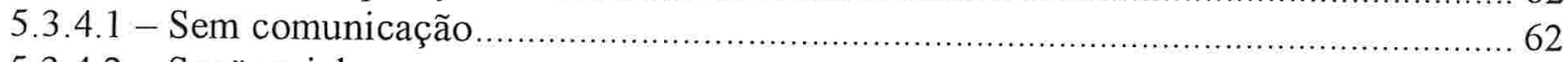

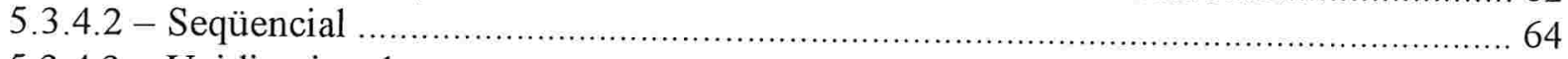

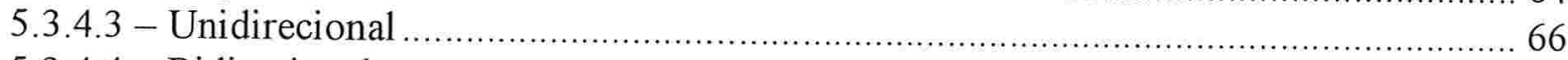

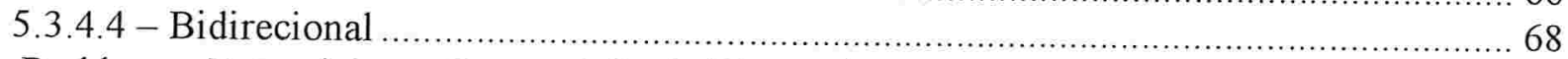

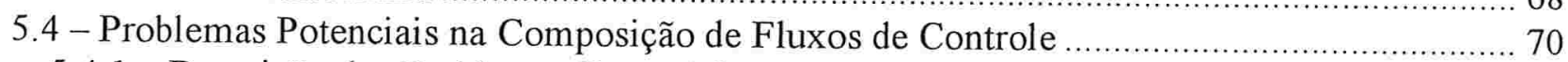

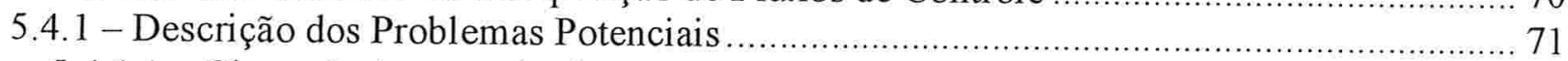

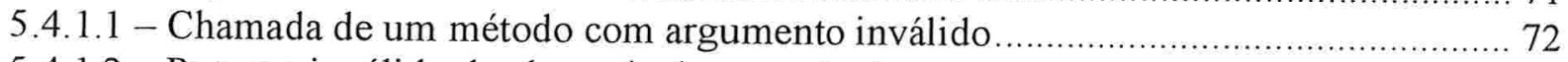

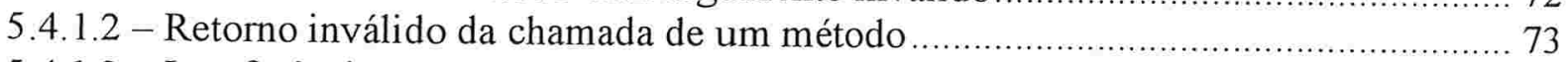

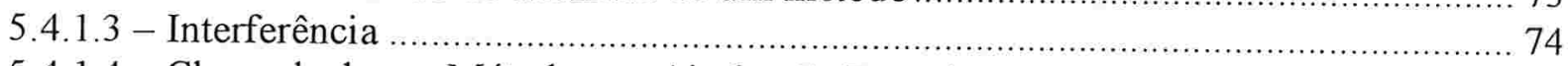

5.4.1.4 - Chamada de um Método que Ainda não Deveria ser Executado (pré-condiçõos do

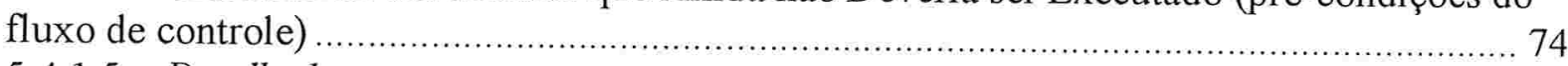

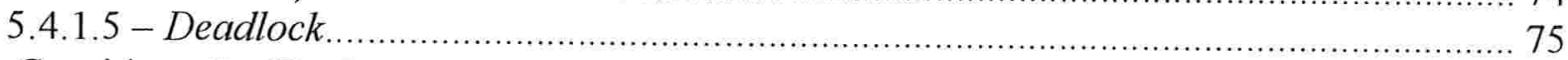

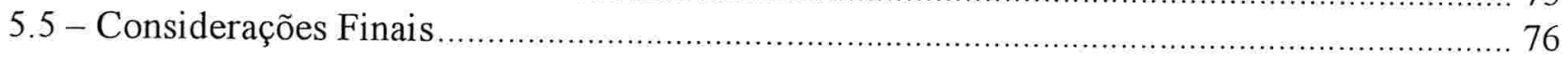

Capítulo 6 - Ferramenta para Composição de Fluxos de Controle de Frameworks Java ........ 79

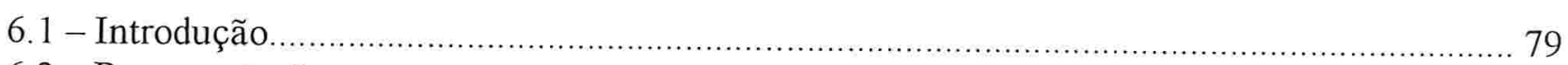

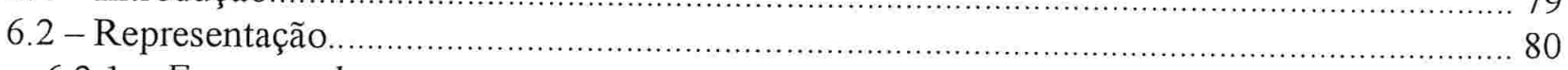

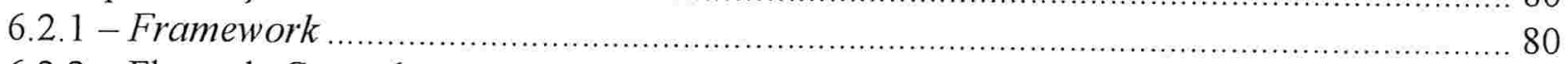

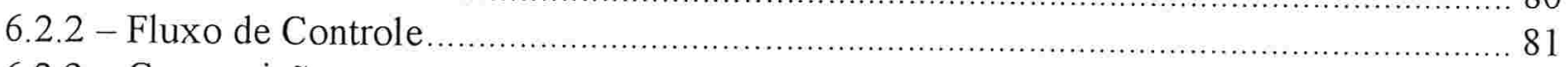

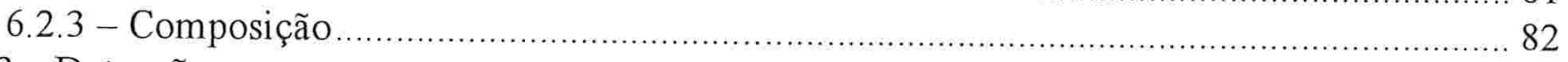

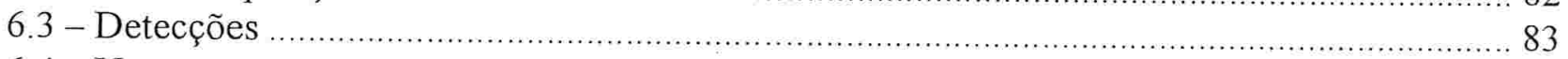

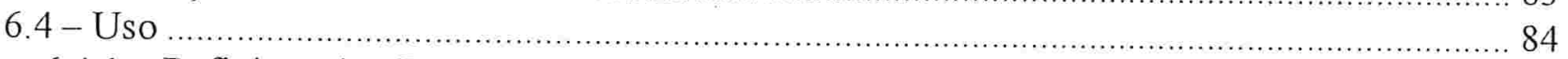

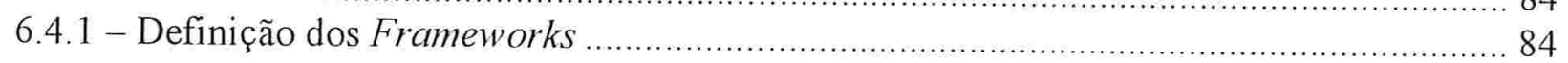

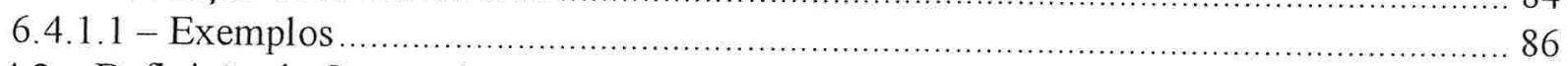

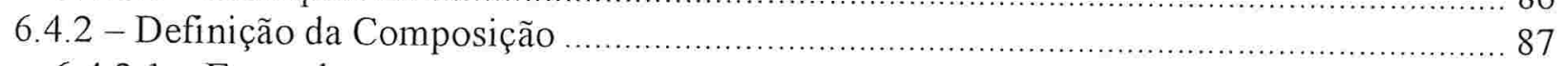

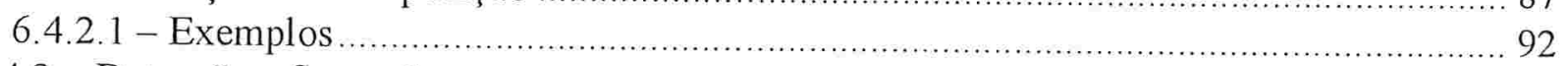

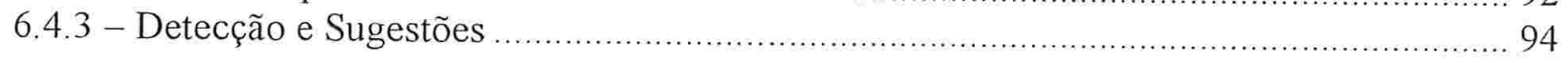


6.4.3.1 -Exemplos.

Capítulo 7 - Conclusões.

7.1 - Contribuições 99

7.2 - Comparação com outras Abordagens.. 100

7.2.1 - Considerações 101

7.3 - Trabalhos Futuros 102

Bibliografia

Apêndice A - Exemplos de Composição dos Frameworks Java. 107

A. 1 - Projeto + Financiamento

A. 2 - Projeto + Publicação

A.3 - Projeto + Espécie

A.4-Publicação+ Espécie. 


\section{Lista de Figuras}

Figura 2.1: Desenvolvimento de Aplicações baseada em frameworks [18]. .................................. 14

Figura 2.2: Componentes de uma aplicação baseada em framework [18] ................................... 15

Figura 2.3: Modelo de Frameworks [33] ........................................................................ 17

Figura 2.4: Duas visões de reutilização [34] ........................................................................... 19

Figura 3.1: Modelo de Controle em Frameworks .................................................................... 28

Figura 3.2: Níveis de Fluxo de Controle em Frameworks [20] .............................................. 30

Figura 3.3 - Representação do Diagrama de Classes em UML [41] …......................................... 32

Figura 3.4 - Representação Gráfica do Fluxo de Controle ............................................................ 34

Figura 3.5: Diagrama de Classes para o Framework Projetos .................................................... 35

Figura 3.6: Fluxo de Controle para o Framework Projetos....................................................... 36

Figura 3.7: Diagrama de Classes para o Framework Espécies ................................................. 37

Figura 3.8: Fluxo de Controle para o Framework Espécies......................................................... 37

Figura 3.9: Diagrama de Classes para Framework Publicação................................................... 38

Figura 3.10: Fluxo de Controle para o Framework Publicação ....................................................... 38

Figura 3.11: Diagrama de Classes para Framework Financiamento .............................................. 39

Figura 3.12: Fluxo de Controle para o Framework Financiamento ............................................ 40

Figura 4.1: Composição de Frameworks [49] ..................................................................... 44

Figura 4.2: Colisão de laços quando se compõe fluxo de controle em frameworks [51] ................ 49

Figura 5.1: Composição de Frameworks Java ......................................................................... 56

Figura 5.2: Composição de Fluxo de Controle Frameworks Java .................................................. 59

Figura 5.3: Diagrama de Classes para a Composição Projeto + Financiamento.............................. 63

Figura 5.4: Fluxo de Controle para a Composição Projeto + Financiamento ................................... 64

Figura 5.5: Diagrama de Classes para a Composição Projeto + Publicação ...................................... 65

Figura 5.6: Fluxo de Controle para a Composição Projeto + Publicação ....................................... 66

Figura 5.7: Diagrama de Classes para a Composição Projeto + Espécie ........................................... 67

Figura 5.8: Fluxo de Controle para a Composição Projeto + Espécie ............................................ 68

Figura 5.9: Diagrama de Classes para a Composição Publicação + Espécie .................................... 69

Figura 5.10: Fluxo de Controle para a Composição Publicação + Espécie ....................................... 70

Figura 6.1: Diagrama de classes para a ferramenta .......................................................... 81 
Figura 6.2: Formulário de definição do framework Projeto.

Figura 6.3: Formulário de definição da Classe Controladora para o framework Projeto. 86

Figura 6.4: Formulário de definição da composição. 88

Figura 6.5: Formulário de definição do novo fluxo de controle-Passo 1. 89

Figura 6.6: Formulários de Extensões do fluxo de controle 90

Figura 6.7: Formulário de definição do novo fluxo de controle - Passo 2. 91

Figura 6.8: Formulário dos problemas encontrados e sugestões. 94

Figura A.1: Diagrama de Classes para a Composição Projeto + Financiamento. 107

Figura A.2: Fluxo de Controle para a Composição Projeto + Financiamento 108

Figura A.3: Diagrama de Classes para a Composição Projeto + Publicação 109

Figura A.4: Fluxo de Controle para a Composição Projeto + Publicação 110

Figura A.5: Diagrama de Classes para a Composição Projeto + Espécie 111

Figura A.6: Fluxo de Controle para a Composição Projeto + Espécie 113

Figura A.7: Diagrama de Classes para a Composição Publicação + Espécie 114

Figura A.8: Fluxo de Controle para a Composição Publicação + Espécie 



\title{
Capítulo 1 - Introdução
}

\begin{abstract}
Software tem sido o fator dominante no custo de desenvolvimento de sistemas baseados em computador. Como os sistemas estão se tornando cada vez maiores e mais complexos, os engenheiros de software estão buscando mecanismos para controlar essa complexidade. Os principais objetivos são: o aumento da produtividade e a diminuição do custo de desenvolvimento. Muitos dos paradigmas de programação têm sido anunciadores da solução para tais problemas. O paradigma orientado a procedimentos e a programação estruturada foram, ambos, populares durante algum tempo. Mas hoje, indicadores apontam para a orientação a objetos $(\mathrm{OO})$ como uma solução promissora [1 e 2]. Um dos principais benefícios da 00 é a reutilização de software.
\end{abstract}

A reutilização de software, em contrapartida ao desenvolvimento de aplicações desde o início, é vista como um princípio que pode levar ao aumento da produtividade do desenvolvimento de software, na medida em que o uso de elementos de software já desenvolvidos e depurados reduz o tempo de desenvolvimento, de testes e as possibilidades de introdução de erros ao longo do desenvolvimento. Anteriormente, a reutilização estava apenas associada à reutilização de código através da chamada de rotinas de bibliotecas de procedimentos, realizada na fase de implementação do sistema. Entretanto, essa é uma forma limitada de reutilização. Maiores benefícios podem ser obtidos quando a reutilização é aplicada também às fases de análise e design no desenvolvimento de software.

A produção de elementos de software reutilizáveis se coloca como um requisito para que ocorra reutilização de software. Nesse aspecto, a OO ajuda aos engenheiros de software na construção de componentes de software, através dos seus princípios como: modularidade; herança; composição; encapsulamento e ligação dinâmica. A principal razão pela qual os sistemas $\mathrm{OO}$ estão sendo bem sucedidos na reutilização de software é a maneira pela qual eles são projetados: enfatizando a parte de design [2]. Mas apenas com a $\mathrm{OO}$ não se consegue altos níveis de reutilização. É necessária uma representação mais abstrata do projeto que junta várias partes do projeto ao invés de se ter algumas classes soltas; tal representação abstrata é chamada de framework. 
Frameworks orientados a objetos ${ }^{1}$ reutilizam design e implementação de software (código) a fim de reduzir o custo e aumentar a qualidade do software. Um framework é uma aplicação semi-completa reutilizável, que pode ser especializada para produzir aplicações personalizadas; eles são específicos para um domínio de aplicação enfatizando a reutilização de código e design. A reutilização de código é possível porque o framework facilita o desenvolvimento de bibliotecas de componentes, as quais herdam grande parte das implementações das superclasses abstratas que fazem parte do framework. A reutilização de design é possível porque ele descreve algoritmos abstratos e as interfaces das classes que o projetista deve implementar e contém restrições que as implementações devem respeitar. A habilidade do framework de permitir a extensão de componentes existentes é uma das suas principais características [2].

Frameworks são uma maneira pela qual os sistemas orientados a objetos conseguem uma reutilização de design. Aplicações orientadas a objetos maiores terminarão por consistir de camadas de frameworks que cooperam entre si e com outros componentes. A maior parte do projeto e do código da aplicação virá dos, ou será influenciada pelos, frameworks que utiliza.

\section{1 - Relação de Frameworks com Outras Formas de Reutilização}

Frameworks são uma forma de reutilizar design e código e têm relações com outras formas de reutilização, a saber: patterns; biblioteca de classes; componentes e uma aplicação orientada a objetos [3].

a) Patterns: representam soluções de problemas recorrentes no desenvolvimento de software em um determinado contexto [4]. A diferença básica entre eles e frameworks, é que os últimos focam a reutilização de designs concretos, algoritmos e implementações em uma linguagem de programação particular, enquanto patterns focam reutilização de designs abstratos e micro-arquiteturas de software. Patterns podem ser vistos como elementos de micro-arquiteturas mais abstratos do framework, os quais documentam e motivam sua semântica de uma maneira efetiva [3]. Design patterns têm sido utilizados com sucesso na documentação [5] e no desenvolvimento de frameworks [6, 7 e 37].

b) Bibliotecas de classes: frameworks estendem os beneficios das bibliotecas de classes de duas maneiras: (i) frameworks definem aplicações semicompletas específicas de domínio, enquanto que bibliotecas de classes

\footnotetext{
${ }^{1}$ Este trabalho trata apenas de framework orientado a objetos e durante o restante do texto será chamado de framework.
} 
são menos específicas de domínio e fornecem um menor escopo de reutilização; e (ii) frameworks gerenciam o fluxo de controle dentro da aplicação (inversão de controle), enquanto que bibliotecas de classes são tipicamente passivas, isto é, não gerenciam o fluxo de controle. Na prática, frameworks e bibliotecas de classes são tecnologias complementares.

c) Componentes: são instâncias de tipos abstratos de dados que podem ser compostos com outros componentes para formar aplicações completas. Em termos de design OO, um componente é uma entidade "caixa preta" que define um conjunto de operações coesivas e pode ser reutilizado tendo somente conhecimento da sintaxe e semântica da sua interface. O relacionamento entre frameworks e componentes é altamente sinérgico [2]. Em geral, frameworks são usados para simplificar o desenvolvimento de infraestrutura, enquanto que componentes são usados para simplificar o desenvolvimento de aplicações para usuários finais [7].

d) Uma aplicação orientada a objeto: descreve a execução de um programa que atende aos requisitos de uma dada especificação. No entanto, um framework captura as funcionalidades de diversas aplicações no domínio, mas não é executável, já que não cobre o comportamento de uma aplicação específica.

Framework está no meio das técnicas de reutilização. É é mais abstrato e flexível do que componente, mas mais concreto e mais fácil de reutilizar do que um pattern puro, porém, menos flexível e menos provável de ser aplicável [7].

\section{2 - Motivação}

Atualmente, experiências significativas de reutilização de design envolvem a utilização de frameworks, ao invés de componentes isolados de software. Objetos e classes são blocos de construção de software muito pequenos para se alcançar altos níveis de reaproveitamento. Frameworks são blocos de construção bem maiores do que objetos e classes, eles definem coleções de classes colaborativas, permitindo a reutilização de design e código. Experiências de sucesso na reutilização de frameworks podem ser encontradas em [8,9, 10, 11, 32, 44, 46, 61 e 64]. O desenvolvimento de aplicações baseadas em frameworks, depois de um período de aprendizado, diminui o custo e o esforço de desenvolvimento, por isso frameworks têm valor comercial $[2,7,18$ e 19]. 
O desenvolvimento tradicional de aplicações baseadas em frameworks está centrado em um único framework, o qual é estendido cobrindo partes específicas da aplicação. Nos últimos anos, temos visto que o desenvolvimento de aplicações é freqüentemente baseado em múltiplos frameworks $[1,12,36,42,50,51 \mathrm{e}$ 52]. Quando usado em conjunto com outros componentes, frameworks podem aumentar significativamente a qualidade e reduzir o esforço de desenvolvimento de software. Porém, alguns desafios precisam ser vencidos para se reutilizar frameworks efetivamente. Um desses desafios é o processo de composição de frameworks com outros componentes.

Composição é um tópico importante para a reutilização efetiva de frameworks, uma vèz que hoje a maioria das aplicações é baseada em vários componentes: frameworks; bibliotecas de classes; componentes legados e design patterns [1, 50 e 51]. Torna-se, dessa forma, necessário o desenvolvimento de técnicas que auxiliem a integração de tais componentes em uma aplicação ou para a criação de novos componentes.

Os problemas de composição vêm do fato que frameworks não foram projetados para ser compostos, mas para ser estendidos e trabalhar como o único framework da aplicação. Composição de frameworks tem vários problemas associados, como: composição de fluxo de controle; composição com sistemas legados; frameworks gap; sobreposição de entidades e composição de funcionalidade de entidades [1, 50 e 51].

\subsection{1 - Exemplo}

Suponha o desenvolvimento de um framework para controle acadêmico. Tal framework deve representar a vida acadêmica do aluno com as disciplinas que ele cursou, seu histórico, etc. Além disso, ele deve representar as bolsas de pesquisa distribuídas aos alunos e para isso devemos ter informações sobre o órgão financiador, a pesquisa e as atividades envolvidas. Para desenvolver esse framework podemos partir de dois frameworks já existentes: (i) Acadêmico: representa a vida acadêmica do aluno com as disciplinas que ele está matriculado e o histórico; para as disciplinas temos informações sobre: o departamento e o professor responsável; e (ii) Bolsa: temos informações sobre: os bolsistas; bolsa de pesquisa e suas atividades (cronograma); pesquisa que a bolsa implementa e o órgão financiador.

A soma dos requisitos dos frameworks acima "casa" com a necessidade do novo framework; podemos obter o novo domínio através da composição dos frameworks citados acima. Quando eles são compostos para a criação de um terceiro framework alguns problemas de composição podem acontecer, por exemplo: 
- Composição de fluxo de controle: cada framework, normalmente, gerencia o seu próprio fluxo de controle, de forma que no novo framework ambos supoem gerenciar o fluxo de controle. Portanto, deve-se verificar que conseqüências isso pode trazer para a composição, por exemplo: colisão de laços de eventos; falta de controle sobre um novo recurso; interferência entre os frameworks; execução incorreta e parada na execução.

- Composição com sistemas legados: além dos frameworks o projetista pode querer incluir um componente legado. A integração desses componentes pode ser problemática, uma vez que eles geralmente não são construídos de maneira $\mathrm{OO}$, dificultando a integração.

- Composição de funcionalidade de entidades: nesse exemplo, temos duas entidades em frameworks diferentes que vão representar uma mesma entidade no framework composto. A classe Aluno no framework Acadêmico é a mesma classe Bolsista no framework Bolsa. No novo framework essas entidades devem ser integradas de forma que satisfaça os requisitos do framework composto.

Neste trabalho nos concentramos no estudo da composição de fluxo de controle. Nesse exemplo específico, poderíamos ter uma composição na qual o framework Acadêmico requisita ao framework Bolsa a troca de um órgão financiador de um aluno não bolsista. Neste caso, seriam requisitados serviços para elementos inexistentes e poderia, por exemplo, interromper o fluxo de controle do framework Bolsa. Este e vários outros tipos de problemas podem aparecer quando dois frameworks são compostos, sem que o projetista perceba a priori aonde os problemas acontecem que é uma tarefa não trivial, dado que o fluxo de controle pode ser muito grande e complexo. Assim, surge a necessidade de realizar um estudo de quais problemas podem acontecer durante tal composição e de desenvolver uma ferramenta que auxilie o projetista a detectar os problemas que podem acontecer durante a composição de fluxos de controle de frameworks. Esses são os principais objetivos deste trabalho.

\section{3 - Abordagem}

Este trabalho trata da composição de fluxos de controle de frameworks Java para a criação de um terceiro framework. Alguns frameworks gerenciam o seu fluxo de controle (framework "que chama"), ou seja, o código do framework chama o código da aplicação quando apropriado. Quando compomos o fluxo de controle de dois frameworks, alguns problemas podem acontecer principalmente por três motivos [1, 13, 50, 51, 52 e 65]: (i) alguns frameworks foram projetados para gerenciar o fluxo de controle da aplicação; (ii) 
framework é construído para ser reutilizado por instanciação (adaptação) e não por composição; e (iii) o tamanho do framework (granularidade), quanto maior o framework mais dificil é realizar a composição dele com outros frameworks. Integrar os fluxos de controle dos frameworks compostos requer adaptações nos fluxos de controle dos frameworks envolvidos. Este trabalho apresenta composição de fluxos de controle de frameworks Java baseado em troca de mensagens e um estudo dos problemas que podem acontecer durante tal composição. Os problemas encontrados durante o estudo foram:

- Chamada de um método com argumento inválido.

- Retorno inválido da chamada de um método.

- Interferência em variáveis.

- Chamada de um método que ainda não deveria ser executado (pré-condições do fluxo de controle)

- Deadlock.

Cada problema foi analisado individualmente, verificando suas causas e conseqüências. Baseado nesse levantamento de problemas foi construida uma ferramenta que auxilia os projetistas na composição de dois frameworks Java: ela detecta que tipos de problemas podem acontecer (somente detecção estática) quando dois frameworks são compostos e sugere formas de contorná-los.

\section{4 - Sumário}

O restante deste trabalho está dividido em 6 capítulos; os capítulos restantes são:

2. Reutilização de Frameworks: trata dos conceitos básicos de frameworks, seus componentes, desenvolvimento e os problemas associados, propriedades desejáveis, alguns exemplos de frameworks comerciais e como desenvolver aplicações baseadas em frameworks. Descreve um modelo de desenvolvimento de frameworks que isola o fluxo de controle em uma entidade separada. Apresenta reutilização de frameworks e as suas formas: por extensão e por composição e apresenta os problemas relacionados à composição.

3. Frameworks Java: mostrar como Java trata as características que uma linguagem de construção de frameworks deve ter: herança; ligação dinâmica e polimorfismo; delegação e composição de objetos. Além 
disso, descreve outras características úteis ao desenvolvimento de frameworks como: pacotes; interfaces; threads; sincronização; tratamento de erros e modelo de eventos. Apresenta um modelo de frameworks Java e como eles gerenciam o fluxo de controle, descrevendo o estilo, os níveis de fluxo de controle e comunicação entre frameworks. Mostra a representação de frameworks utilizada nesse trabalho e alguns exemplos de frameworks Java.

4. Composição de Fluxos de Controle de Frameworks: apresenta o conceito de composição de software e composição de frameworks, descreve os problemas associados à composição de frameworks. Apresenta composição de fluxo de controle de frameworks Java e como alguns trabalhos tratam o problema de composição de fluxo de controle.

5. Composição de Fluxos de Controle de Frameworks Java Baseada em Troca de Mensagens: descreve como compor frameworks e seu fluxo de controle, sendo que os componentes dos frameworks se comunicam apenas por troca de mensagens. Mostrando as restrições dessa forma de composição, os novos elementos envolvidos e como implementá-la. Define as formas de composições: sem comunicação; seqüencial; unidirecional e bidirecional, exemplificando cada uma delas. Apresenta um levantamento de problemas para cada forma de composição descrita. Além disso, descreve os problemas encontrados e as conseqüências dos problemas para o novo fluxo de controle.

6. Ferramenta para a Composição de Fluxos de Controle de Frameworks Java: descreve a estrutura, funcionamento e uso de uma ferramenta construída para verificar que tipos de problemas de fluxo de controle podem acontecer durante a composição de dois frameworks Java. Apresenta exemplos de uso da ferramenta.

7. Conclusões: apresenta as contribuições do trabalho, comparação com outras abordagens, trabalhos futuros e considerações finais. 


\section{Capítulo 2 - Reutilização de Frameworks}

Frameworks são uma importante forma de se reutilizar design. Este capítulo trata da reutilização de frameworks e como eles se encaixam numa abordagem para reutilizar design OO. Para isso são apresentados: frameworks e seu desenvolvimento; suas propriedades desejáveis; alguns exemplos de frameworks comerciais e os problemas associados ao seu desenvolvimento. Além disso, mostra o desenvolvimento de aplicações baseadas em frameworks e os problemas relacionados. O capítulo apresenta, ainda, um modelo de desenvolvimento de frameworks que isola o fluxo de controle em uma entidade separada, e descreve as formas de reutilizar frameworks: por extensão e por composição, bem como os problemas associados à composição de frameworks.

\section{1 - Reutilização de Design 00}

O principal benefício da orientação a objetos é o grau de reutilização oferecido. Alcançar um alto grau de reutilização significa desenvolver menos código, com uma maior produtividade, maior qualidade e menor tempo de desenvolvimento. Reutilizar linhas de código é a forma mais simples e mais limitada de reutilização, por exemplo, através de cortar e colar de um programa em outro [2 e 7].

A reutilização de elementos de software pode ocorrer também no nível de design, sendo mais importante do que código [14 e 15]. A reutilização de código consiste na utilização direta de trechos já desenvolvidos. A reutilização de design consiste no reaproveitamento de concepções de arquitetura de uma aplicação em outra aplicação, não necessariamente com a utilização da mesma implementação. Reutilização se aplica a todos os produtos intermediários gerados durante o processo de desenvolvimento de software, incluindo: requisitos; documentos; especificações de sistemas e design [15 e 18]. Quanto mais alto o nível de abstração mais importante a reutilização [2, 7 e 15].

Design é a atividade de produzir uma descrição de como executar uma tarefa de tal maneira que satisfaça os requisitos dos clientes e quaisquer restrições impostas pelo ambiente em que o sistema está sendo usado. As abordagens tecnológicas utilizadas para reutilizar design são [15]: 
- Arquiteturas de software: fornecem uma descrição abstrata das decisões organizacional e estrutural evidentes em um sistema de software. O conceito de arquitetura de software é: "aspectos estruturais que incluem estrutura do sistema e controle global, protocolos para comunicação, sincronização e acesso a dados, atribuição de funcionalidade para elementos de design, distribuição física, composição de elementos de design, desempenho e seleção entre alternativas de design" [15].

- Frameworks: são as implementações atuais dos componentes de arquiteturas comuns a uma família de aplicações, incluindo: aspectos de design; implementação do fluxo controle e a divisão de responsabilidades.

- Design patterns: tem como objetivo formalizar a documentação de experiência de projetistas, flexibilizando a reutilização desse conhecimento. Design patterns permitem que os novatos não cometam os mesmos erros de desenvolvimento que os mais experientes encontraram e determinaram uma solução [4].

Este trabalho trata da reutilização de frameworks, por isso ela será tratada mais especificamente durante o restante desse capítulo.

\section{2-Frameworks}

Todo software tem funcionalidades específicas do problema que ele trata. Contudo, várias aplicações dentro do mesmo domínio podem conter funcionalidades em comum, chamada parte genérica de um domínio de aplicação. Os frameworks implementam a parte genérica de um domínio de aplicação e definem os locais onde as extensões podem ser feitas para dar suporte a soluções específicas (aplicações).

Um framework é um esqueleto de uma aplicação ou subsistema para um domínio particular de aplicação. Ele é, basicamente, uma coleção de classes abstratas, concretas e a relação existente entre elas. Além disso, ele pode ser visto como uma arquitetura para vários subsistemas. A idéia principal é a arquitetura resultante de um processo de análise de domínio ser representada por classes genéricas escritas em uma linguagem de programação orientada a objetos. Essas classes codificam o conhecimento geral relativo ao domínio de aplicação em termos de um programa [2]. Um framework captura as decisões de projeto que são comuns ao seu domínio de aplicação [4]. 
Na programação $\mathrm{OO}$, devido às características de herança e ligação dinâmica, uma nova classe pode ser implementada a partir de uma existente fornecendo somente aquilo que é diferente. Em frameworks, o mesmo princípio é aplicado a aplicações inteiras ou subsistemas. Dessa forma, o esforço em desenvolver uma nova aplicação é proporcional à diferença entre a funcionalidade de uma aplicação particular e a funcionalidade que o framework fornece. O principal objetivo é a reutilização, e consiste atualmente, numa das formas mais poderosa de reutilizar design $[2,7,15,18$ e 20].

\subsection{1 - Componentes de um Framework}

Frameworks diferem das aplicações tradicionais porque algumas das suas partes, chamadas de pontos flexíveis, ou hot-spots [16], podem ter uma implementação diferente para cada instância do framework. Um framework modela o comportamento de uma família de aplicações: sua parte central (núcleo ou kernel) representa as semelhanças entre as aplicações, enquanto o comportamento específico da aplicação é fornecido pelos pontos de flexibilização [17].

a) Núcleo: consiste de classes abstratas e concretas, as quais definem a estrutura e o comportamento genéricos do framework, formando a base para o desenvolvimento das aplicações. A funcionalidade comum em um domínio específico é capturada em contratos, que formalizam exatamente que partes do framework são reutilizáveis, impondo uma estrutura comum para todas as aplicações que usam o mesmo framework [16]. A implementação e funcionalidade do núcleo são geralmente escondidas do usuário, como eles formam o esqueleto de todas as aplicações, eles têm um impacto direto sobre o desempenho de uma aplicação. O núcleo do framework é representado por métodos templates, que definem um comportamento abstrato, um fluxo de controle genérico e a interação entre objetos.

b) Pontos de flexibilização: reutilizar frameworks significa adaptar alguns componentes e ou blocos para uma necessidade especifica, sobrepondo alguns métodos de suas subclasses. No projeto de frameworks, vários aspectos que não podem ser antecipados devem ser formulados genericamente de forma a permitir uma fácil adaptação posterior (hot-spot) [16]. Um hot-spot permite um usuário adaptar uma classe especifica da aplicação, seja pela seleção de um conjunto de classes fornecidas pelo framework "caixa-preta" ou por programar uma classe ou subsistema "caixa-branca". Hot-spot tem um grande impacto na reutilização e na flexibilidade de um framework [16]. Hot-spots são implementados através de métodos hook. Um método hook é um método abstrato que geralmente não possui uma implementação específica associada (é vazio). O único propósito desse método é proporcionar maior flexibilidade posteriormente. 


\subsection{2- Desenvolvimento de Frameworks}

Projetar um framework difere de projetar uma aplicação comum em pelo menos dois aspectos. Primeiro, o nível de abstração é diferente. framework é um meio de fornecer uma solução genérica para um conjunto de problemas similares ou relacionados em dado domínio, enquanto aplicações fornecem uma solução concreta para um problema particular. Segundo, frameworks são por sua natureza incompletos. Considerando que uma aplicação tem todos os componentes necessários para executar uma determinada tarefa, um framework tem lugares incompletos (hot-spots) que precisam ser estendidos para uma aplicação específica [18].

Em vários casos práticos framework são específicos a uma única aplicação [19]. A fim de aumentar o potencial de reutilização de um framework, o projetista deve procurar uma solução que cubra o contexto desejado e implementá-la de uma forma extensível e reutilizável, ou seja, o projetista deve ser capaz de perceber o ponto de equilíbrio entre a generalidade e a especificidade do framework para o domínio de aplicação desejado.

O projeto de um framework é por si só uma atividade de pesquisa. O projetista deve entender as decisões do projeto e organizá-las em um conjunto de classes abstratas, concretas e seus relacionamentos, que representam o comportamento básico para um subsistema. Sendo assim, o projetista desenvolve uma teoria do domínio do problema e a expressa segundo um modelo orientado a objetos [20]. Em termos ideais, um framework deve abranger todos os conceitos gerais de um domínio de aplicação, deixando apenas aspectos particulares para serem definidos nas aplicações específicas. Nesse caso, na geração de aplicações, o usuário do framework não deve precisar criar classes que não sejam subclasses de classes abstratas do framework. Se isso for alcançando, o framework terá conseguido, de fato, ser uma generalização do domínio [21].

Embora alguns frameworks tenham sido desenvolvidos com sucesso nos últimos anos [14, 22, 23, 24, 25 e 64], projetar frameworks de boa qualidade é uma tarefa muito dificil [26 e 27]. Vários métodos foram propostos para dar suporte ao desenvolvimento de frameworks [16, 26, 28, 29, 58, 61 e 67]. Quase todos eles dividem o desenvolvimento do framework em duas partes: a parte comum e a parte que será estendida.

Como visto acima o desenvolvimento de framework é diferente do desenvolvimento de aplicações tradicionais. As seguintes atividades fazem parte de um simples modelo de desenvolvimento de frameworks [56]: (i) análise de domínio; (ii) design de arquitetura; (iii) design do framework; (iv) implementação do 
framework; (v) teste do framework; (vi) testes da aplicação; e (vii) documentação. Entre os principais problemas encontrados durante o desenvolvimento de frameworks podemos citar [1 e 56]:

- Escopo do domínio: é o problema de determinar o tamanho certo do domínio. Se o domínio é muito grande pode ser difícil demonstrar a utilidade e a aplicabilidade do framework. Por outro lado, se um domínio é muito pequeno, o framework resultante tende a ser sensível a mudanças no domínio. O escopo do domínio deve ser cuidadosamente balanceado.

- Documentação de frameworks: os métodos de documentação de sistemas 00 não são adequados à documentação de frameworks, uma vez que o método deve cobrir dois propósitos: (i) a necessidade de comunicar a informação sobre o design do framework e outras informações relacionadas; e (ii) a necessidade de documentar informações sobre como usar o framework.

- Modelo de negócios para domínios de frameworks: um dos principais problemas para o gerenciamento de desenvolvimento de framework é que não existe nenhum modelo de negócios específicos para framework, ou seja, não há informações sobre as vantagens financeiras da sua utilização. Alguns modelos de negócios foram formulados [56], mas nenhum foi testado industrialmente. Outros modelos de negócios para reutilização em geral não satisfazem os requisitos para frameworks [1].

- Métodos de desenvolvimento de framework: métodos existentes não são suficiente para o desenvolvimento de frameworks, uma vez que frameworks têm um design incompleto e necessitam de uma fase extra de desenvolvimento para preencher esses locais que são incompletos.

Um bom framework deve ter algumas propriedades desejáveis [26 e 30]:

- Fácil de usar: a fim de melhorar o entendimento do framework pelo usuário, a interação (interface e fluxo de controle) entre as aplicações e o framework deve ser simples e consistente.

- Extensível: se novos componentes ou propriedades podem ser adicionadas ao framework facilmente, então ele é extensivel.

- Flexível: é a habilidade de utilizá-lo em mais de um contexto. Em geral, isso se aplica para o domínio coberto pelo framework.

- Completo: embora framework seja incompleto, uma vez que ele não pode cobrir todas as variações dentro de um domínio, completude relativa é uma propriedade desejável. O framework deve fornecer a implementação de operações comuns que o projetista pode escolher. 
- Consistente: nomes devem ser usados de maneira consistente dentro do framework, para aumentar o entendimento e ajudar a reduzir erros na sua utilização.

\subsubsection{1 - Exemplos de Frameworks Comerciais}

Os primeiros exemplos de frameworks encontrados na literatura têm origem no ambiente Smalltalk. O Model View Controladora (MVC), foi talvez o primeiro framework largamente utilizado, ele servia para desenvolver interfaces de usuários baseadas em: modelos; visões e controles [18]. Depois do MVC vários frameworks foram desenvolvidos com sucesso para os mais variados domínios e linguagens. Alguns frameworks encontrados na literatura foram:

a) MVC (Model View Controller) [18]: foi desenvolvido para o Smalltalk-80. O MVC usa um paradigma que a entrada, o sistema central e a parte visual são separadas explicitamente e manipulada por três tipos de objetos. O Model gerencia os dados e comportamentos específicos da aplicação. O View gerencia as visões de saída. O objeto Controller interpreta as entradas do usuário através do teclado, mouse, etc. $\mathrm{O}$ comportamento do MVC pode ser herdado, estendido e modificado para fornecer um sistema poderoso e flexível.

b) ET++[22 e 31]: ele tem uma biblioteca de classes homogênea, integrando interface do usuário, estruturas de dados e suporte para entrada e saída de objetos com frameworks de aplicação de alto nível. ET++ foi projetado para facilitar o desenvolvimento de aplicações com interfaces de usuários seguindo uma metáfora de área de trabalho. Experiências mostram que aplicações baseadas no ET++ podem reduzir o código fonte em até $80 \%$, comparado com escrever a aplicação sem o framework [22].

c) CORBA (Common Object Request Broker Architecture) [23]: é um padrão de arquitetura mantido pelo Object Management Group (OMG). CORBA é um framework que ajuda a desenvolver aplicações distribuídas, ele encapsula detalhes de protocolos de comunicação, transporte de redes e plataformas de implementação.

d) Input Method Framework [25]: desenvolvido em Java pela SUN, capacita projetistas de componentes a interagir com métodos de entrada com grande conjunto de caracteres, como chinês, japonês ou coreano. $\mathrm{O}$ framework define classes e interfaces que habilitam os componentes a receber textos baseados nesses conjuntos de caracteres, através de métodos de entrada. 


\subsection{3 - Desenvolvimento de Aplicações Baseadas em Frameworks}

A maneira mais comum de instanciar um framework é herdar de classes abstratas definidas na hierarquia do framework e escrever o código que será chamado por ele. Porém, nem sempre é fácil identificar, especialmente para usuários que não têm experiência, que código é necessário e onde tal código deve ficar, uma vez que a hierarquia de classes do framework pode ser muito complexa. O desenvolvimento de aplicações baseadas em framework é mostrado na Figura 2.1.

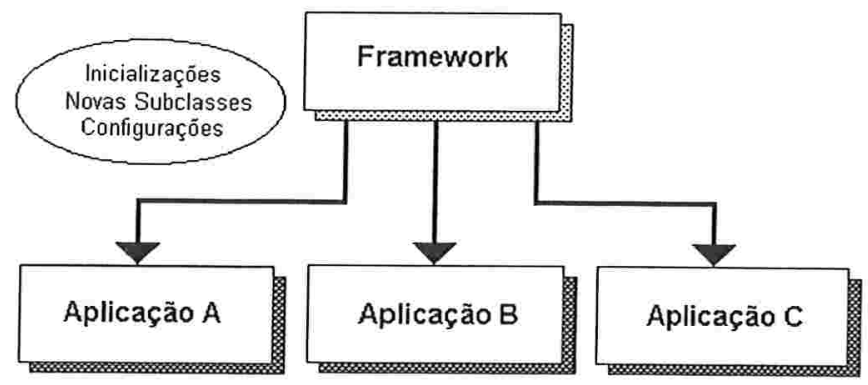

Figura 2.1: Desenvolvimento de Aplicações baseada em frameworks [18].

Há três maneiras básicas de gerar aplicações a partir de um framework [18]: (i) combinando instâncias das classes concretas do framework; (ii) definindo novas classes; ou (iii) a partir da combinação das duas possibilidades. A possibilidade de usar uma ou outra forma é uma característica particular de cada framework, definida em seu projeto. O projeto do framework estabelece a flexibilidade possível, impondo uma limitação (combinação de objetos ou criação de novas classes) a ser obedecida pelo usuário. Cada framework deve dispor de uma documentação específica para ensinar o usuário a gerar aplicações.

$\mathrm{Na}$ instanciação do framework a partir da criação de classes, fica imposto um conjunto de classes que deve ser definido pelo usuário (extensão das classes do framework). Além de um conjunto obrigatório de subclasses, o usuário não é totalmente livre para criar ou alterar funcionalidade a partir da criação de classes, uma vez que a posse do controle da aplicação está com as classes do framework e não com as classes do usuário. Diferentes partes podem ser identificadas dentro de uma aplicação desenvolvida a partir de um framework como mostra a Figura 2.2. 


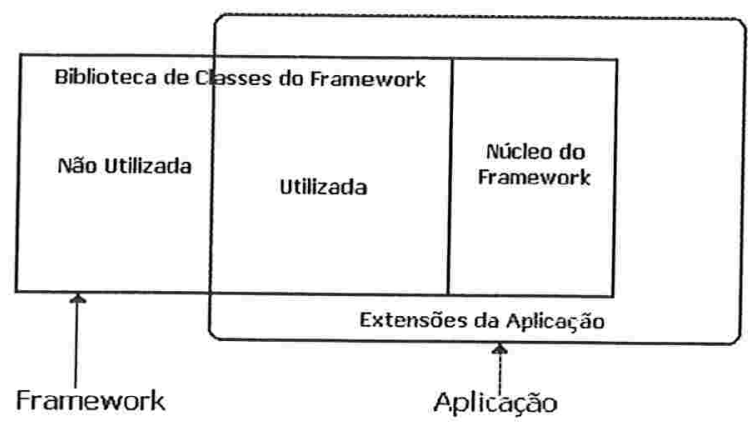

Figura 2.2: Componentes de uma aplicação baseada em framework [18].

Os componentes descritos acima são [18]:

- Núcleo do framework: consiste de classes abstratas e concretas que definem as estruturas e comportamentos genéricos do framework, formando a base para o desenvolvimento de aplicações.

- Biblioteca de classes: extensões ao núcleo do framework consistindo de componentes concretos que podem ser usados com pouca ou nenhuma modificação pelos projetistas da aplicação.

- Extensões da aplicação: extensões específicas para cada aplicação, a parte que diferencia as aplicações derivadas de um mesmo framework. As extensões são conectadas ao framework através de métodos hooks.

- Aplicação: em termos de framework, consiste do núcleo do framework, as bibliotecas de classes utilizadas e qualquer extensão específica necessária.

- Bibliotecas de classes não utilizadas: geralmente, nem todas as classes do framework serão necessárias em uma aplicação que pode ser desenvolvida.

Antes de citar os problemas no uso de framework é importante mostrar as fases de seu uso [1]: (i) identificação dos requisitos; (ii) procura; (iii) entendimento; (iv) investigação de possíveis adaptações; (v) seleção; (vi) adaptação - integração; e (vii) documentação. Os problemas encontrados durante o desenvolvimento de aplicações baseadas em frameworks são [1]:

- Aplicabilidade do framework: na prática, a questão é se a aplicação "casa" com o domínio do framework. Deve-se verificar se é mais útil construir uma aplicação sem o framework ou construir uma baseada em um framework existente. 
- Estimativas de incremento: a maioria do tempo é gasto com o entendimento do framework e a menor parte e gasto com implementação da aplicação, dessa forma, as atuais técnicas de estimativas de incremento não se adaptam a frameworks.

- Entendimento do framework: pode ser um pré-requisito para avaliar a aplicabilidade do framework e a quantidade de adaptação exigida e como a adaptação pode ser executada. Entendimento do framework normalmente é difícil porque eles são grandes, complexos e a documentação é incompleta.

- Verificação dos incrementos específicos da aplicação: em aplicações baseadas em vários frameworks é dificil verificar os incrementos específicos da aplicação que está sendo desenvolvida. A verificação deve ser baseada sobre a especificação de que requisitos os incrementos necessitam.

\subsection{4 - Um Modelo de Frameworks}

Como descrito na Seção 2.2.2, existem vários métodos para o desenvolvimento de frameworks. Este trabalho se abstrai da forma de construção, ou seja, o projetista pode escolher aquele método que melhor se adapte aos seus requisitos. Porém, existe um modelo que tal framework deve obedecer. Este modelo isola o fluxo de controle do framework em uma entidade separada conseguindo uma maior visibilidade do fluxo de controle, facilitando assim a identificação e o entendimento. Esse modelo foi apresentado em [33] e existem alguns frameworks disponíveis que foram construídos utilizando a proposta apresentada [8, 11, 22 24, 29 e $32]^{2}$. Nesse modelo um framework $(F)$ é descrito como:

- Uma classe concreta $C$ que será chamada de classe Controladora de $F$. $C$ tem um método chamado "run", tal método decide primariamente como controlar o fluxo de controle entre os vários métodos das classes de $F$. Além do método "run" muitos frameworks incluem um mecanismo para iniciar, a fim de permitir que alguma informação sobre a aplicação seja passada para o framework. A fim de obter um modelo simples e uniforme, é assumido que a classe Controladora $C$ fornece um método "initialize" que manipula essas tarefas. Para usar a aplicação construída baseada em $F$, o "programa principal" da aplicação, deve primeiro chamar a função "initialize" e depois chamar o método "run" e inicia o uso da aplicação, sendo que o fluxo de controle fica sob a responsabilidade do framework.

\footnotetext{
${ }^{2}$ Sendo que $[8,11$ e 22] já tinham sido desenvolvidos antes da publicação do artigo que descreve o modelo.
} 
- Zero ou mais outras classes concretas $C 1, \ldots, C n$.

- Uma ou mais classes abstratas $A 1, \ldots, A n$.

Uma classe $A$ é abstrata se pelo menos um dos seus métodos for abstrato. Uma classe onde todos os seus métodos não são abstratos é chamada de classe concreta. A representação gráfica do modelo é dada pela Figura 2.3, sendo que as linhas contínuas são classes concretas e as pontilhadas são abstratas.

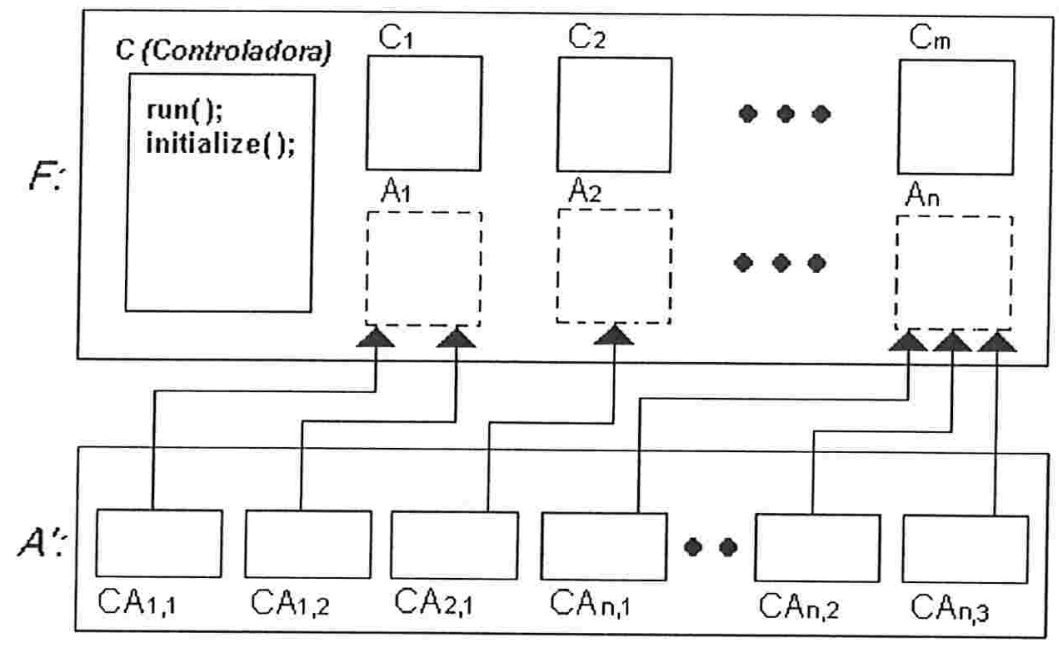

Figura 2.3: Modelo de Frameworks [33].

Uma aplicação $(A)$ construída a partir desse framework $(F)$ deve derivar algumas classes das classes abstratas do framework, fornecendo definição para alguns ou todos os métodos abstratos. Usa-se $A$ ' para representar o código adicional fornecido pela aplicação, dessa forma temos que $A=F A^{\prime}$. Se definições são fornecidas para cada uma das classes derivadas em $A$ ', para todas as funções virtuais da classe base correspondente de $F$, então a aplicação será completa, caso contrário ela ainda será um framework, apenas um pouco menos abstrato. O "programa principal" da aplicação terá um objeto, chamado de $c$ do tipo da classe C, $c$ será iniciado primeiro, seguido pela chamada de "initialize" e depois de "run".

De acordo com [33], uma das mais importantes contribuições que o framework oferece é o fluxo de controle, evitando que o projetista da aplicação se preocupe em controlar o fluxo de controle entre os vários métodos de várias classes. Nesse modelo, isso fica evidenciado pela função "run". Muitos dos framework existentes se enquadram nesse modelo, pelo menos conceitualmente. Alguns apresentam diferenças sintáticas, por exemplo, a função que controla a aplicação pode não se chamar "run", ou a classe pode não se chamar Controladora. Este trabalho considera que os frameworks utilizados na composição foram construídos tendo como base esse modelo, pelo menos de uma forma conceitual, ou seja, existe um método específico que inicia o fluxo de controle. 


\section{3 - Reutilização de Frameworks}

Em um dado domínio de aplicação, o processo de análise de domínio de algumas aplicações existentes pode identificar características arquitetônicas comuns e descrever os aspectos variáveis. Uma arquitetura genérica pode ser desenvolvida para uma família de produtos em um domínio de aplicação, de forma que haja uma regra bem definida para cada componente. Uma implementação de tal arquitetura é chamada de framework. O principal objetivo dos frameworks é reutilizar grupos inteiros de classes relacionadas que fornecem um conjunto de serviços para um domínio particular.

Enfatizando a reutilização de projeto, o conceito de frameworks atinge a reutilização de arquiteturas de componentes de software [4]. Um framework dita a arquitetura genérica da aplicação, deixando que o usuário do framework (projetista da aplicação específica), concentre-se nos detalhes particulares da aplicação, especializando as classes genéricas e adicionando funcionalidade. Como um framework é definido em função do conjunto de classes abstratas, ele não conhece as subclasses concretas que determinarão o comportamento específico de cada aplicação. Isso faz com que os relacionamentos também sejam definidos sobre as classes abstratas, fazendo com que o projetista da aplicação que usa o framework determine quais as subclasses concretas, específicas da aplicação, estão envolvidas nos relacionamentos.

Frameworks permitem ao usuário reutilizar designs abstratos e componentes. O design de um framework incorpora decisões sobre a distribuição de fluxo de controle e responsabilidades globais, os protocolos seguidos pelos componentes quando se comunicam e implementações para cada um dos algoritmos principais. Uma vez que o framework é desenvolvido, o projetista somente tem que construir subclasses que implementem o comportamento específico de uma aplicação dentro do domínio, reutilizando as interfaces e o código geral implementado nas classes do framework. Desse modo, a reutilização do projeto é realizada através da especialização das classes genéricas do framework. Ao contrário das abordagens tradicionais para reutilização de software, as quais se limitam basicamente à construção de classes; frameworks permitem reutilizar não somente componentes isolados, mas toda uma estrutura de software desenvolvida para um domínio específico [2].

Existem duas formas de se reutilizar um framework: (i) por extensão, o framework é adaptado para uma instância específica de uma aplicação, o mecanismo utilizado é a herança; e (ii) por composição, dois ou mais frameworks são compostos para criar um novo framework ou uma nova aplicação. 


\subsection{1 -Reutilização de Frameworks por Extensão}

A fim de reutilizar um framework por extensão, o usuário deve herdar de suas classes e especializálas sobrecarregando métodos. Há dois estilos de frameworks: "chamados" e "que chamam";

- Framework "chamado": não contém o fluxo de controle, ele é mais parecido com uma biblioteca de classes. Uma aplicação implementada a partir deste framework deve definir o fluxo de controle e chamar os métodos do framework.

- Framework "que chama": tem um fluxo de controle bem definido que se refere ao fluxo de controle utilizado pela aplicação. Aspectos importantes do fluxo de controle são: os recursos que o framework gerencia e se ele usa simples ou múltiplos fluxos de execução [42].

Cada tipo tem uma forma de reutilização diferente.A Figura 2.4 mostra os dois estilos [34].

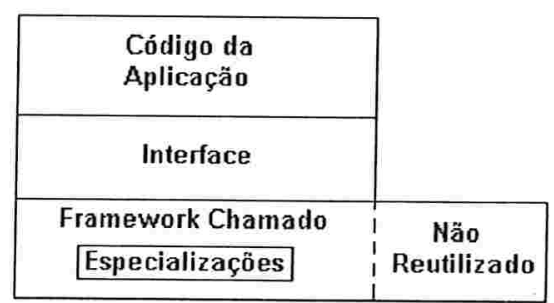

(a) Reutilização de um Framework chamado.

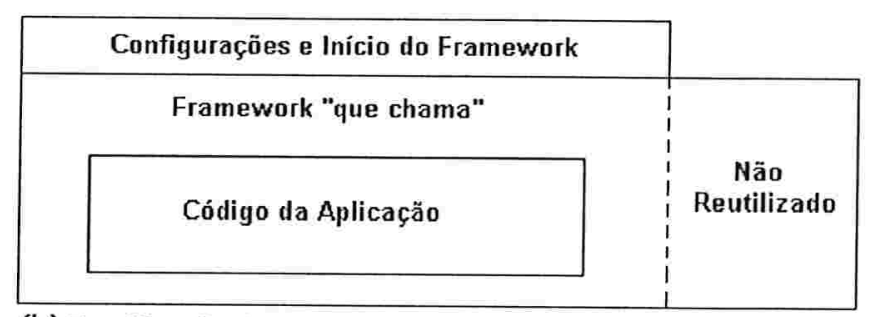

(b) Reutilização de um Framework "que chama".

Figura 2.4: Duas visões de reutilização [34].

A Figura 2.4a apresenta reutilização de um framework "chamado"; o estilo é similar a bibliotecas de classes, exceto por três diferenças: (i) o usuário especializa e estende um framework "chamado" usando técnicas $\mathrm{OO}$ padrão (herança e composição), tornando-o mais flexível do que bibliotecas de classes; (ii) reutilização de tipos de dados (classe) é freqüentemente sobre herança, em lugar de composição; (iii) há menos liberdade para escolher entre os serviços de frameworks porque os dados e serviços estão empacotados em classes reutilizadas como uma unidade. Projetistas podem fazer a transição direta de bibliotecas de classes para frameworks "chamados", porque essas diferenças são pequenas, mas isso também significa que as possíveis melhoras devido à reutilização são menores.

A Figura $2.4 b$ apresenta reutilização de um framework "que chama". Depois que a aplicação inicia o framework, ela passa o controle para o framework. Essa abordagem conduz a altas taxas de reutilização e aumento de produtividade comparado ao framework "chamado". Porém, essas taxas exigem mudanças no 
desenvolvimento tradicional de software. Por exemplo, projetistas devem ajustar o design do framework, com isso a aplicação faz somente aquilo que o framework permite, isso significa menos liberdade de design. Projetistas devem também obedecer as regras do framework, isso significa que eles devem ter um maior conhecimento de frameworks "que chamam" do que frameworks "chamados".

\subsection{2 -Reutilização de Frameworks por Composição}

Frameworks também podem ser reutilizados por composição; nessa forma, dois ou mais frameworks são compostos para criar um novo framework ou para construir uma aplicação. O grande problema dessa abordagem é o fato que frameworks não estão sendo construídos para serem compostos, apenas para serem estendidos [35], além disso, o tamanho e a complexidade do framework influencia muito na composição [13].

Para compor frameworks deve-se compor seus aspectos estáticos e dinâmicos. Deve-se ainda verificar a forma de composição (sem comunicação, seqüencial, unidirecional ou bidirecional) e como os frameworks se comunicam para trabalharem em conjunto. Aspectos estáticos são as classes e interfaces. Aspetos dinâmicos são o fluxo de controle e as comunicações entre os frameworks, ou por mensagens ou por eventos. Deve-se ainda considerar se há comunicação bidirecional ou unidirecional entre eles. Reutilização de frameworks por composição será tratada mais especificamente no restante desse trabalho.

Hoje as aplicações estão cada vez mais baseadas em múltiplos frameworks. Problemas com composição surgem quando necessitamos construir uma aplicação baseada em mais de um framework. Os problemas primários de composição de frameworks são [1]: (i) composição de controle de framework; (ii) composição com sistemas legados; (iii) frameworks gap (carência de requisitos); (iv) sobreposição de entidades e (v) composição de funcionalidade de entidade. Por se tratar do assunto desse trabalho, os problemas de composição de frameworks serão descritos em mais detalhes no Capítulo 4.

\section{4 - Considerações Finais}

Framework é uma tecnologia que está sendo usada com sucesso na reutilização de software, uma vez que eles permitem reutilizar design e código. O desenvolvimento de aplicações baseadas em frameworks aumenta a produtividade e a qualidade do software. Inicialmente, os frameworks foram usados isoladamente 
para o desenvolvimento de aplicações, mas com o aumento da complexidade das aplicações e o aumento da disponibilidade de frameworks nos mais variados domínios [1, 14, 22, 23, 24, 25, 31 e 32], surgiu a necessidade de se usar vários frameworks ao mesmo tempo, através da reutilização.

Reutilização é o requisito não funcional mais importante quando se projeta frameworks; isto influencia as decisões tomadas durante o design e resulta no paradoxo de reutilização de framework [36]. $\mathrm{O}$ paradoxo é o resultado de duas forcas contraditórias: generalidade (probabilidade do framework ser reutilizado "como é") e suporte à reutilização (fração das aplicações resultantes que podem ser reutilizadas "como é" do framework). Os dois fatores estão inversamente relacionados, uma vez que a decisão de design entre duas ou mais alternativas reduz potencialmente o fator de generalidade e vice-versa. Para mudar essa situação temos: (i) colocar o maior esforço de desenvolvimento nas entidades mais óbvias; (ii) as decisões de design devem enfatizar a reutilização; e (iii) limitar o domínio, de forma que um número maior de aplicações possa ser instanciado.

$\mathrm{O}$ uso de frameworks tem alguns problemas associados como: desenvolvimento de frameworks; composição de frameworks; desenvolvimento de aplicações baseadas em frameworks e evolução e manutenção de frameworks (a correção de um erro no framework deve ou não ser corrigido na aplicação também?). O presente trabalho trata o problema de composição de frameworks, em particular: como compor os fluxos de controle implementados pelos frameworks.

Nesse capítulo foram apresentados os problemas de se usar frameworks, tais problemas acontecem porque o método tradicional de desenvolvimento $\mathrm{OO}$ não se adapta complemente às características de frameworks, mas mesmo com esses problemas frameworks estão sendo usados cada vez mais pela industria nos mais variados domínios $[1,14,22,23,24,25,31$ e 32]. Os novos frameworks desenvolvidos são baseados em vários frameworks e componentes, dessa forma tentar solucionar os problemas de composição de frameworks é importante para se conseguir um mais alto índice de produtividade em frameworks. 


\section{Capítulo 3 -Frameworks Java}

Orientação a objetos é um requisito básico para uma linguagem ser usada na construção de frameworks [14]. O desenvolvimento e o uso de frameworks utilizam: herança; ligação dinâmica; composição de objetos e delegação. Embora diferentes tipos de framework tenham sido desenvolvidos usando linguagens procedurais, o paradigma $\mathrm{OO}$ oferece conceitos mais poderosos para a construção dos mesmos [37]. Este capítulo apresenta frameworks Java, mostrando Java como uma linguagem para desenvolvimento de frameworks e um modelo de frameworks Java, dividido em: uma parte estática (classes e interfaces) e uma parte dinâmica (fluxo de controle e comunicação entre frameworks).

\section{1 - Java Como uma Linguagem para Construção de Frameworks}

As características gerais que uma linguagem para a construção de framework são [37]: herança; ligação dinâmica; composição de objetos e delegação. Abaixo é apresentado como Java trata tais características:

a) Herança: é possível definir classes (subclasses) em termos de outras classes (superclasses). Uma subclasse herda estados, na forma de declaração de variáveis; e comportamentos, na forma de métodos, de suas superclasses e de todos os seus ancestrais. Uma subclasse pode usar esses membros (variáveis e métodos) como eles são ou pode anular ou sobrecarregar os métodos. Os itens abaixo resumem o princípio de herança em uma definição de classes Java [63]:

- Os membros da superclasse declarados como public ou protected.

- Os membros da superclasse com nenhuma forma de acesso especificada, contanto que a subclasse esteja no mesmo pacote da superclasse.

- Não herdam os membros da superclasse se a subclasse declara um membro com o mesmo nome.

- Não herdam os membros declarados como private da superclasse. 
b) Delegação: é usada quando um objeto precisa de um comportamento definido em um outro objeto. Uma forma de obter tal comportamento é delegar o comportamento para o outro objeto. Na delegação um objeto obtém alguma ou toda a funcionalidade por coordenar as ações de um ou mais objetos. Dois objetos estão envolvidos no tratamento de uma solicitação: um objeto "receptor" delega operações para o objeto "delegado". Para usar delegação em Java, deve-se usar variáveis de instâncias de um objeto que possui referências para outros objetos. Um objeto "receptor" solicita ajuda de objetos "delegados" pelo suporte a referências em variáveis de instâncias. Objetos "receptores" delegam aos objetos "delegados" via chamada explícita de métodos.

c) Ligação dinâmica e polimorfismo: permite ao framework tratar um objeto sem considerar sua implementação. O projetista da aplicação deriva uma nova classe do framework escrevendo o código da classe, seguindo o modelo fornecido pelas superclasses abstratas. O mecanismo que torna polimorfismo possível é a ligação dinâmica (dynamic binding). Quase todos os métodos de instância em Java são ligados dinamicamente. O método de instância chamado em tempo de execução será determinado pela classe atual do objeto e não pelo tipo da referência. Para obter o benefício do polimorfismo nos programas Java, deve-se enviar uma mensagem para um objeto sem conhecimento da classe atual dele, quando se escreve o código que chama o método, o programador não precisa necessariamente saber a classe atual do objeto. Em tempo de execução a JVM (Java Virtual Machine) determina a classe atual do objeto cada vez que a chamada do método é requisitada pelo programa. Baseado nesta informação, a JVM chama a implementação do método pertencente ao objeto. Um dos beneficios primários da ligação dinâmica e polimorfismo é a facilidade de mudança [37].

d) Composição de objetos: a maneira mais fácil para um componente fornecer um serviço exigido não disponível dentro dele é delegar uma requisição para outro componente capaz de fornecer o serviço requisitado. Para alcançar isto, o componente precisa ser estendido com o comportamento que delega certas requisições para outros componentes. A composição deve ser usada para solicitar ajuda de outros objetos. Para realizar composição usa-se delegação. A composição de objetos fornece alternativa à herança para a combinação de comportamentos. Novas funcionalidades podem ser acrescentadas a uma aplicação pela composição de objetos existentes, ao invés de definir novas subclasses das classes existentes. Por outro lado, o uso intenso da composição de objetos pode tornar o design mais dificil de compreender [63]. 
Além dessas características gerais que uma linguagem para desenvolvimento de frameworks deve ter, Java tem outras características úteis ao desenvolvimento de frameworks, por exemplo: interface; pacote; tratamento de erros; threads; sincronização e controle de concorrência e modelo de eventos.

e) Interface: define um conjunto de métodos, mas não os implementam. Ela é uma coleção nomeada de definição de métodos (sem implementações). As interfaces podem ser usadas para definir um protocolo de comportamento podendo ser implementado por qualquer classe em qualquer lugar na hierarquia de classe. Interfaces são mais abstratas do que classes, uma vez que elas nada dizem sobre representação e código [38]. Métodos em uma interface são sempre públicos e abstratos e as variáveis são sempre de classes [39]. Uma classe que implementa uma interface aceita implementar todos os métodos definidos na interface, aceitando assim um certo comportamento. Interfaces são úteis pelo seguinte [39]:

- Capturam similaridades entre classe não relacionadas sem forçar relacionamentos artificiais entre elas.

- Declaram métodos que devem ser implementados em uma ou mais classes.

- Descobrem uma interface de programação de um objeto sem descobrir sua classe.

Interfaces são úteis na construção de frameworks porque permitem ao programador definir um conjunto de funcionalidades sem ter qualquer idéia de como essa funcionalidade será definida posteriormente (aplicação). Elas definem o comportamento de um objeto ao declarar um conjunto de características para ele. A finalidade principal das interfaces é declarar métodos abstratos que serão definidos em outras classes. Java faz uma separação clara entre classes e interface. Uma interface representa o tipo de um conjunto de objetos sem menção da sua implementação. Java implementa a noção de hierarquia de tipos (interfaces) separadas da hierarquia de classes.

f) Pacote: é um mecanismo que divide o espaço de nomes de classes em pedaços mais gerenciáveis. Os pacotes são, ao mesmo tempo, um mecanismo de nomeação e de restrição de visibilidade. Frameworks são organizados como conjunto de pacotes para evitar a colisão de nomes das classes dos frameworks com as classes da aplicação e de outros frameworks. A estrutura de nomes para um pacote é hierárquica, os membros de um pacote são classes e interfaces.

g)Tratamento de exceções: permite lidar com condições anormais de funcionamento de um programa. A utilização desse recurso torna o software mais robusto, seguro e bem estruturado. Exemplos de condições anormais são: acesso a índice inválido em um vetor, chamada de um método para um objeto nulo, etc. Todo 
programa profissional Java deve ter implementado tratamento de exceções e com frameworks não deve ser diferente. Quando se escreve programa Java utilizando o recurso de tratamento de exceções, deve-se tomar duas ações básicas: lançar uma exceção e tratar uma exceção. Uma exceção será lançada quando for verificada uma condição anormal do funcionamento de um programa, então o método que está sendo executado é imediatamente terminado e o controle passa para o método que o chamou. Caso exista um tratamento implementado, a exceção para de se propagar nesse método. Se não ocorrer um tratamento, outras chamadas de métodos são encerradas, podendo culminar com o término do programa.

h) Threads: são linhas de execução que executam dentro de um processo. Geralmente as threads compartilham as mesmas regiões de memória (lightweight threads). Isso facilita a sua comunicação, porque um objeto em uma thread pode chamar um método em uma outra thread com pouca sobrecarga para o sistema operacional. Cada thread pode ser visto como um mini-programa separado, iniciado por um programa e executado em paralelo. Uma thread tem acesso a todos os objetos do programa e pode chamar métodos ou acessar variáveis dentro dele.

Java permite ter múltiplos fluxos de controle dentro de um programa (Multithreaded). Isso é extremamente útil na prática, principalmente em frameworks que geralmente manipulam várias atividades ao mesmo tempo. A máquina virtual Java pode suportar várias threads ao mesmo tempo em que executam independentemente, operando sobre valores e objetos residindo na memória principal compartilhada. Java suporta programas que, embora concorrentemente, exibem ainda um comportamento determinístico, por fornecer mecanismos para sincronizar as atividades concorrentes das threads.

i) Sincronização e controle de concorrência: quando duas ou mais threads acessam ao mesmo tempo um mesmo objeto, uma thread pode interferir na execução da outra, podendo ter resultados diferentes daqueles executados em um contexto de uma simples thread. A principal ferramenta para evitar interferências em Java é a palavra chave syncronized, que pode ser aplicada como um qualificador para qualquer método ou qualquer bloco de código dentro de um método Java. A principal aplicação de sincronização é permitir que somente uma thread ao mesmo tempo obtenha acesso a um objeto. Para sincronizar threads, Java usa monitores, mecanismo de alto nível que permite que somente uma thread, em um dado tempo, execute a região de código protegida pelo monitor. Java é uma das poucas linguagens de programação OO que incorpora threads e construções de controle de concorrências relacionadas sem necessitar de ferramentas especiais ou sistemas de suporte. Java contém algumas construções básicas especialmente projetadas para suportar controle de concorrência [37]: 
- A classe java. lang. Thread, usada para iniciar e controlar novas atividades.

- As palavras reservadas syncronized e volatile, usadas para controlar a execução do código em objetos que podem participar de múltiplas threads.

- Os métodos wait(), notify() e notifyAll() definidos em java.lang.object, usados para coordenar atividades através das threads.

j) Modelo de eventos: é uma coleção de abstrações que especificam como trocar informações entre objetos de uma maneira padronizada. A complexidade da informação trocada entre os objetos pode variar muito. 0 modelo de eventos de Java é baseado em delegação, quando a máquina virtual Java detecta um evento, ela notifica a interface listener apropriada de acordo com o tipo de evento e então essa interface toma as ações necessárias. Qualquer evento que um programa deseje manipular deve ter uma interface listener associada. $\mathrm{O}$ modelo fornece uma maneira robusta e extensível de manipular eventos que podem ser aplicados para todos os tipos de eventos. Há três partes no modelo de eventos [40]:

1. Objeto Event: uma instância de uma classe Java que contém as características de um evento. Conceitualmente, eventos são um mecanismo para propagar notificações de mudanças de estados entre um objeto fonte e um ou mais objetos receptores. Eventos são organizados em uma hierarquia de classes de eventos.

2. Interface listener: uma vez que o modelo de eventos de Java é baseado em chamada de métodos, precisa-se de uma maneira de definir e agrupar métodos gerenciadores de eventos. Os métodos gerenciadores de eventos devem ser definidos em uma interface EventListener que herda de Java. util. EvenListener. Uma classe que deseja manipular qualquer conjunto de eventos definido em uma interface EventListener deve implementar essa interface.

3. Fonte de evento: mantém uma lista de interfaces listeners que estão interessadas em receber eventos que ele produz. Quando esse objeto gera um evento, ele notifica todas as interfaces listeners registradas que um determinado evento ocorreu. 


\section{2 - Frameworks Java}

Um framework Java é um conjunto de classes concretas, abstratas e o relacionamento entre elas, podendo também incluir uma hierarquia de interfaces que podem ser implementadas pelas classes. Além disso, alguns frameworks podem implementar um modelo de controle que se refere ao fluxo de execução usado por um framework.

\subsection{1 - Conjunto de Classes e Interfaces}

É a parte estática do framework, ela é importante porque nela será definido o fluxo de controle que o framework implementa. Geralmente, a parte estática do framework Java é implementa dentro de um ou mais pacotes. A parte estática do framework é composta de:

- Pacotes: normalmente os frameworks são implementados em pacotes e subpacotes; os pacotes contêm classes e interfaces.

- Hierarquia de classes: um conjunto de classes concretas e abstratas, sendo que as classes abstratas devem se tornar concretas na instanciação do framework.

- Hierarquia de interfaces: conjunto de interfaces que devem ser implementadas pelas classes do framework ou da aplicação.

\subsection{2 - Fluxo de Controle}

O fluxo de controle de frameworks é composto dos objetos que ele cria e da ordem de chamada dos métodos, algumas vezes pré-definidas outras vezes dependendo da entrada do usuário ou das relações com outros sistemas. Frameworks geralmente assumem estar no controle do programa em que eles são usados. Isso significa que of framework pode iniciar e executar tarefas específicas.

Quando um fluxo de controle passa por uma operação, diz-se que, em determinado momento, o local do controle está na operação. Se essa operação estiver definida para alguma classe, também se diz que, em determinado momento, o local do controle está em uma instância específica dessa classe. Pode haver vários 
fluxos de controle em uma mesma operação e, portanto, em um único objeto, pode haver diferentes fluxos de controle em diferentes operações, mas ainda resulta em vários fluxos de controle em um único objeto.

Em um sistema concorrente, existe mais de um fluxo de controle, ou seja, mais de uma coisa pode ocorrer ao mesmo tempo. Existem vários fluxos de controle simultâneos, cada um com sua raiz independente, baseada em um processo ou em uma thread. Quando mais de um fluxo de controle está em um único objeto simultaneamente, um fluxo de controle pode interferir no outro. Este fato pode acarretar interferências e condições de conflito. A solução desse problema em sistemas $\mathrm{OO}$ consiste em tratar um objeto como uma região crítica, adicionando sincronização entre os métodos que acessam tal região crítica.

Neste trabalho estamos considerando um modelo de fluxo de controle, onde o framework cria os objetos e chama os método em uma determinada ordem. Entre os métodos que o framework chama, pode haver um método que inicia um laço de eventos, como apresentado na Figura 3.1.

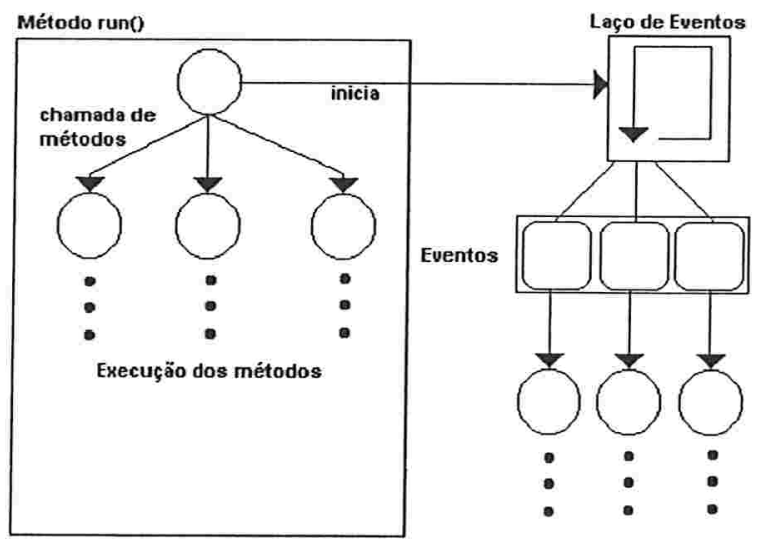

Figura 3.1: Modelo de Controle em Frameworks

Um laço de eventos é um laço que espera por eventos do sistema operacional e, dependendo do evento que acontece, executa uma tarefa predeterminada. Quando uma aplicação pergunta a um sistema operacional do evento, o sistema operacional verifica se qualquer outra aplicação precisa executar qualquer tarefa e então fornece tempo para executar tal tarefa. O sistema operacional fornece para a aplicação original o evento pedido. Contanto que, cada aplicação peça eventos do sistema operacional numa base regular e freqüente, a cada aplicação será dado um tempo para executar. Como conseqüência, o sistema é capaz de fornecer ao usuário a percepção de que várias aplicações são executadas simultaneamente. Quando um framework tem o laço de eventos da aplicação ele controla todos os eventos daquela aplicação e decide que métodos chamar em respostas aos eventos gerados. 
Uma das mais importantes contribuições que um framework faz para uma aplicação derivada dele é o fluxo de controle implementado nos métodos hook. Com isto, o projetista da aplicação não deve se preocupar sobre este importante e dificil assunto [33]. Para implementar uma aplicação baseada em um framework o projetista deve somente redefinir os métodos para executar as tarefas específicas da aplicação.

\subsubsection{1 - Estilos de Fluxo de Controle}

Um framework pode incorporar um estilo de fluxo de controle que especifica como as partes do framework interagem. De acordo com [42] existem quatro estilos: (i) dirigido a eventos: eventos externos são recebidos e processados na ordem que eles surgem; o sistema fica ocioso durante o intervalo entre dois eventos. Esse estilo é usado na maioria dos frameworks existentes; (ii) polling: o framework continuamente monitora controles externos e age quando o controle muda; (iii) passo a passo: o framework tem um grafo dirigido de ações que o usuário deve seguir; o usuário apenas pode se mover imediatamente para frente ou para traz; e (iv) batch: ações são executadas em uma seqüência pré-determinada, sem intervenção externa.

Esses estilos não são exclusivos. Um mesmo framework pode implementar mais de um estilo de fluxo de controle dependendo do momento da execução.

\subsubsection{2 - Níveis de Fluxo de Controle}

Referem-se à interação entre componentes de diferentes níveis. Existem três níveis de fluxo de controle em um framework:

- Método das classes: cada método de classe que contém uma implementação associada tem um fluxo de controle.

- Classes: algumas classes representam um fluxo de controle para uma família de objetos; tais classes são chamadas de classes ativas [41].

- Framework: o fluxo de controle do framework envolve a relação entre as classes do framework e as classes da aplicação. O fluxo de controle global (framework) também é o fluxo de controle da aplicação (framework "que chama"). A Figura 3.2 mostra a relação entre os fluxos de controle dentro de um framework. 


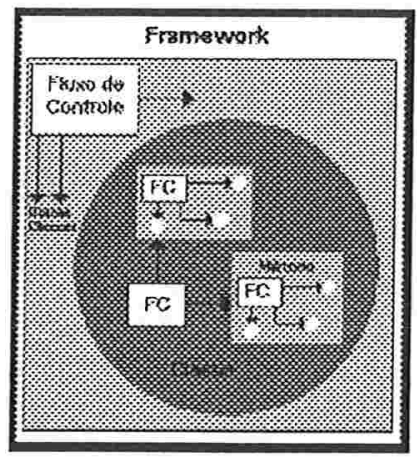

Figura 3.2: Níveis de Fluxo de Controle em Frameworks [20]

\subsection{3 - Comunicação entre Frameworks}

Quando frameworks são compostos (ou em uma aplicação ou para criação de um novo framework), devem existir mecanismos para permitir a comunicação entre os componentes dos frameworks evolvidos na composição. Em Java os objetos se comunicam com outros objetos através do envio de mensagens. Mensagens são valores de tipos de dados trocados pelos objetos. A chegada de alguma mensagem em um objeto é chamada de evento. Eventos são estímulos em algum ponto no tempo que causam uma reação no objeto que recebeu o estímulo. Sendo assim, as comunicações podem ser realizadas através desses dois mecanismos:

a) Passagem de mensagens: é usada quando a mensagem enviada pelo componente tem uma referência explícita para o componente que está recebendo a mensagem. A passagem de mensagens deve ser usada quando se sabe para qual componente enviar a mensagem. Em Java, os objetos se comunicam através da chamada de métodos. Quando um objeto A deseja executar um método de um objeto B, A envia uma mensagem (chamada de métodos) para B. Os dois principais beneficios das mensagens são: (i) um comportamento de objeto é expresso através de seus métodos e (ii) objetos não precisam estar em um mesmo processo ou até mesmo em uma mesma máquina para enviar e receber mensagens [63].

b) Passagem de eventos: é usada quando um componente não conhece para quem enviar a comunicação, ou a comunicação é feita para múltiplos componentes. Manipulação de eventos é a noção mais avançada de passagem de mensagens. Eventos podem ser externos ou internos. Os eventos externos são aqueles passados entre o sistema e seus usuários, por exemplo, pressionar um botão. Eventos internos são aqueles passados entre objetos que vivem no interior do sistema [41]. Eventos são entidades atômicas que se referem a um simples ponto no tempo, ou seja, ele é definido como uma ocorrência instantânea, não consome tempo. Dois 
eventos ocorrem de forma causal quando um evento ocorre em função de uma ocorrência anterior de outro evento. Eventos não relacionados de forma causal são chamados concorrentes [43].

\section{3 - Representação de Frameworks Java}

A representação de frameworks é diferente da representação de outros tipos de software orientados a objetos. Essa diferença vem do fato que frameworks devem ser representados pela parte estática, parte dinâmica, os pontos em que os frameworks devem ser estendidos e como fazer a sua instanciação. Métodos de representação de design OO como OMT e UML, fornecem visões estáticas (diagramas de classes e de objetos) e dinâmicas (diagramas de atividades, de seqüência, de colaboração e transição de estados, etc.), mas não fornecem meios de explicitar como o framework deve ser estendido e como fazer a sua instanciação. Nesse trabalho um framework será representado apenas pela parte estática (diagrama de classes utilizando a notação UML) juntamente com o seu fluxo de controle.

\subsection{1 - Diagrama de Classes}

Mostra a estrutura estática do modelo: em particular, os componentes que existem, tais como: classes, sua estrutura, seus relacionamentos com outros componentes, etc. Diagrama de classes não tem nenhuma informação sobre o tempo. Ele é uma coleção de classes, interfaces e seus relacionamentos conectados como um grafo. Os principais elementos do diagrama de classes são:

- Classe: é um descritor para um conjunto de objetos com estrutura, comportamento e relacionamentos similares (Figura 3.3 - 1A).

- Interface: é um especificador para uma operação externamente visível de uma classe, componente ou outra entidade, sem especificação da estrutura externa (Figura 3.3 - 1B).

- Metaclasse: é uma classe cujas instâncias são classes (Figura 3.3 - 1C).

- Objetos compostos: representam um objeto feito de partes menores, é a instância de uma classe composta, sem implicar a agregação entre a classe e duas partes (Figura 3.3 - 1D).

- Pacote: um conjunto de classes e interfaces, utilizado para evitar conflito de nomes (Figura 3.3 1E). 
- Multiplicidade: especifica o limite da cardinalidade permitida que um conjunto pode assumir, pode ser dado como regras dentro de associações (Figura 3.3 - 2A).

- Associação: um relacionamento entre classes, as associações podem ser: binárias (duas classes); auto-relacionamento (uma classe com ela mesma) e n-ária (três ou mais classes) (Figura 3.3 2B).

- Generalização: é um relacionamento entre um elemento mais geral e um mais específico (Figura $3.3-2 \mathrm{C})$.

- Composição: é uma forma de agregação com propriedade forte e os ciclos de vida das partes coincidem com o do todo. As partes da composição podem incluir classes e associações (Figura $3.3-2 D)$.

A Figura 3.3 mostra a representação gráfica do diagrama de classes em UML.

Companentes

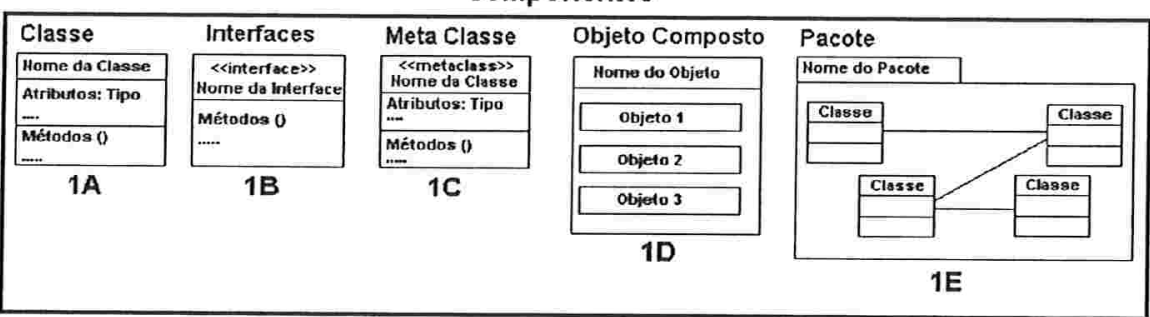

Relacionamentos

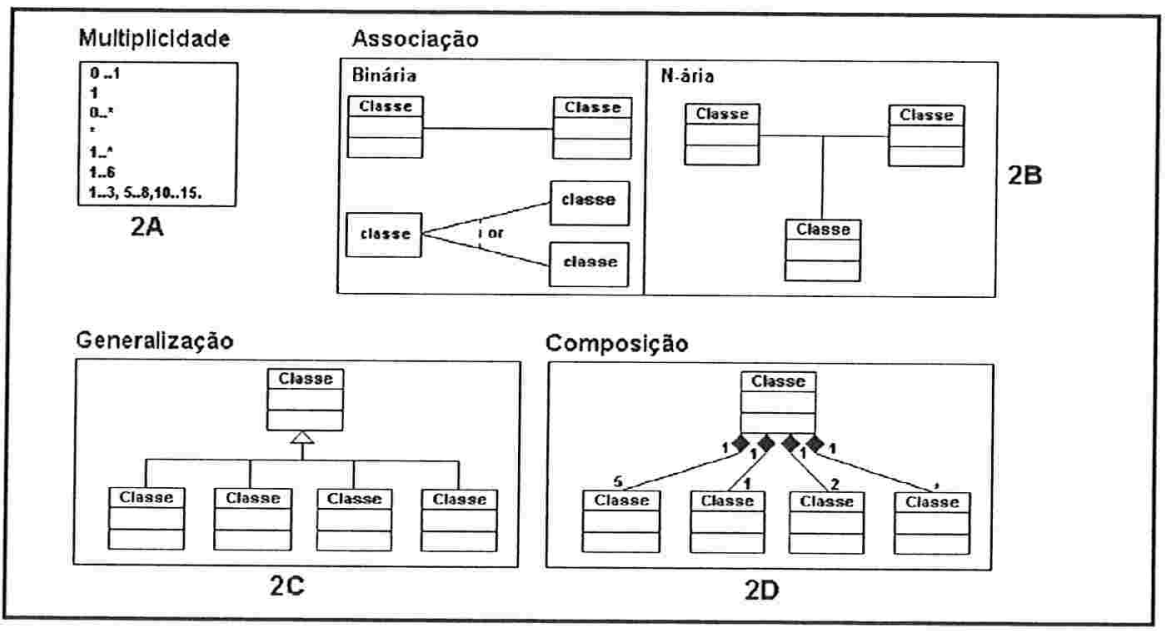

Figura 3.3 - Representação do Diagrama de Classes em UML [41] 


\subsection{2 - Fluxo de Controle}

Uma representação de fluxo de controle para a composição deve contemplar os vários aspectos que devem ser considerados quando se compõe fluxos de controle de frameworks. Os aspectos que devem ser representados são:

- Objetos (classes) e Métodos: para uma classe temos que ter informações sobre: variáveis e métodos. Cada método, por sua vez, é representado por sua interface (argumentos e retorno), as variáveis que lê e modifica, os métodos que chama e pré-condições, objetos e fluxo de controle, sendo que todas essas informações podem ser obtidas a partir do código fonte do framework (Figura $3.4-1$ ).

- Formas de execução: o modo como os métodos podem ser executados devem ser diferenciados, os tipos de execução podem ser: (i) seqüencial: um método executa primeiro e quando termina o outro executa (Figura 3.4 - 2.A); (ii) paralela: dois ou mais métodos executam ao mesmo tempo (Figura 3.4 - 2.B); e (iii) condicional: um método, para executar, depende de alguma condição. Neste caso a condição deve ser representada também (Figura 3.4 -2.C).

- Solicitação de serviços do outro framework (troca de mensagem): solicitação de mensagem inter-frameworks, essa chamada pode ser dos mesmos tipos acima (com ou sem retorno e com ou sem argumento) (Figura $3.4-3$ ).

Alguns desses aspectos devem ser representados graficamente, como: chamada de métodos; solicitação de serviços entre frameworks; etc. Outros não precisam: variáveis que os métodos lêem, modificam, etc. Na Figura 3.4 temos uma descrição gráfica das estruturas citadas acima baseado em [55] 

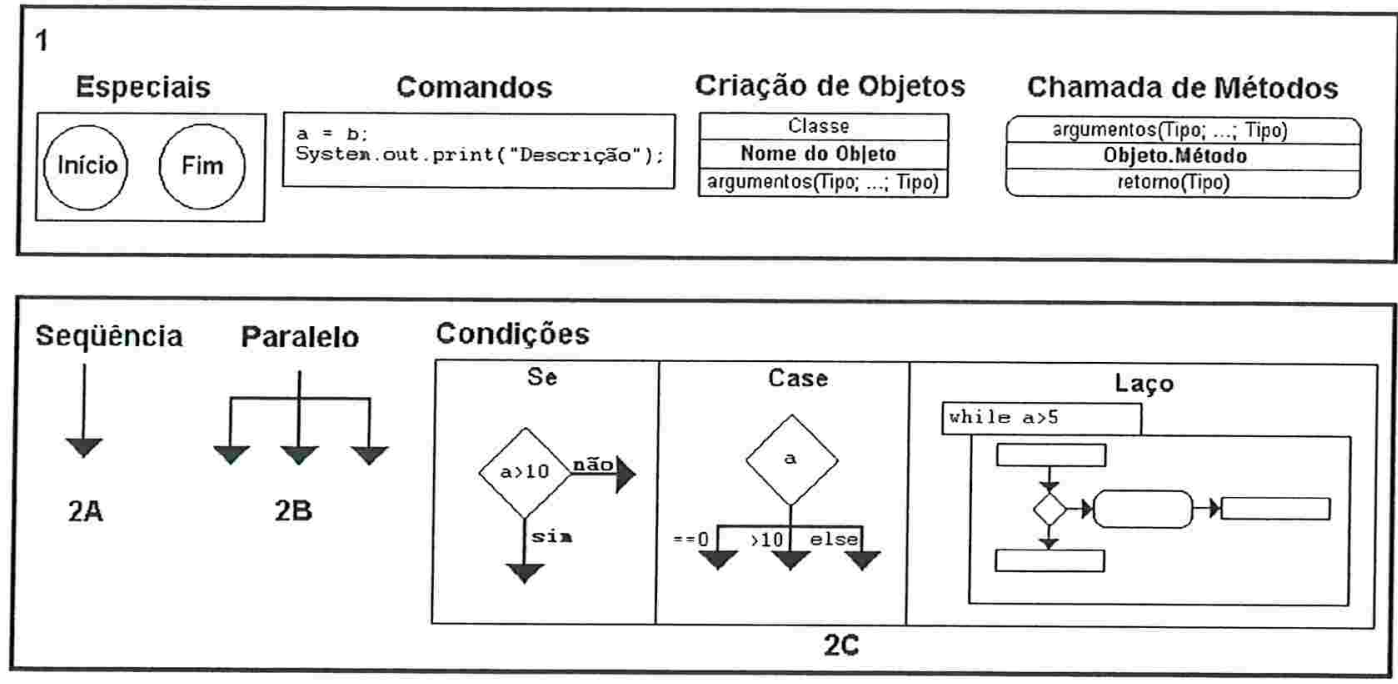

3 Troca de mensagens entre Frameworks

\begin{tabular}{|c|c|}
\hline Método & Objeto \\
\hline Argumentos(Tipo;...;Tipo) & Método \\
\cline { 2 - 2 } & retorno(Tipo) \\
\hline
\end{tabular}

Figura 3.4 - Representação Gráfica do Fluxo de Controle.

\section{4 - Exemplos de Frameworks Java}

Nessa seção são apresentados exemplos de frameworks desenvolvidos em Java. Tais frameworks estão implementados como parte da representação dos dados do programa MADAM (Mangrove Dinamics and Management), e foram projetados para fins didáticos, eles não foram construídos utilizando um estudo extensivo de domínio. São apresentados quatro exemplos de frameworks: Projetos, Espécies, Publicações e Financiamento.

\subsection{1 - Framework Projetos}

Descreve como inserir informações a respeito de dados em projetos. Cada projeto tem um coordenador, pesquisadores, algumas linhas de pesquisa e informações associadas. As informações são descritas pelo relacionamento das seguintes classes: método, local e parâmetro. O diagrama de classes para esse framework é apresentado na Figura 3.5. 


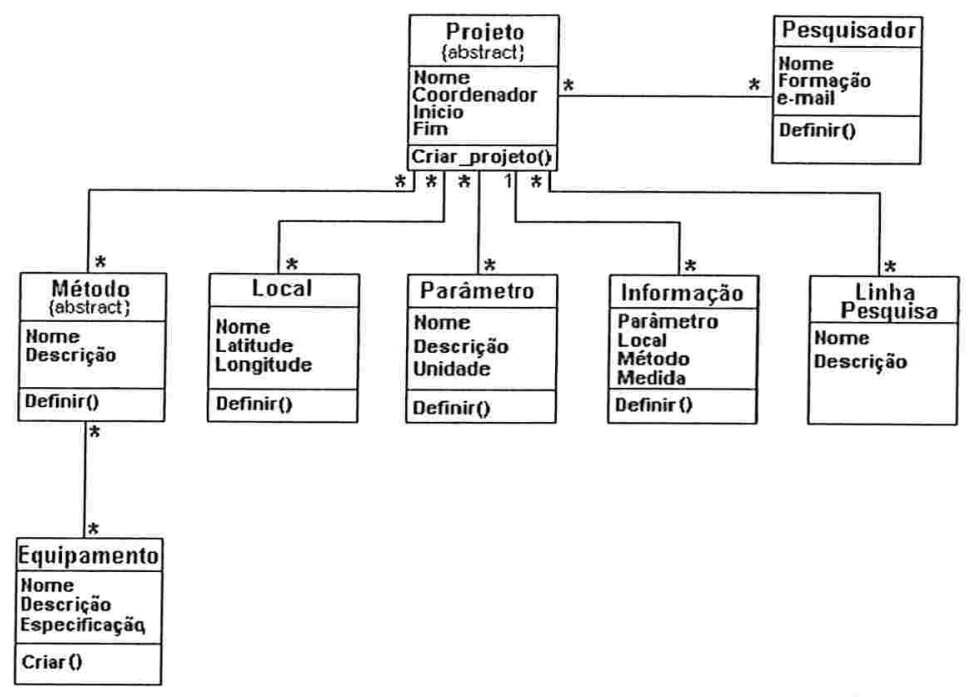

Figura 3.5: Diagrama de Classes para o Framework Projetos

O fluxo de controle mostra a ordem que os objetos devem ser criados e métodos devem ser chamados. Para o framework Projetos, o fluxo de controle foi implementado da seguinte forma: deve-se primeiro criar um projeto chamando o método Criar_projeto (), tal método cria um objeto da classe Projeto. Depois de criado o objeto deve-se definir os pesquisadores envolvidos no projeto (Definir_coordenador() e Definir_pesquisador()). Definidos o projeto e os pesquisadores deve-se definir as informações do projeto, para isso deve-se primeiro definir os locais (Definir_local()), métodos (Definir_metodo()), equipamentos (Definir_equipamento()), parâmetros (Definir_parametro()). A partir dessa definição pode-se inserir todas as informações relacionadas a um determinado projeto. 


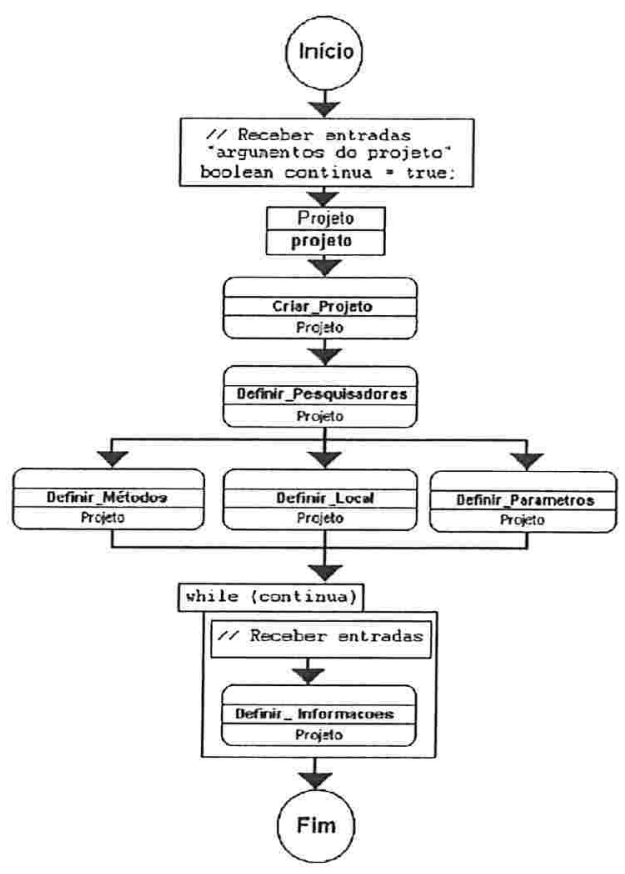

Figura 3.6: Fluxo de Controle para o Framework Projetos

Para desenvolver uma aplicação baseada nesse framework o projetista deve estender a classe Proj eto e a classe Metodo, de forma que elas deixem de ser abstratas. Depois o projetista deve definir os pesquisadores, e definir as informações relacionadas.

\subsection{2 - Framework Espécies}

Construído para representar dados sobre a taxonomia de espécies científicas. Existem na literatura vários tipos de taxonomia, por isso o framework deve ser geral o suficiente para que a maioria das taxonomias disponível seja representada. A classificação escolhida foi dividida em: espécies; gênero; família; classe; filo e reino. 


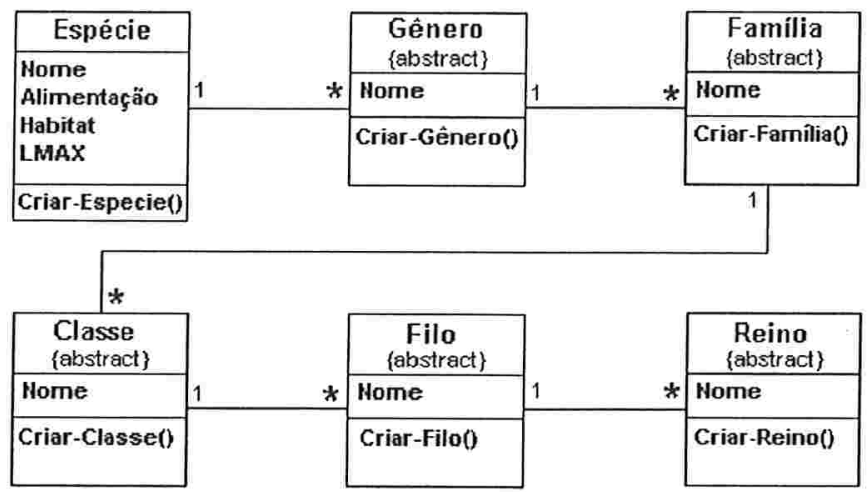

Figura 3.7: Diagrama de Classes para o Framework Espécies

O fluxo de controle é para a definição de uma nova espécie (Criar_especie ()). Cada espécie tem um gênero relacionado, caso o gênero ainda não exista, ele deve ser criado (Criar_genero()) e assim por diante. A Figura 3.8 apresenta graficamente o fluxo de controle.

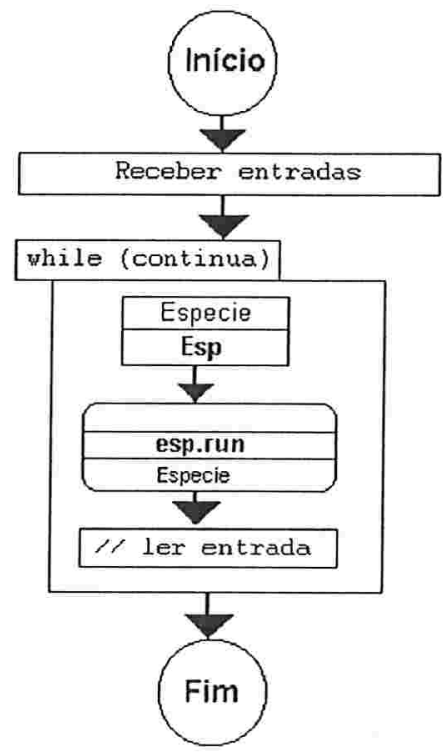

Figura 3.8: Fluxo de Controle para o Framework Espécies

Para construir uma aplicação desse framework o projetista deve escolher quais classes farão parte da sua taxonomia, por exemplo: somente espécie, gênero e família. A partir dessa definição, deve-se, na aplicação, tornar as classes concretas. 


\subsection{3 - Framework Publicação}

Criado para representar todos os tipos de publicações, as publicações são divididas em cinco tipos: livro, capítulo de livro, tese, revista científica e artigo de anais. Para cada publicação ainda estão disponíveis informações sobre os autores e palavras chave.

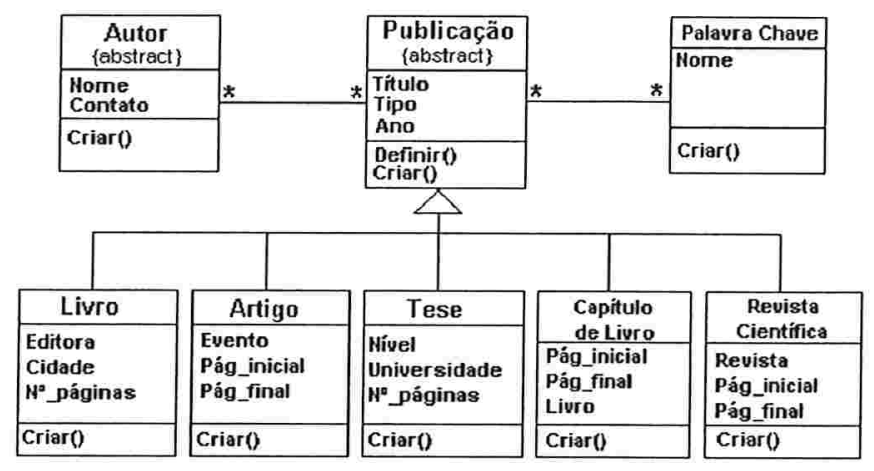

Figura 3.9: Diagrama de Classes para Framework Publicação

O fluxo de controle consiste na criação de uma nova publicação, para isso o usuário deve chamar o método criar_publicacao() da classe Publicacao, esse método cria os autores (criar_autor()) e as palavras chaves (criar_palavrachave()), depois um método de criar um tipo específico de publicação é criado, dependendo da entrada.

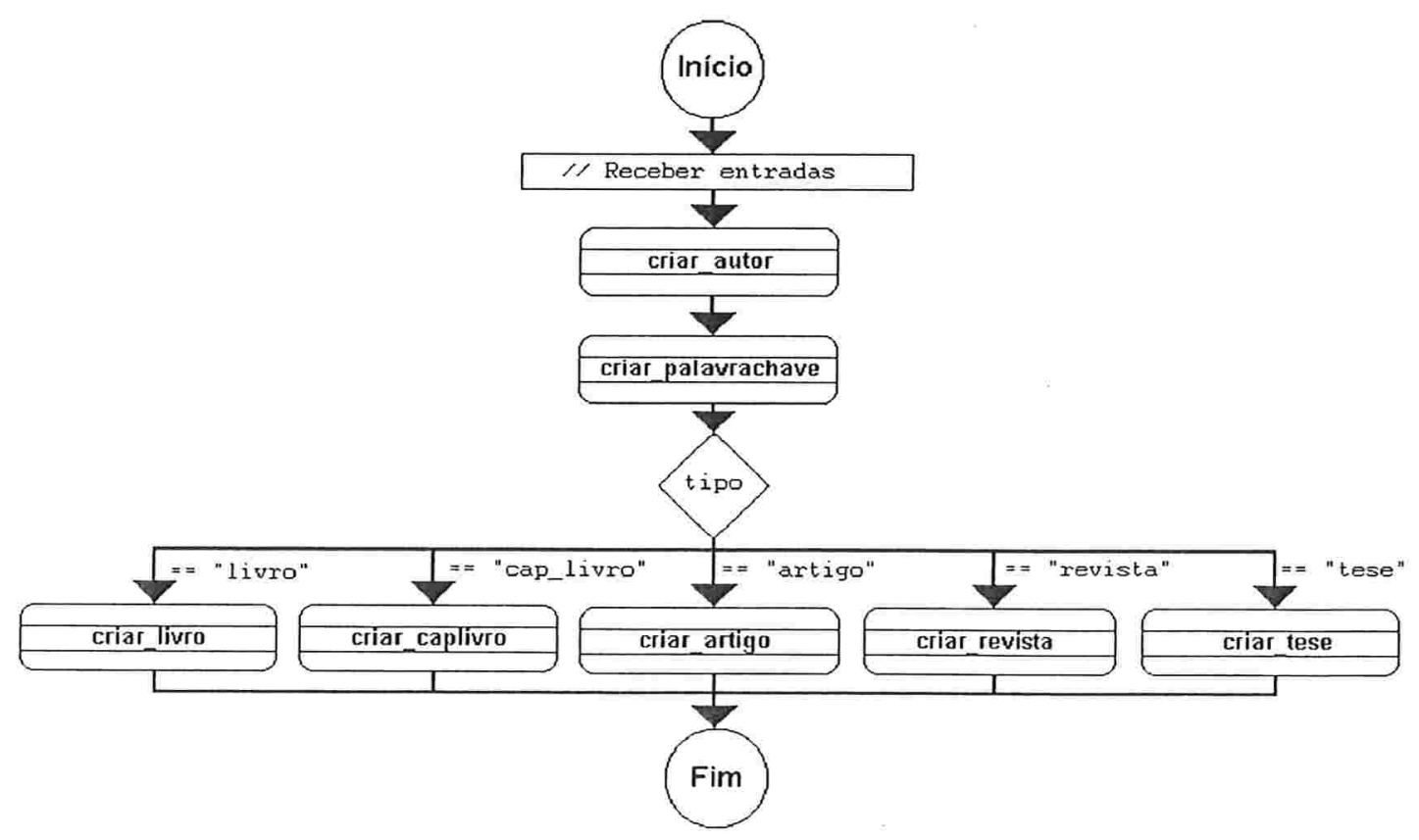

Figura 3.10: Fluxo de Controle para o Framework Publicação 
Aplicações derivadas desse framework devem ser criadas estendendo as classes Publicacao e Autor com as informações desejadas, sendo que todos os relacionamentos entre as classes foram criados nas classes abstratas.

\subsection{4 - Framework Financiamento}

Desenvolvido para representar dados sobre o financiamento de projetos de pesquisa através da distribuição de bolsas de pesquisa para bolsistas.

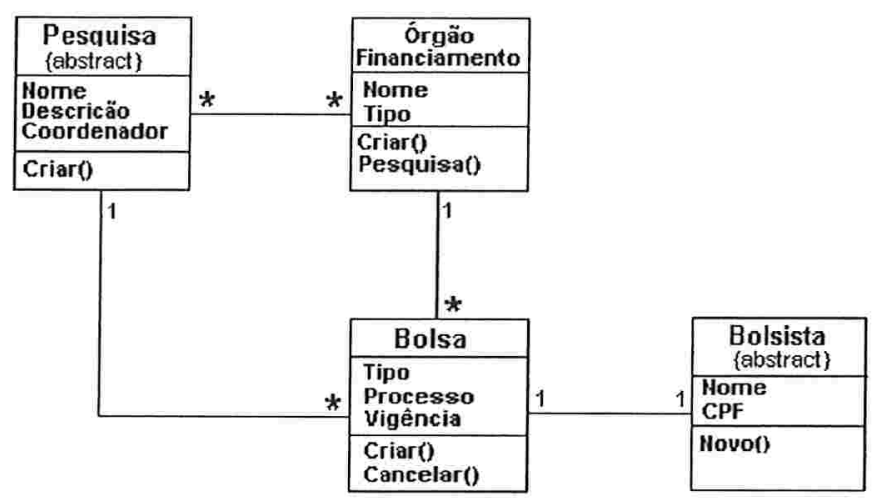

Figura 3.11: Diagrama de Classes para Framework Financiamento

O framework deve ser usado para relacionar as pesquisas com as bolsas distribuídas pelos vários órgãos de financiamento, dessa forma o fluxo de controle do framework deve criar os objetos: pesquisa (Definir_Pesquisa()) e órgão de financiamento (Definir_orgaofinanciamento()), para em seguida relacionar a pesquisa com o órgão de financiamento (Definir_financiamento ()). Definidas as pesquisas, os órgãos financiadores e o financiamento, deve-se definir todas as bolsas(Definir_bolsa()) e bolsistas (Definir_bolsista()) para essa determinada pesquisa. 


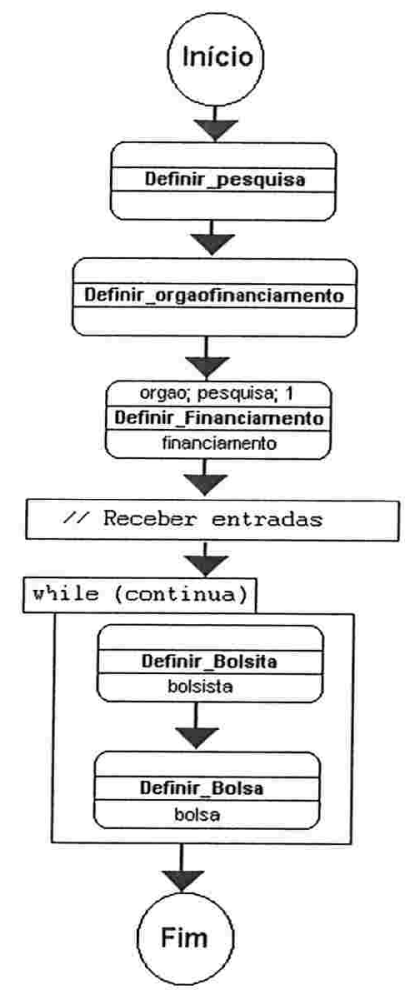

Figura 3.12: Fluxo de Controle para o Framework Financiamento

\section{5 - Considerações Finais}

Java é hoje uma das linguagens mais utilizadas para o desenvolvimento de frameworks nos mais variados domínios. Isso acontece porque Java tem algumas características importantes ao desenvolvimento de frameworks, entre elas podemos citar:

a) Portabilidade: a principal contribuição de Java é a interface de programação universal para todos os computadores. Isso significa uma grande portabilidade para o framework desenvolvido em Java, ele executa automaticamente em qualquer sistema que tem uma implementação da máquina virtual Java, não necessitando recompilar o framework para cada plataforma.

b) Eficiente: Java foi criada para ser usada em computadores pequenos, por isso, ela exige pouca memória. Ela é mais eficiente que grande parte das linguagens de "scripting", mas sua eficiência ainda está longe da linguagem $C$. 
c) Documentação: fornece um meio de desenvolver documentação de framework, através da ferramenta JavaDoc, essa ferramenta documenta aplicações de maneira sofisticada baseada em HTML e Java.

d) Segurança: um certo grau de segurança é muito importante em desenvolvimento de frameworks. Java é consideravelmente segura.

e) Bibliotecas padrão: Java tem algumas coleções de classes e interfaces úteis para a programação. Por exemplo, o pacote java util tem algumas classes que facilitam o desenvolvimento de estrutura de dados, por exemplo: Enumeration; Vector; Stack; Hashtable; etc.

f) Carregamento de classes dinâmico: o sistema em tempo de execução de Java carrega as classes sob demanda, quando as classes são necessárias. Além disso, Java pode carregar classes de redes ou explicitamente via mecanismo java. lang. ClassLoader.

g) Linguagem voltada para internet: Java é a principal linguagem para desenvolvimento de programas para a internet. Hoje, grande parte das aplicações precisam ser voltadas para a internet.

h) Ambiente distribuído: entre os atrativos de Java está a facilidade que oferece para desenvolver aplicações para execução em sistemas distribuídos ou em ambiente cliente-servidor, usando os mecanismos da Internet, tais como os protocolos TCP/IP e UDP. Aplicações distribuídas mais elaboradas podem ser desenvolvidas usando uma arquitetura de objetos distribuídos, onde aplicações orientadas a objetos lidam diretamente com referências a objetos em processos remotos. Java oferece duas alternativas nessa direção, RMI (Remote Method Invocation), uma solução 100\% Java, e Java IDL, esta uma solução integrada à arquitetura padrão CORBA.

Graças a essas características, vários frameworks comerciais e acadêmicos foram desenvolvidos em Java [25, 32, 44, 45, 46 e 47]. Devido ao crescimento do número de frameworks Java, surge a necessidade de reutilizá-los tanto por extensão quanto por composição. Este trabalho estuda a composição de fluxo de controle de frameworks Java, onde a única forma de comunicação possível entre os frameworks é através da troca de mensagem; tal composição é apresentada no próximo capítulo. 


\section{Capítulo 4 - Composição de Fluxos de Controle de Frameworks}

Este capítulo apresenta composição de frameworks e, em particular, composição de fluxos de controle de frameworks e os seus tipos: por eventos e por troca de mensagens, descrevendo os problemas associados à composição de frameworks e à composição de fluxo de controle. Além disso, são apresentados alguns trabalhos relacionados à composição de fluxo de controle e como eles resolvem esse problema.

\section{1 - Composição de Software 00}

As principais técnicas de reutilização no desenvolvimento de software OO utilizam a composição de software. Tal composição está baseada em mecanismos utilizados na construção de classes, as quais permitem indicar o que cada objeto faz sem especificar como realizar suas tarefas, ou pelo menos, sem permitir que outros objetos dependam da forma como ele as realiza.

Composição de software pode ser definida como "a construção sistemática de aplicações de componentes que implementam abstrações pertencentes a um domínio de problema particular" [48]. Algumas abordagens para definir composição de software em domínio específico de aplicações são [48]: (i) linguagens de quarta geração: facilitam o desenvolvimento de interfaces baseadas em formulários para aplicações baseadas em dados; (ii) geradores de aplicações: uma linguagem ou interface de alto nível que descreve configurações de aplicações, gerando código fonte; (iii) bibliotecas de componentes e construtores: uma linguagem de alto nível ou ferramenta gráfica usada para combinar e configurar componentes de software existentes; e (iv) frameworks: padrões de componentes de software especificados como classes abstratas ou concretas, e aplicações programadas pela especialização e extensão das classes do framework.

Há diferentes níveis de composição de software [48]: o primeiro nível é o das construções de programação em uma linguagem particular, o segundo nível é o de soluções de componentes de domínio específico e o terceiro nível é o de componentes específicos de domínio da aplicação. Este último nível é o 
mais difícil de se obter, uma vez que somente pode ser alcançado depois da coleta e abstração das experiências de um número suficiente de aplicações específicas no domínio.

Como notado por Oscar Nierstrasz [48], frameworks são uma prática promissora, mas alguns problemas estão relacionados à sua composição:

a) Linguagens:

- Como, em geral, componentes de software e mecanismos de composição podem ser especificados?

- Como se pode especificar arquiteturas genéricas e frameworks?

- Como se pode especificar aplicações como composições, de forma que suas arquiteturas sejam explícitas?

b) Ferramentas:

- Como dar suporte à especificação de requisitos dirigidos a frameworks?

- Que tipos de sistemas de informação de software são necessários para gerenciar os artefatos de software relevantes?

- Que tipos de ferramentas interativas podem ajudar na construção e manutenção de aplicações formadas por componentes?

c) Métodos:

- Que métodos existentes podem ser estendidos para adaptar o desenvolvimento de aplicações baseadas em frameworks?

- Que técnicas e métodos podem ajudar no desenvolvimento e evolução do framework (em oposição a aplicações individuais)?

\section{2 - Composição de Frameworks}

O desenvolvimento de aplicações é, cada vez mais, baseado em múltiplos frameworks que precisam ser compostos com outros componentes. O principal problema de composição de frameworks é que eles não foram projetados para serem compostos, mas para serem reutilizados individualmente. A composição de frameworks pode ser realizada de duas maneiras: (i) compor dois ou mais frameworks para criar um novo 
framework com as características dos primeiros e, opcionalmente, algumas características adicionais; e (ii) criar uma aplicação derivada de vários frameworks, nesse caso o produto resultante é uma aplicação que tem como base dois ou mais frameworks. Este trabalho trata da composição de dois frameworks para a criação de um terceiro framework, sendo que os frameworks são desenvolvidos em Java.

Pode-se também identificar duas variantes da composição de framework: horizontal e vertical. Composição horizontal é a situação aonde os frameworks compostos podem ser encontrados na mesma camada em um sistema de software. Composição vertical indica a situação onde um framework depende do serviço de um outro(s) frameworks. Outro tópico importante é a forma de comunicação entre os frameworks, podendo ser: unidirecional ou bidirecional. Comunicação bidirecional é mais difícil de se tratar na composição.

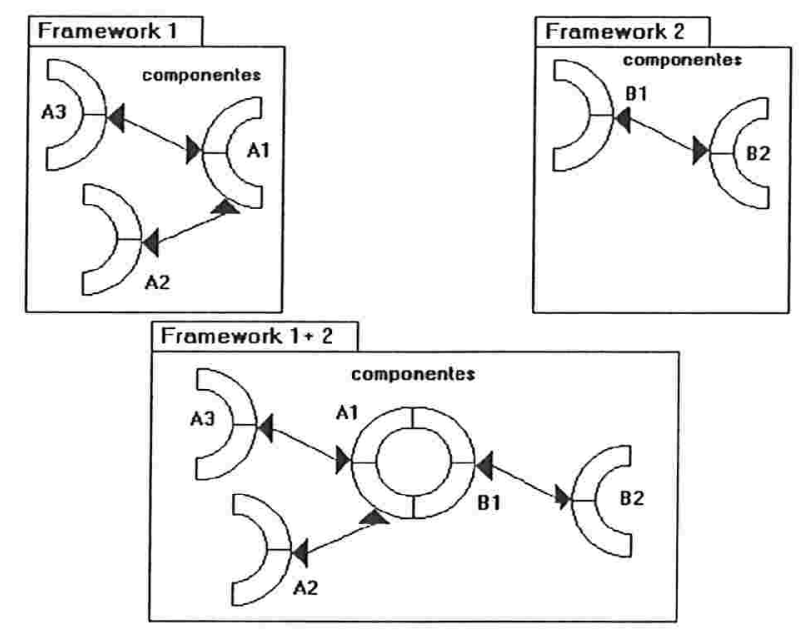

Figura 4.1: Composição de Frameworks [49]

A Figura 4.1 apresenta um esquema da composição de frameworks, onde um framework é representado por um conjunto de componentes que deve ser composto com os componentes do outro framework. Para realizar essa composição, os aspectos estáticos e dinâmicos dos frameworks devem ser compostos. Aspectos estáticos são as classes e interfaces. Os aspectos dinâmicos são o fluxo de controle e as comunicações entre os frameworks. Compor frameworks não é uma tarefa trivial, uma vez que vários aspectos devem ser levados em consideração: número de frameworks; forma de composição; meio de comunicação; etc. A seção seguinte apresenta os problemas gerais e as causas que podem acontecer durante a composição de frameworks. 


\subsection{1 - Problemas e Causas}

Quando dois ou mais frameworks são compostos, alguns problemas podem acontecer. Os problemas gerais de composição de frameworks são [1, 12, 50 e 56]:

a) Composição de fluxo de controle: uma das características que mais diferencia os frameworks é a habilidade de fazer uso extensivo de ligação dinâmica. Em bibliotecas de classes ou procedimentais, o código da aplicação chama rotinas na biblioteca e o código da aplicação é o fluxo de controle. Para frameworks OO a situação é invertida e freqüentemente o código do framework gerencia o fluxo do controle e chama o código da aplicação quando apropriado. Quando dois frameworks são compostos, os seus fluxos de controle têm que ser compostos de alguma forma.

b) Composição com sistemas legados: um framework apresenta um design para uma aplicação em um domínio particular. Baseado neste domínio, o projetista pode construir uma aplicação concreta através da extensão de um framework, derivando subclasses. Quando a classe do framework somente contém comportamento para a funcionalidade interna do framework, mas não o comportamento específico exigido pela aplicação, o projetista pode querer incluir componentes legados na aplicação que necessitam ser integrados com o framework, porém, não é trivial integrar os componentes legados na aplicação, uma vez que frameworks utilizam $\mathrm{OO}$ e os componentes legados podem não utilizar mecanismos $\mathrm{OO}$.

c) Frameworks gap: também conhecido como carência de requisitos, ocorre quando dois ou mais frameworks são compostos e a estrutura resultante ainda não cobre os requisitos das aplicações. Se o framework for "chamado" o problema pode ser resolvido com uma interface adicional, incluindo a funcionalidade existente e os requisitos adicionais de funcionalidade. No caso do framework for "que chama" e está faltando funcionalidade, um software intermediário é necessário para resolver o problema.

d) Sobreposição de entidades: dois ou mais frameworks podem conter representações de uma mesma entidade do mundo real modeladas sob perspectivas diferentes. Quando compomos dois frameworks, as duas diferentes representações devem ser integradas ou compostas, uma vez que elas representam a mesma entidade no mundo real. Se as representações das propriedades são mutuamente exclusivas, ou seja, uma não influencia a outra, a integração pode ser resolvida por herança múltipla (ou equivalente). Porém, muito freqüentemente estas pré-condições não acontecem e existem propriedades partilhadas ou dependentes entre as representações. 
e) Composição de funcionalidade de entidade: algumas vezes uma funcionalidade da entidade do mundo real tem que ser modelada através de composição de funcionalidades de diferentes sistemas. Considere o caso de uma estrutura de software típica com três camadas, cada uma representada por um framework. No topo tem a camada de interface do usuário, no meio a camada específica do domínio da aplicação e em baixo a camada de persistência. Uma entidade do mundo real é representada em um framework específico do domínio da aplicação, embora alguns aspectos tenham que ser representados na camada da interface do usuário e a entidade tem que ser feita persistente para alguns tipos de transações. Só compondo as respectivas classes dos três frameworks não resultará no comportamento desejado.

As causas para os problemas citados na seção anterior podem ser resumidas como: coesão do framework; cobertura do domínio, intenção do design, falta de padrões e falta de acesso ao código fonte [1, $12,50$ e 56$]$ :

a) Coesão do framework: estabelece a coesão entre as entidades no framework. Para uma classe em uma biblioteca de classes ou em outro framework substituir uma classe dentro do framework, ela deve não somente ter que representar o comportamento do domínio apropriado, mas também o comportamento coesivo. Uma vez que ele é muito específico para o framework.

b) Cobertura do domínio: um framework não precisa cobrir completamente o domínio que ele pertence, mas pode conter classes para um subconjunto das entidades relevantes no domínio. Quando dois frameworks são compostos, pode-se encontrar nenhuma sobreposição de domínio, pouca sobreposição ou uma grande sobreposição. Uma sobreposição grande pode causar a composição de um framework ser mais trabalhosa do que escrever um novo.

c) Intenção de design: frameworks são intencionalmente projetados para serem reutilizados por adaptação, mas não por composição. A intenção do design deve ser definida explicitamente para facilitar o engenheiro de software decidir sobre a possibilidade de compor um framework. Além disto, deve estar clara a forma de comunicação do framework.

d) Falta de padrões: por ser uma tecnologia relativamente nova, ainda não existem padrões para modelagem, representação e adaptação dos frameworks existentes. Dessa forma, acontecem problemas para interoperação de frameworks devido às várias suposições (decisões de design) que os projetistas fizeram ao desenvolvê-lo. 
e) Falta de acesso ao código fonte: pode ser uma limitação prática, por exemplo, quando o framework foi entregue para ser reutilizado na forma de código compilado ou conceitual, devido à dificuldade (ou impossibilidade) de entendimento do código. Acesso ao código fonte é importante, uma vez que a composição do framework pode exigir editar o código do framework. Se o acesso ao código fonte não está disponível, a única maneira de se alcançar o comportamento adicional exigido pelo framework é através de uma envoltura encapsulada ao framework, causando problemas de desempenho.

Na tabela abaixo estão relacionados os problemas de composição e suas respectivas causas, identificando a causa primária e os fatores que podem complicar a composição [1 e 50].

\begin{tabular}{||c|c|c|c|c|c||}
\hline \hline & $\begin{array}{c}\text { Composição } \\
\text { de Controle }\end{array}$ & $\begin{array}{c}\text { Sistemas } \\
\text { Legados }\end{array}$ & $\begin{array}{c}\text { Frameworks } \\
\text { Gap }\end{array}$ & $\begin{array}{c}\text { Sobreposição } \\
\text { de Entidades }\end{array}$ & $\begin{array}{c}\text { Funcionalidade } \\
\text { de Entidade }\end{array}$ \\
\hline $\begin{array}{c}\text { Comportamento } \\
\text { Coesivo }\end{array}$ & $\begin{array}{c}\text { Fator que } \\
\text { complica }\end{array}$ & Causa primária & - & $\begin{array}{c}\text { Fator que } \\
\text { complica }\end{array}$ & Fator que complica \\
\hline $\begin{array}{c}\text { Cobertura de } \\
\text { domínio }\end{array}$ & - & - & Causa primária & Causa primária & - \\
\hline $\begin{array}{c}\text { Intenção de } \\
\text { Design }\end{array}$ & Causa primária & $\begin{array}{c}\text { Fator que } \\
\text { complica }\end{array}$ & - & $\begin{array}{c}\text { Fator que } \\
\text { complica }\end{array}$ & Causa primária \\
\hline $\begin{array}{c}\text { Falta de Padrões } \\
\text { Falta de acesso a } \\
\text { Código Fonte }\end{array}$ & $\begin{array}{c}\text { Fator que } \\
\text { complica }\end{array}$ & $\begin{array}{c}\text { Fator que } \\
\text { complica }\end{array}$ & - & $\begin{array}{c}\text { Fator que } \\
\text { complica }\end{array}$ & Fator que complica \\
\hline \hline
\end{tabular}

Tabela 4.1: Relacionamento entre os problemas e suas causas [1]

De acordo com os problemas citados anteriormente sobre composição de frameworks, pode-se identificar dois grupos de problemas: de design e de implementação.

- Problemas de design: framework gap; sobreposição de entidades e composição de funcionalidade.

- Problemas de implementação: composição de fluxo de controle e composição com código legado. 
O presente trabalho trata da composição de fluxo de controle em frameworks. Para esse problema os aspectos que mais influenciam na composição são: frameworks são projetados para serem estendidos e não compostos; granularidade do framework e os recursos que tais fluxos de controle gerenciam.

\section{3 - Composição de Fluxos de Controle de Frameworks}

Frameworks freqüentemente gerenciam os fluxos de controle chamando o código da aplicação quando apropriado. Para utilizar um framework, basta implementar o código específico da aplicação que será chamado pelo framework (callbacks); o fluxo de controle da aplicação é determinado pelo framework.

Durante a composição de frameworks, os seus fluxos de controle também devem ser compostos. Quando os dois ou um dos frameworks for "chamado", não haverá problemas, uma vez que o novo framework ou um outro framework "que chama" gerenciará o fluxo de controle. Os problemas de composição de fluxo de controle acontecem quando desejamos compor frameworks "que chamam"; ambos esperam ser a entidade gerenciadora do fluxo de controle da aplicação. A causa principal para este problema é que ambos os frameworks são intencionalmente projetados para adaptação e não para composição, e frameworks "que chamam" são intencionalmente projetados para gerenciar o fluxo de controle.

Para compor de maneira correta os fluxos de controle é preciso realizar mudanças em um ou ambos os fluxos de controle. Mudanças no fluxo de controle dos frameworks envolvidos requer adaptações no código fonte. Neste trabalho consideramos o acesso ao código fonte. Alguns problemas podem aparecer quando dois fluxos de controle não estão corretamente compostos em um framework:

- Colisão de laços (overlap): dois laços de controle tentam controlar o mesmo recurso.

- Falta de controle (gap): um novo recurso tem que ser adicionado ao framework ou à aplicação, mas os frameworks não foram projetados para controlar tal recurso.

- Interferência: a execução do fluxo de controle de um framework interfere na execução do outro, seja por uma troca de mensagens, pela geração de eventos ou pelo compartilhamento de memória.

- Execução incorreta: qualquer um dos frameworks pode ter uma execução incorreta, uma vez que eles não foram projetados para ser reutilizados por composição e utilizados em conjunto com outros frameworks. 
- Parada na execução: acontece quando as interações entre os frameworks impossibilitam a continuação da execução de um ou ambos os frameworks, por exemplo, quando acontece uma situação de deadlock.

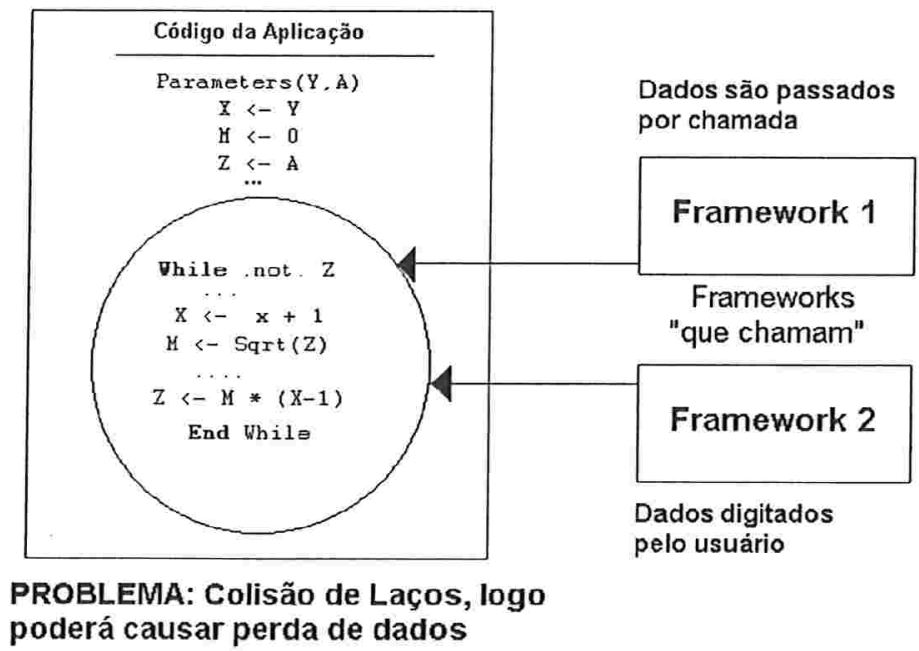

Figura 4.2: Colisão de laços quando se compõe fluxo de controle em frameworks [51].

Na Figura 4.2, podemos ver, por exemplo, o problema de colisão de laços. Neste exemplo, temos dois frameworks "que chamam" disputando a chamada e o controle de um método. Neste caso, podem ocorrer erros quando os dois frameworks chamam o mesmo método e este possui algum laço de execução; ambos interagem de forma distinta com o método. Enquanto um aciona a sua interface passando parâmetros, o outro recebe do usuário informações que serão processadas para serem enviadas ao método. Devido às velocidades com que os parâmetros são enviados, podem ocorrer problemas de retorno de valor, pois os dados podem ser mesclados e uma resposta não satisfatória será enviada a ambos os frameworks, por não se saber por quem ou quando os dados foram passados.

\subsection{1 - Tipos de Composição de Fluxo de Controle}

Como a composição de fluxo de controle de frameworks é realizada efetivamente quando um framework se comunica com outro, os tipos de composições existentes são semelhantes às formas de comunicação entre frameworks descritas na Seção 3.2.3, ou seja, através da passagem de mensagens e passagem de eventos. Tal definição é puramente didática, uma vez que elas geralmente acontecem ao mesmo tempo durante a composição de frameworks. 
a) Baseada em troca de mensagens: nesse tipo de composição, os frameworks se comunicam apenas por troca de mensagens. Uma mensagem para ser enviada, deve ter uma referência explícita para o componente que recebe a mensagem, ela só pode ser usada quando se sabe de antemão para quem a mensagem é destinada. Podemos identificar quatro variantes na composição por troca de mensagens: sem comunicação, comunicação seqüencial, comunicação paralela unidirecional e comunicação paralela bidirecional. Esse trabalho trata especificamente a composição de fluxo de controle baseada em troca de mensagens, por isso, ela será mais detalhada no restante do trabalho.

b) Baseada em eventos: é usada quando não se sabe para quem enviar a mensagem, ou quando a mensagem tem múltiplos destinatários (componentes). A composição baseada em eventos se efetiva quando um evento é gerado (interno ou externo) e ambos os frameworks são capazes de responder a esse evento. Quando isso acontece, deve-se verificar a existência de interferências na execução dos dois frameworks. Tal composição é mais difícil de tratar do que a baseada em troca de mensagens, porque quando se usa eventos, vários componentes podem responder a um mesmo evento, gerando várias respostas para uma mesma comunicação. Pode-se dividir esse tipo de composição em quatro sub-tipos: sem eventos compartilhados, com eventos externos compartilhados, com eventos internos compartilhados e com eventos internos e externos compartilhados.

\section{4 - Trabalhos Relacionados}

Existem alguns trabalhos na literatura citando o problema de fluxo de controle em composição de software ou frameworks. Nessa seção apresentaremos como alguns trabalhos solucionaram o problema de composição de fluxo de controle [1, 13, 42, 51 e 52].

a) Concorrência: apresentada em [1 e 42], pode somente ser usada quando não há necessidade para o framework ou para o código da aplicação ser notificado sobre eventos e/ou mensagens de outros frameworks. Ela consiste em dar para cada framework seu próprio fluxo de controle em lugar de fundi-los. Uma desvantagem dessa abordagem é que os objetos específicos da aplicação que potencialmente são acessados por mais de um framework necessitam ser estendidos com código de sincronização, uma vantagem é o fato de não acessar o código fonte dos dois frameworks.

b) Wrapping (envoltura): consiste em encapsular cada framework por um "wrapper" interceptando todas as mensagens enviadas para e pelo framework e notificando as entidades interessadas no framework. Isso 
permite algum nível de integração de eventos nas aplicações baseadas em frameworks, mas, baseadas somente em eventos externos; eventos internos não são interceptados e conseqüentemente não podem ser tratados [1].

c) Remover e reescrever: quando a integração do fluxo de controle torna-se muito difícil, ou se são necessárias notificações dos eventos internos do framework para a aplicação ou para o outro framework, uma solução é remover as partes relevantes do laço de controle do framework e escrever um laço de controle específico (para a aplicação ou para o novo framework), que satisfaça as necessidades dos frameworks envolvidos. Isso requer acesso ao código fonte e pode ser muito difícil uma vez que o laço de controle pode não estar centralizado em uma única entidade do framework. Essa solução é a abordagem que consume mais esforço para a implementação [1].

d) Frameworks menores: Em [42] aconselha-se dividir um ou ambos os frameworks em serviços fornecidos pelos frameworks e um dos fluxos de controle removido. Se um framework não pode ser dividido, então o framework resultante pode não ser satisfatório, ou o sistema existente pode ter que ser re-desenvolvido. Freqüentemente, um framework pode não esperar controlar completamente um recurso ou serviço, mas ter somente um controle temporário; isso pode exigir uma coordenação com o framework que tem o fluxo de controle.

Em [13] para resolver os problemas de composição de framework foi criado o conceito de framelets, ou seja, um pequeno framework que nunca tem o controle da aplicação, ele sempre é um framelet "chamado". A proposta é dividir os frameworks em framelets facilitando o entendimento. O framelet opera em um universo de granularidade muito pequeno, de forma a ter o seu design simplificado e sua interface bem definida e estável. Essa abordagem é recomendada para que um framework seja composto de vários framelets. Porém, quando a composição for entre uma aplicação gerada por um framework composto por vários framelets, esta vantagem desaparece, pois, neste caso, o que se tem é um sistema grande no qual o código fonte não existe, e a colagem do framelet com as classes do sistema agora legado fica comprometida, pois não há como se saber nada sobre o design deste novo sistema legado.

e) Integração de laço de eventos: Em [52] é apresentado design de um framework (Blob Streaming) para imagens eletrônicas médicas. O framework foi desenvolvido a partir de outros frameworks, design patterns e bibliotecas de classes. Tal framework deve reagir a eventos de múltiplas fontes, cada uma dessas fontes tem seu próprio laço de eventos. A abordagem escolhida para resolver o problema foi combinar os múltiplos laços de eventos em um único laço. O framework usa o design pattern REACTOR [53] que fornece um mecanismo 
para integrar os eventos desmultiplexando e despachando eventos de múltiplos frameworks. Uma vantagem de se integrar os múltiplos laços de eventos é não afetar o software interno ou a interface do framework.

f) Abstract Design View (ADV) e Abstract Design Object (ADO): [51] apresentou os problemas sobre composição de frameworks inicialmente discutido por Mattsson [1] $]^{3}$, adaptados para frameworks desenvolvidos para a Web (WebFrameworks). Assim, alguns novos problemas foram identificados, e uma nova teoria foi utilizada para dar suporte aos problemas identificados e aos novos decorrentes da mudança da plataforma de desenvolvimento. Como referencial teórico para abordar o problema, utilizou-se Abstract Design View (ADVs) e Abstract Design Object (ADOs), que enfatiza: (i) reutilização; (ii) "Separation of Concerns"; e (iii) separação da interface do usuário da aplicação.

O problema de fluxo de controle também existe nesta plataforma, por exemplo, uma applet Java pode encontrar conflitos na obtenção dos dados oriundos de queries que podem ser atualizadas, sem que a applet tenha sido notificada. Desta forma, uma informação pode estar sendo transmitida de forma errônea. ADVs/ADOs define um conjunto de propriedades para a construção de um design flexível. A teoria serviu como base para a criação de uma linguagem chamada WebCompose que permite a composição de WebFrameworks para a geração de novas aplicações em plataforma Web. ADVs/ADOs mostrou-se muito eficaz para os problemas identificados de composição de WebFrameworks, que pode ser visto como um conjunto de serviços que permitem colaboração entre si e composição por meio de papeis (roles). As composições dos serviços definem o perfil de uma aplicação a ser gerada.

\section{5 - Considerações Finais}

Existem alguns problemas associados à composição de frameworks, entre eles composição de fluxo de controle. Existem duas formas de se compor fluxo de controle: por troca de mensagens e por eventos. Quando os fluxos de controle não são corretamente compostos podem acontecer alguns problemas como: colisão de laços (overlap); falta de controle (gap); interferência; execução incorreta e parada na execução.

Foram estudados alguns trabalhos de composição de frameworks para se obter uma melhor descrição do problema e que tipos de soluções já foram realizadas. Dos trabalhos acima citados, apenas um trata de composição de fluxo de controle para frameworks desenvolvidos em Java, mas restrito a frameworks

\footnotetext{
${ }^{3}$ Os mesmos problemas utilizados como base nesse trabalho.
} 
desenvolvidos para ambientes Web [51]. Os outros trabalhos [1, 13 e 42] apresentam soluções gerais independente da linguagem utilizada. A utilidade de se estudar alguns trabalhos que tratam de composição é verificar os pontos comuns das várias abordagens, tais pontos podem ser resumidos em:

a) Sincronização: a necessidade de usar código de sincronização entre os frameworks também ficou evidente pela análise dos trabalhos. A sincronização deve acontecer quando se tem acesso a objetos compartilhados. Java tem uma definição implícita de sincronização que satisfaz à necessidade.

b) Acesso ao código fonte: quase todos os trabalhos afirmam que a falta de acesso ao código fonte dificulta consideravelmente, ou impossibilita, a solução do problema. Então acesso ao código fonte é importante para a solução dos problemas de composição de fluxo de controle, nesse trabalho consideramos o acesso ao código fonte.

c) Soluções para domínios específicos e baseados em novos conceitos: a maioria das soluções encontrada foi para domínios específicos ou tiveram que ser criados novos conceitos como framelets ou ADVs/ADOs, para resolver os problemas.

d) Integração de eventos: um ponto de acordo é a necessidade de integrar eventos de múltiplas fontes ou múltiplos laços de eventos. Daí surge a necessidade de criar uma estrutura que gerencie o envio e o despacho dos eventos. Essa estrutura normalmente evita que os frameworks compostos capturem diretamente os eventos do sistema operacional, os eventos devem passar antes por essa estrutura que decide para qual ou para quais frameworks entregar o evento.

Dos trabalhos citados nenhum trata de composição baseada somente na troca de mensagem. Este trabalho trata da composição apenas por trocas de mensagens. Quando só existe essa forma de comunicação a composição dos fluxos de controle fica mais controlável. No próximo capítulo será apresentado como se compor fluxo de controle em frameworks desenvolvidos em Java, sendo que objetos e componentes executando em fluxos de controles diferentes podem se comunicar apenas por troca de mensagens. Tais composições podem ser realizadas pelos frameworks que respeitem algumas restrições como: ausência de memória compartilhada; conjuntos de eventos que consegue manipular são disjuntos e fluxo de controle isolado; tais restrições serão mais detalhadas na Seção 5.1. Além disso, é apresentado um estudo dos problemas que podem acontecer quando se compõe fluxo de controle de frameworks dessa maneira. 


\section{Capítulo 5 - Composição de Fluxos de Controle de Frameworks Java Baseada em Troca de Mensagens}

Este capitulo trata da composição de fluxos de controle de frameworks desenvolvidos em Java, mostrando os elementos envolvidos e como fazer a composição entre eles. Além disso, define as formas de composição baseada em troca de mensagens: sem composição; seqüencial; unidirecional e bidirecional, mostrando como implementar cada uma delas. Baseado nas formas de composição foi feito um levantamento dos problemas que podem acontecer para tais composições.

\section{1 - Escopo do Trabalho}

Para os objetivos deste trabalho, composição de framework é a composição da parte estática do framework (classes e interfaces) mais a composição do fluxo de controle. A composição só é realizada quando houver uma comunicação entre os frameworks, através da chamada de um método (troca de mensagem), sendo essa a única forma de comunicação entre os objetos envolvidos nos diferentes frameworks. Para efeito de tratamento dos problemas para esse tipo de composição, consideramos inicialmente:

- Tratamento apenas da composição de fluxo de controle: os outros problemas de composição de frameworks, tais como: composição com sistemas legados; frameworks gap; sobreposição de entidades e composição de funcionalidade, não são tratados.

- Frameworks "que chamam": os problemas de composição de fluxos de controle só acontecem quando ambos os frameworks gerenciam o fluxo de controle (framework "que chama"). Sendo assim, consideramos que os dois frameworks gerenciam o fluxo de controle da aplicação.

- Frameworks devem possuir fluxo de controle isolado: como apresentado na Seção 2.2.4. Por isolado entende-se: separado em um método que inicie o fluxo de controle, o que acontece na maioria, mas não em todos os frameworks.

- Não há compartilhamento de espaço de nomes entre os frameworks: eles devem ter nomes de classes, interfaces e objetos definidos no fluxo de controle diferentes, uma vez que na construção 
do novo framework eles vão executar em uma mesma região de memória e nomes iguais podem causar conflitos.

- Falta de suporte a eventos compartilhados: em frameworks que trabalham em um mesmo domínio de problema, existe uma grande probabilidade que uma parte dos eventos que eles manipulam sejam os mesmos. Aqui, consideramos conjuntos disjuntos de eventos para os frameworks sendo compostos.

- Os frameworks são corretos e não serão alterados: os frameworks envolvidos na composição são considerados corretos e para não adicionar erros e eles, toda e qualquer modificação no framework deve ser feita via extensão.

- Acesso ao código fonte: consideramos o acesso ao código fonte dos frameworks utilizados na composição.

Isso deve ser considerado para podermos isolar apenas os problemas de troca de mensagem, uma vez que é a única forma de comunicação entre os frameworks.

\section{2 - Composição de Frameworks Java}

Para realizar a composição de fluxo de controle deve-se também realizar a composição da parte estática do framework. Para isso, deve-se juntar as classes e interfaces dos dois frameworks e definir os novos elementos do framework composto. Como não existe nome de classes e interfaces iguais, a parte estática do novo framework é a soma dos elementos existentes nos frameworks envolvidos na composição (hierarquia de classes e hierarquia de interfaces) mais os novos elementos desenvolvidos para o novo framework. Uma forma de realizar tal composição é apresentada na Figura 5.1. 


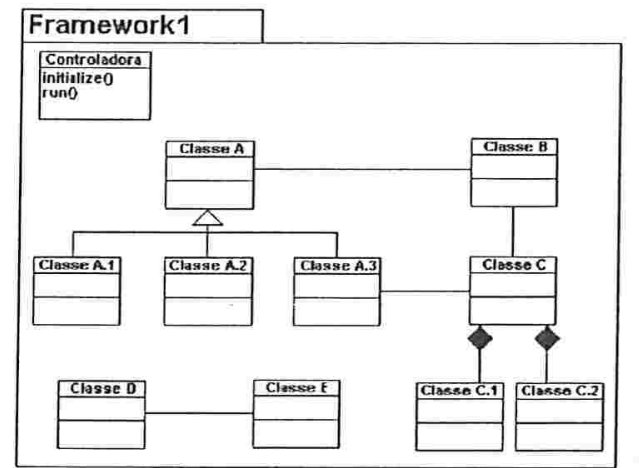

Framework 2

Conkroladora initializeo
runn()
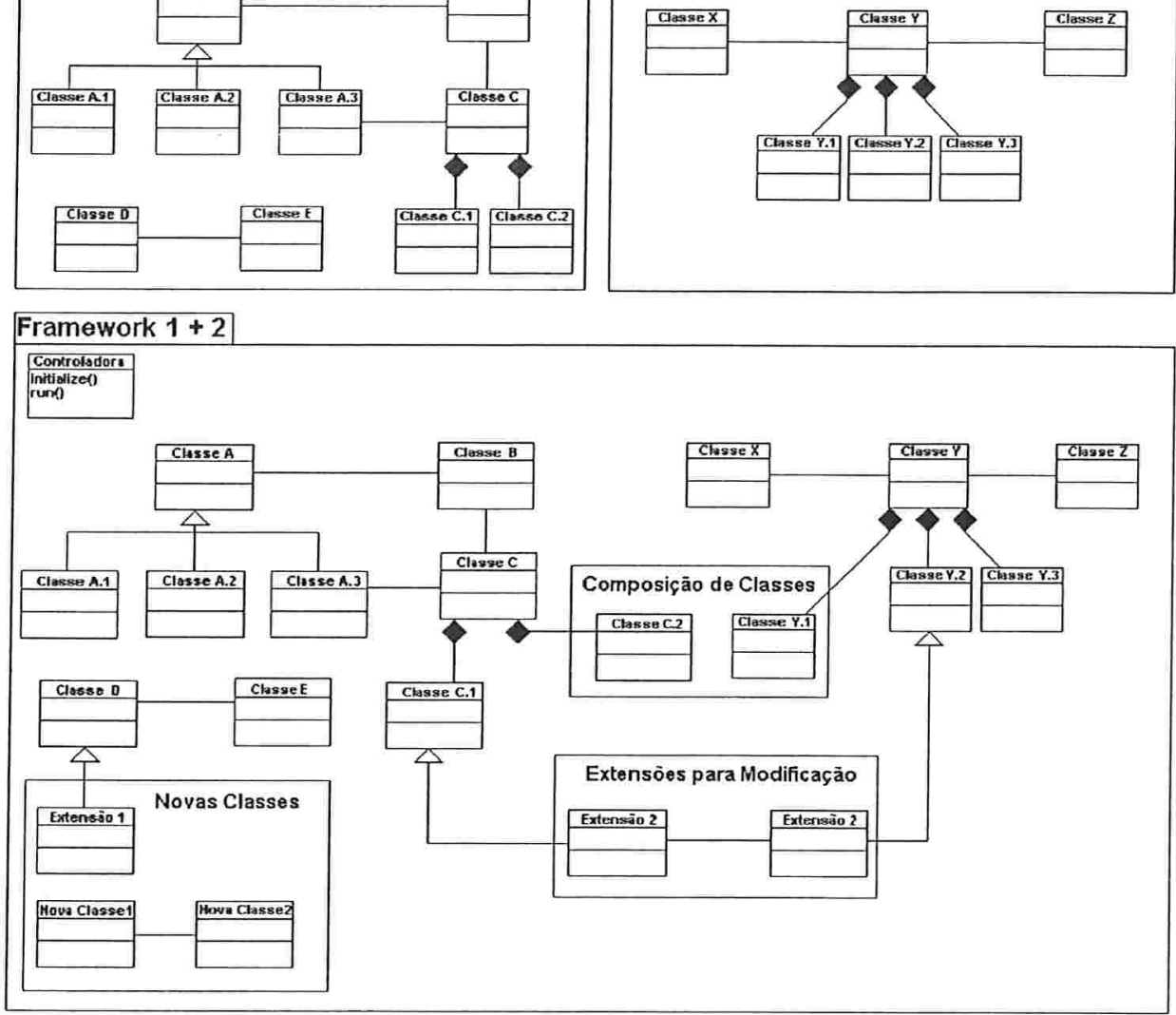

Figura 5.1: Composição de Frameworks Java

Os novos elementos do framework são:

- Novas classes: uma classe no framework composto pode ser definida de três formas: (i) nova classe: uma classe é criada, podendo ser estendida da hierarquia de classes de um dos frameworks ou independentemente; (ii) extensão de classe para modificação: quando uma classe necessita de modificação, o projetista deve estender uma classe existente da hierarquia de classe de um dos frameworks e adicionar as modificações necessárias; e (iii) composição de classes: a classe é criada pela composição de duas classes existentes nos frameworks diferentes, um exemplo de composição de classes é apresentado na Seção 5.2.1.

- Novas interfaces: podem ser criadas baseadas nas interfaces existentes em ambos os frameworks ou criadas independentemente. 
- Uma nova classe Controladora: ou semelhante, uma classe que tem dois métodos: um que inicia o fluxo de controle (run ()) e outro que a aplicação passa argumentos para o framework (initialize()).

\subsection{1 - Exemplo de Composição de Classes}

Como os frameworks envolvidos na composição não têm memória compartilhada, a única forma de composição acontece quando temos duas classes que representam a mesma entidade ou entidades semelhantes. Quando isso acontece, devemos realizar a composição de classes; o framework composto possui esta classe composta a partir de classes dos frameworks originais. Uma forma de realizar composição de classes em Java é através da delegação dos métodos das classes envolvidas [63]. No exemplo abaixo é construída uma classe Dispositivo que é ao mesmo tempo Impressora e Scanner. A classe Dispositivo é implementada a partir de duas classes existentes: Impressora e Scanner.

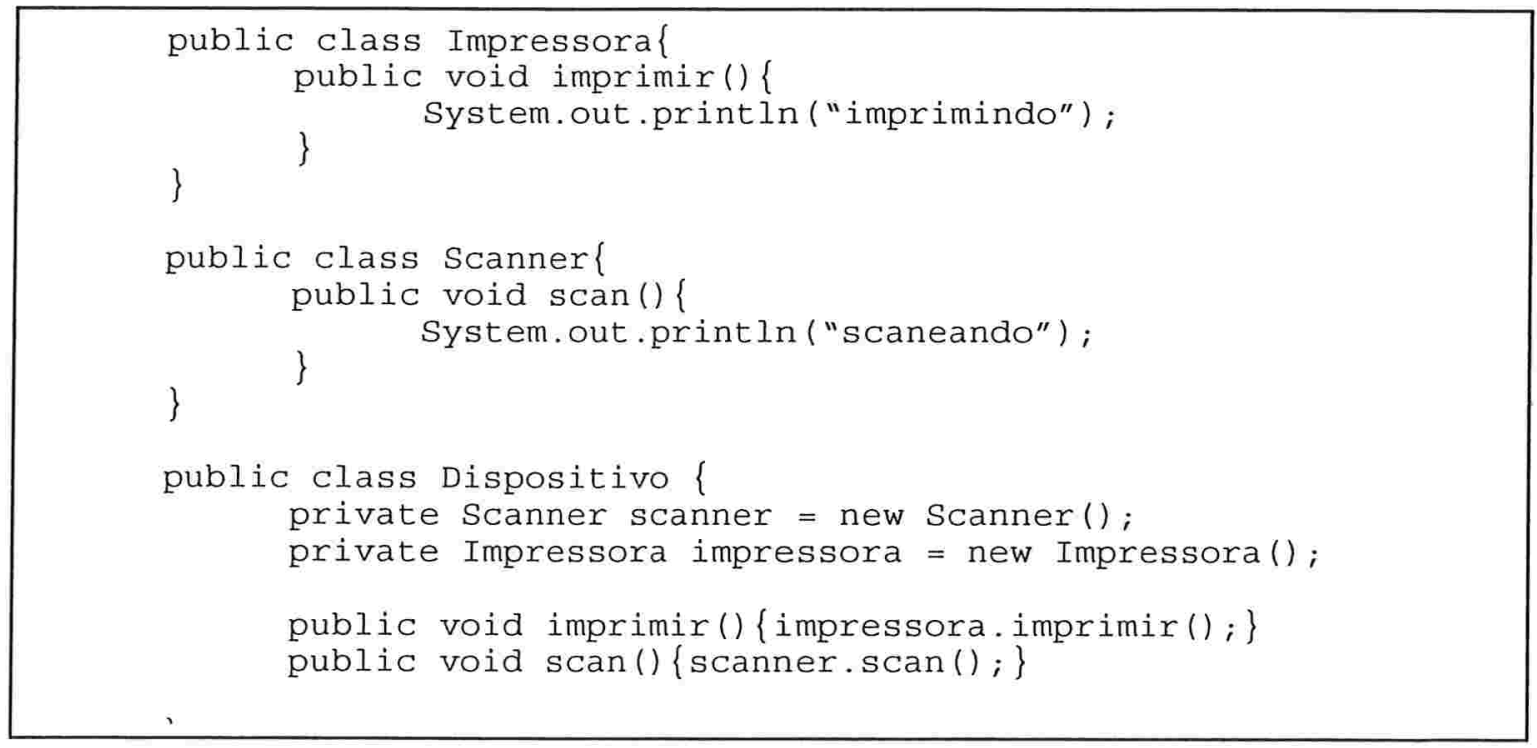

Nesse tipo de composição existe uma classe "receptora" (classe Dispositivo), e duas classe "delegadas" (Impressora e Scanner). Com composição, a reutilização de código é obtida pela classe "receptora" que deve explicitamente chamar um método na classe "delegada" da sua própria implementação do método, evitando reescrever os métodos pertencentes às classes "delegadas". 


\subsection{2 - Novo Framework}

O novo framework é a soma das classes e interfaces disponíveis nos dois frameworks, os novos elementos (classes, interfaces e classe Controladora) definidos no framework composto, mais a composição do fluxo de controle; todas as classes disponíveis nos frameworks isoladamente estão disponíveis no framework composto, sendo que existe apenas uma classe Controladora; tal classe deve ter dois métodos: (i) um método que inicia o fluxo de controle (run ()) e (ii) um método que as aplicações passem argumentos para o framework (initialize ()). Tal método pode ser implementado pela chamada dos dois métodos já disponíveis nos frameworks. A composição do método run () determina o fluxo de controle do novo framework é descrito a seguir.

\section{3 - Composição de Fluxos de Controle de Frameworks Java Baseada em Troca de Mensagens}

Quando dois frameworks "que chamam" são compostos, ambos esperam gerenciar o fluxo de controle na aplicação. Sendo assim, o projetista deve dispor de mecanismos que controlam como os frameworks gerenciam os fluxos de controle. Na forma de composição descrita abaixo, um novo fluxo de controle é criado baseado nos fluxos de controle dos frameworks envolvidos na composição. Nesta composição, o novo framework assume o fluxo de controle, ou seja, ele gerencia a criação de objetos, chamada de métodos dos dois frameworks, controla o laço de eventos através de um adaptador de eventos, e controla as mensagens enviadas de um framework para o outro (troca de mensagem).

O novo fluxo de controle deve iniciar os fluxos de controle dos frameworks de alguma forma. Essa iniciação depende da forma de composição desejada, podendo ser seqüencial ou paralela. Na seqüencial, um framework é iniciado primeiro e quando ele está terminando o outro framework é ativado. Na composição paralela os dois frameworks podem executar ao mesmo tempo. Quando não existe troca de mensagens, a composição é realizada dando a cada framework a gerência do seu próprio fluxo de controle, não importando a forma como eles executam. A Figura 5.2 mostra como é realizada a composição de fluxos de controle. 

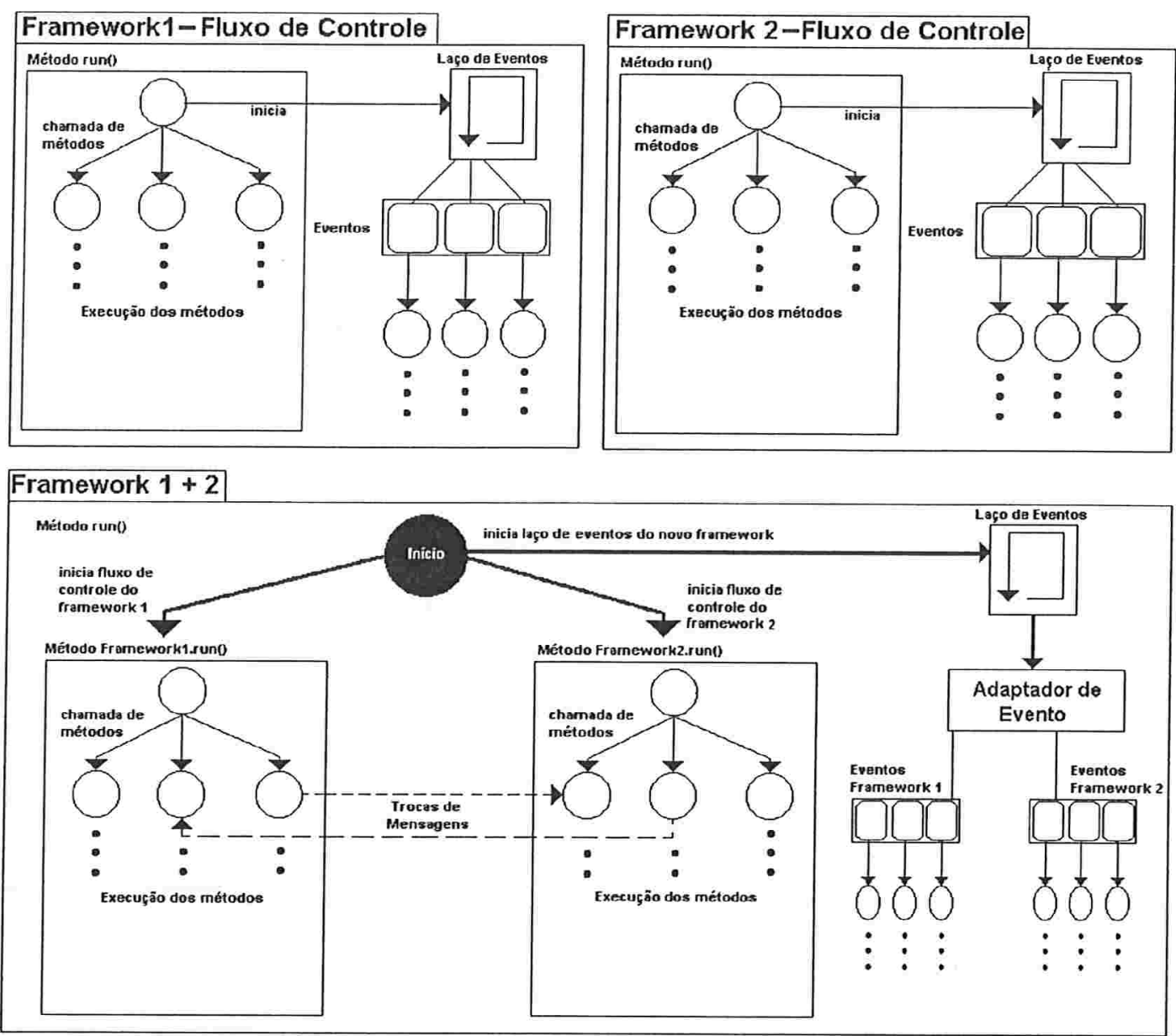

Figura 5.2: Composição de Fluxo de Controle Frameworks Java

\subsection{1 - Novos Elementos}

Além dos elementos pertencentes aos fluxos de controle dos frameworks envolvidos na composição (eventos, criação de objetos, chamada de métodos, fluxo de controle e laço de eventos), outros elementos podem ser criados:

a) Adaptador de eventos: implementa as interfaces de todos os eventos manipulados pelos frameworks. Quando um evento acontece, essa interface registra o evento e decide que método chamar em resposta ao evento. Os adaptadores de eventos são descritos no modelo de eventos Java como um mecanismo que se interpõe entre a fonte de eventos e as interfaces listeners. Adaptadores de eventos desacoplam a entrega do recebimento do evento. Sendo assim, o framework que implementa o adaptador de eventos controla todos os eventos registrados no adaptador. Para a composição, esse mecanismo é interessante porque o novo 
framework controla todos os eventos dos dois frameworks, além disso, fica mais simples adicionar novos eventos ao framework composto, para isso basta que o adaptador registre a interface do novo evento e depois implemente o comportamento desejado.

b) Troca de mensagem: durante a troca de mensagens a composição é realmente efetivada. A mensagem sempre é realizada entre métodos dos diferentes frameworks. Ela pode ser com argumento ou sem argumento, ou ainda com ou sem retorno, dependendo da interface (signature) do método.

c) Novo fluxo de controle: o novo fluxo de controle é a execução dos fluxos de controle dos frameworks envolvidos na composição. O novo fluxo de controle depende: da forma de composição desejada; das trocas de mensagens; do meio de comunicação e do tipo de implementação, cada um desses tópicos será visto nas seções seguintes.

\subsection{2 - Meios de Comunicação}

Para realizar a composição de frameworks, deve-se implementar comunicações entre eles; nesse trabalho estamos considerando que a única forma de comunicação possível é através da troca de mensagem. Dessa forma, para um framework se comunicar com outro ele deve enviar uma mensagem (chamada de método) para o outro framework.

O primeiro ponto que deve ser considerado para a comunicação é o local onde a troca de mensagem é feita, para isso deve-se definir uma nova classe no framework composto. Tal classe pode ser criada de qualquer uma das três formas apresentadas na Seção 5.2: (i) nova classe; (ii) extensão de classe para modificação; e (iii) composição de classes. Definida a classe, deve-se implementar a comunicação em um dos seus métodos, para isso temos duas opções:

- Método existente: a comunicação é feita através de um método existente em uma classe do framework que faz a chamada. Isso acontece quando a classe é estendida para modificação ou através da composição de classes.

- Novo método: um novo método é adicionado à classe do framework que faz a chamada. Pode acontecer em qualquer forma de definição de classe. 
Definido o local da comunicação, deve-se realizar a chamada de método em si; para realizar isso deve-se decidir sobre qual tipo de objeto a chamada será feita; nesse caso temos duas opções:

a) Novo objeto: é criado no framework que faz a chamada. Tal objeto deve ser derivado da classe que contém o método que vai ser chamado. Depois de criado o objeto, a chamada pode ser feita normalmente. Quando um novo objeto é criado ele tem acesso apenas às variáveis da classe que ele é derivado, além das variáveis públicas das outras classes do framework.

b) Objeto existente: a chamada é realizada para um objeto já existente no framework que recebe a chamada. Para isso, o projetista deve saber quais são os objetos definidos pelo fluxo de controle do framework que recebe a chamada e depois realizar a chamada. Nesse caso, o projetista deve implementar tratamento de erros padrão de Java, para o caso do objeto chamado ainda não ter sido criado ou já ter sido destruído pelo outro fluxo de controle. Quando se utiliza um objeto existente ele tem acesso a todas as variáveis da classe que ele é derivado, as variáveis públicas das outras classes do framework, mais o estado do objeto (variáveis de instâncias).

Independentemente do local que a comunicação será feita, deve-se estender o fluxo de controle do framework qúe faz a chamada, para que o método que contém a comunicação possa fazer parte do fluxo de controle, uma vez que ele não existia no fluxo de controle original. A extensão do fluxo de controle pode ser feita de três formas:

- Substituição de um objeto em um nó existente: um objeto de um nó do fluxo de controle é substituído por outro objeto. Normalmente acontece quando uma classe é estendida ou composta e a troca de mensagem é feita em um método já definido. Assim, basta que o projetista defina um objeto derivado da classe criada mantendo a chamada, uma vez que o método já existia no fluxo de controle.

- Substituição de um método de um nó existente: nesse caso, o método é substituído em um nó. Normalmente acontece quando a troca de mensagem é implementada em um novo método. Dessa forma, o projetista deve primeiro definir o objeto baseado na classe estendida e depois substituir o nome do método.

- Novo nó: um novo nó é adicionado ao fluxo de controle. O objeto desse nó pode ser um novo objeto ou um objeto já definido no framework que recebe a chamada. 


\subsection{3 - Implementação do Novo Fluxo de Controle}

O novo fluxo de controle é uma ordem pré-determinada de execução dos fluxos de controle dos frameworks que serão compostos. Os fluxos de controle podem executar em paralelo ou seqüencialmente, dependendo da forma de execução desejada. O fluxo de controle geralmente é composto pelas chamadas de métodos e pelo início de um laço de eventos. No caso do novo fluxo de controle, ele deve chamar os fluxos de controle dos frameworks compostos mais o adaptador de eventos. Temos três formas de implementar o novo fluxo de controle:

- Fazer a chamada do método que inicia o fluxo de controle: o novo fluxo de controle é uma chamada para os métodos que iniciam os dois fluxos de controle.

- Criar uma thread para cada fluxo de controle: consiste em criar uma thread para cada fluxo de controle dos frameworks, baseado no método que inicia o fluxo de controle. O novo fluxo de controle consiste da chamada das threads.

- Copiar e colar: os fluxos de controle de ambos os frameworks são copiados e depois colados em um novo método que inicia o fluxo de controle do framework composto.

Para implementar o novo fluxo de controle temos que levar em consideração: a forma de composição (sem comunicação, seqüencial, unidirecional e bidirecional); os meios de comunicação e as mudanças no fluxo de controle. Cada um desses tipos de implementação é mais adequado para uma forma de composição e meio de comunicação, como será descrito na Seção 5.3.4.

\subsection{4 - Formas de Composição}

Foram definidas quatro formas de composição de fluxo de controle baseada em troca de mensagens: sem comunicação; seqüencial; unidirecional e bidirecional.

\subsubsection{1 - Sem comunicação}

A forma de composição mais simples. Acontece quando os dois fluxos de controle compostos não se comunicam, não há memória compartilhada e os domínios dos eventos são distintos. Nessa forma, cada fluxo 
de controle é completamente independente do outro. Como não existe nenhuma comunicação entre eles, os fluxos de controle podem executar de qualquer forma, gerando sempre o mesmo resultado. O novo fluxo de controle é constituído pela execução dos dois fluxos de controle, não importando se eles executam em paralelo, ou seqüencialmente, uma vez que o resultado da execução será o mesmo. A implementação do fluxo de controle pode ser feita de qualquer uma das formas citadas acima: fazer a chamada do método que inicia o fluxo de controle; criar uma thread para cada fluxo de controle e copiar e colar.

Para exemplificar a composição sem comunicação vamos compor o framework Projeto (Seção 3.4.1) com o framework Financiamento (Seção 3.4.4). O novo framework deve ser usado para representar projetos e pesquisas juntamente com suas fontes de financiamento. Para realizar a composição temos que primeiro compor a parte estática dos frameworks; para isso a classe Projeto deve ser estendida de forma a representar uma pesquisa (classe Pesquisa). A Figura 5.3 abaixo mostra o diagrama de classes do framework composto.

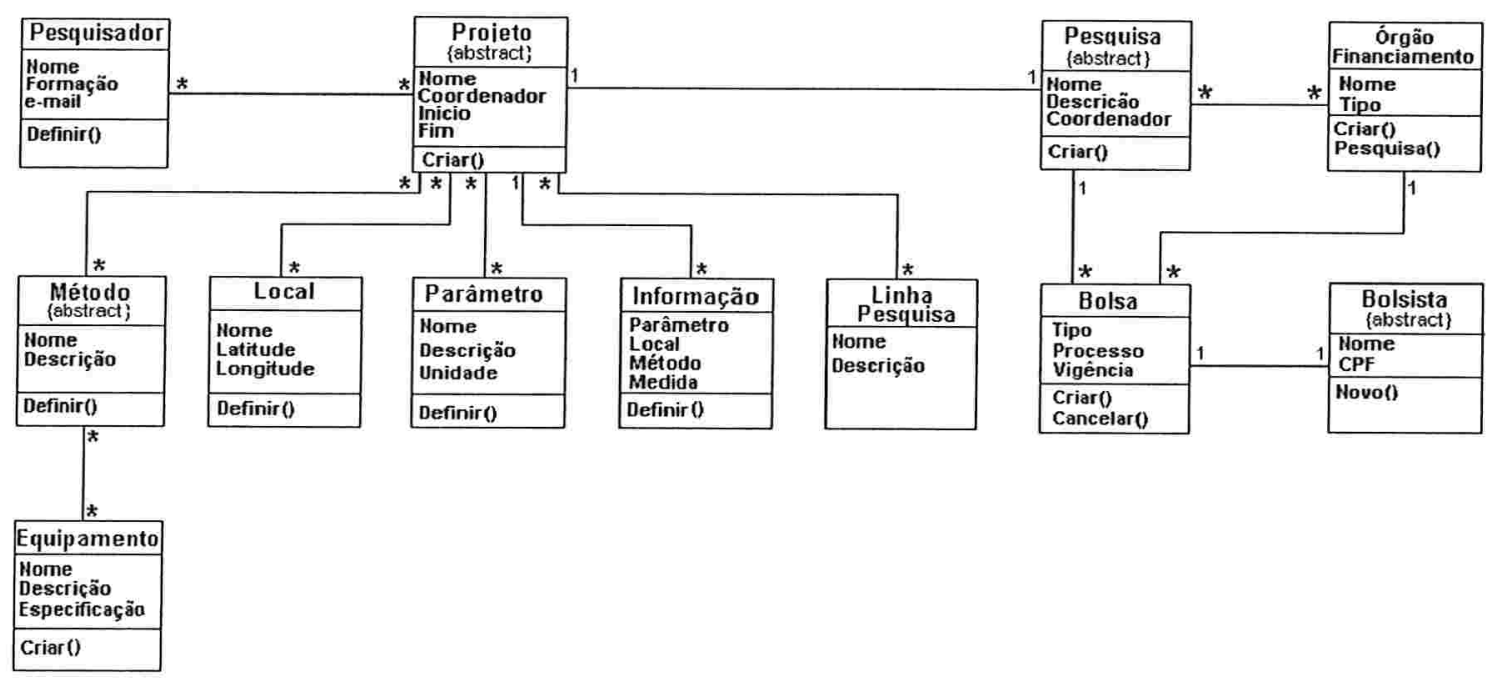

Figura 5.3: Diagrama de Classes para a Composição Projeto + Financiamento

O novo fluxo de controle é a chamada do fluxo de controle dos dois frameworks, uma vez que não há troca de mensagens, eles não se relacionam em nenhum ponto. A implementação do novo fluxo de controle pode ser feita pela chamada dos dois fluxos de controle através da chamada do método que inicia cada fluxo de controle (seqüencial) ou pela criação e ativação de uma thread para cada fluxo de controle (paralelo). Para o exemplo citado acima, foi construída uma thread para cada fluxo de controle. 

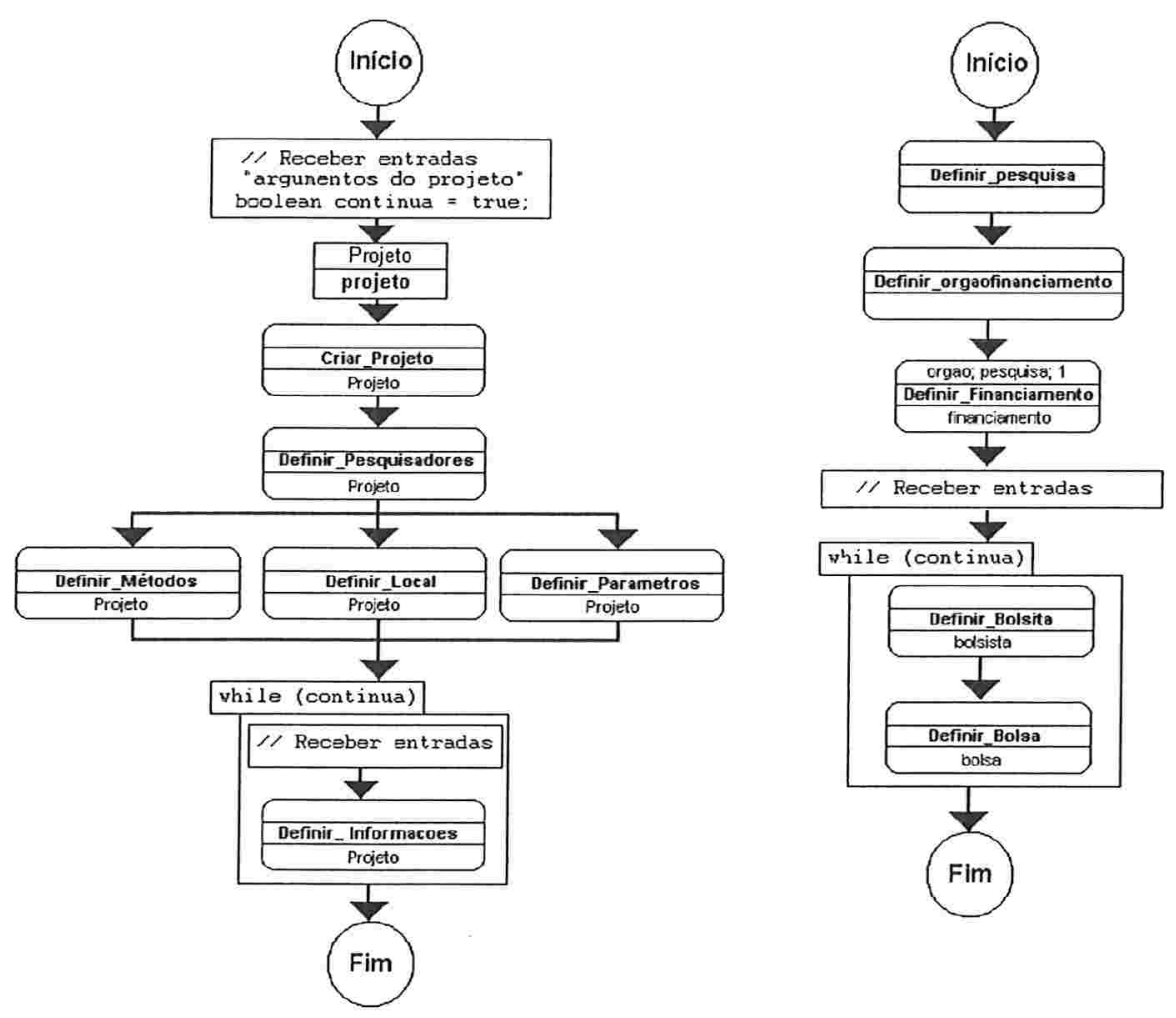

Figura 5.4: Fluxo de Controle para a Composição Projeto + Financiamento

\subsubsection{2 - Seqüencial}

Nessa forma de composição existe apenas uma chamada entre os fluxos de controle envolvidos: quando um framework previamente determinado está terminando sua execução, ele, através da passagem de uma mensagem, inicia a execução do fluxo de controle do outro framework. O novo fluxo de controle é uma seqüência pré-determinada dos fluxos de controle que vão ser compostos. Quando o fluxo de controle definido para executar primeiro estiver terminando a sua execução normal, ele ativa o segundo fluxo de controle. Depois da passagem de mensagem, o primeiro fluxo de controle é desativado.

A implementação dessa composição pode ser feita chamando o método que inicia o fluxo de controle do framework que vai executar primeiro, sendo que esse framework antes de terminar faz uma chamada para o método que inicia o outro fluxo de controle, para ativar o outro framework. Uma outra forma de implementação é copiar e colar o código dos fluxos de controle dos frameworks. 
Como exemplo de composição seqüencial temos a composição do framework Projeto (Seção 3.4.1) com o framework Publicação (Seção 3.4.3). A composição foi realizada para o novo framework tratar de projetos mais as publicações realizadas durante a vigência do mesmo. Para isso, foi criado um relacionamento entre as classes Proj eto e Publicacao. Dessa forma, um projeto pode ter várias publicações associadas. A Figura 5.5 apresenta o diagrama de classes para o framework composto.

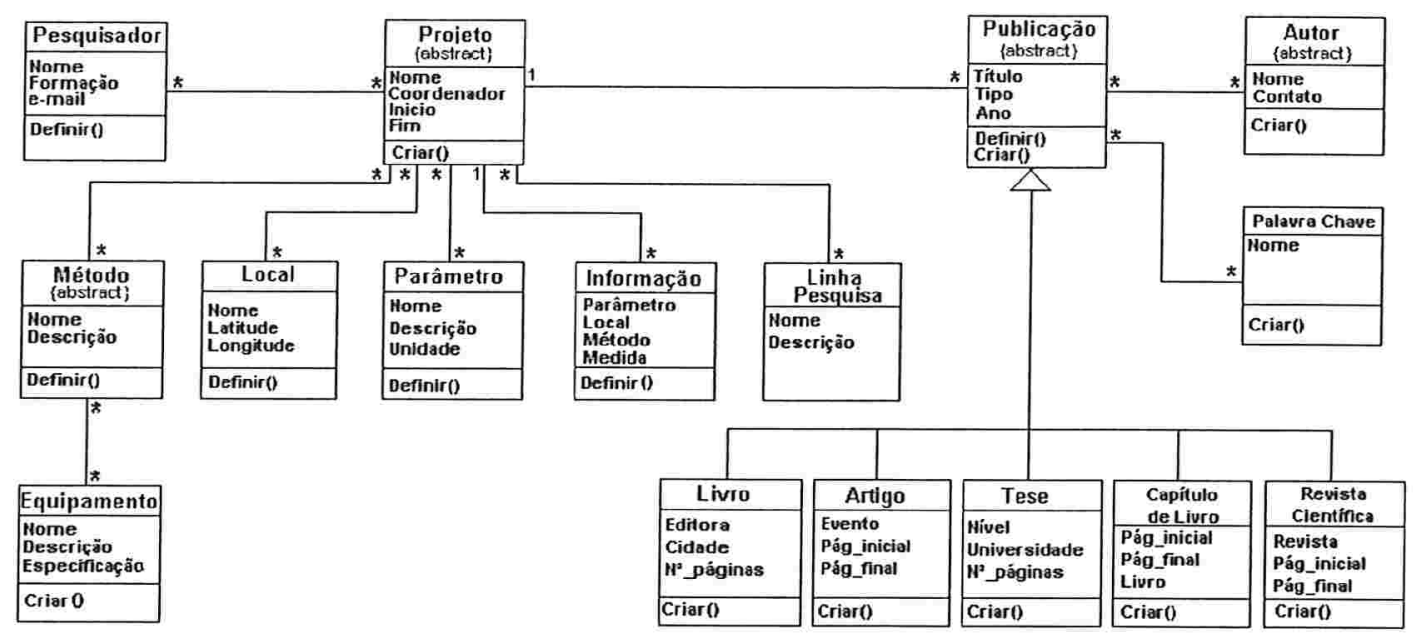

Figura 5.5: Diagrama de Classes para a Composição Projeto + Publicação

O fluxo de controle do novo framework é a execução do fluxo de controle do framework Projeto, sendo que quando esse framework estiver terminando sua execução, o fluxo de controle do framework Publicação é ativado para definir as publicações referentes àquele projeto e o framework Projeto é desativado. A comunicação foi realizada num novo método chamado Definir_publicacao() que chama o método que inicia o fluxo de controle do framework Publicação. A representação gráfica do novo fluxo de controle é dada pela Figura 5.6. 


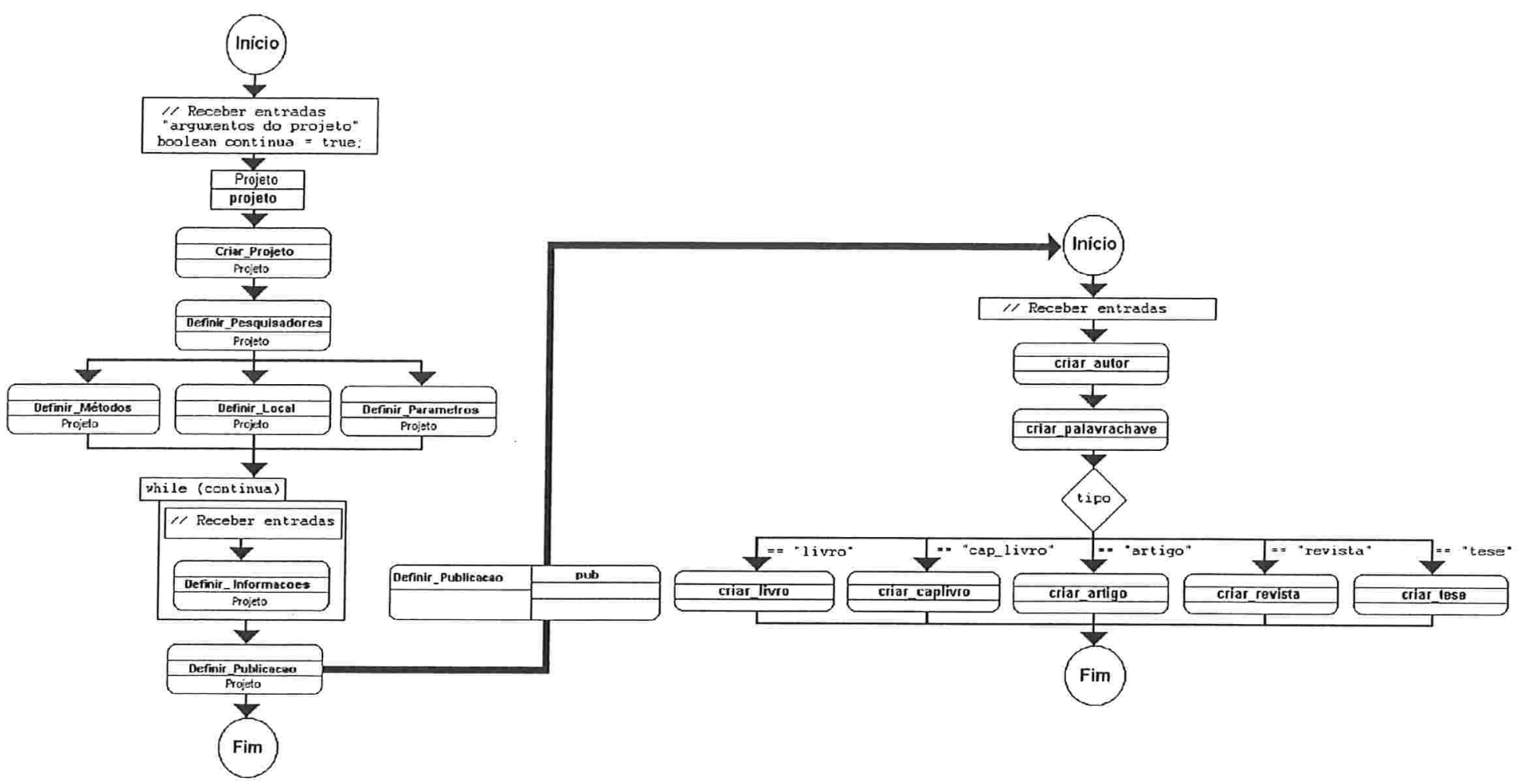

Figura 5.6: Fluxo de Controle para a Composição Projeto + Publicação

A implementação do novo fluxo de controle é feita pela extensão do fluxo de controle do framework Projeto (para adicionar o novo método Definir_publicacao ()). Em seguida, o projetista deve realizar a chamada do método que inicia o fluxo de controle estendido desse framework.

\subsubsection{3 - Unidirecional}

$\mathrm{Na}$ composição através da troca de mensagens unidirecional, apenas um framework manda mensagens para o outro, sendo que podem existir várias trocas de mensagens. Nesse caso, duas variantes de comunicação podem ser estabelecidas: chamada sem retorno e chamada com retorno.

O novo fluxo de controle é a execução, ao mesmo tempo, dos dois fluxos de controle dos frameworks, sendo que em alguns pontos um framework solicita serviços do outro. A forma de execução pode ser tanto em paralelo quanto intercalado, dependendo da composição. A implementação do novo fluxo de controle para a composição unidirecional deve ser feita criando uma thread para cada método que inicia os fluxos de controle dos diferentes frameworks. 
Como exemplo de composição unidirecional, temos a composição do framework Projeto (Seção 3.4.1) com o framework Espécie (Seção 3.4.2). Tal framework deve ser usado para representar informações de projetos, sendo que as informações geradas pelos projetos são relacionadas a alguma taxonomia de espécie. Para realizar isso, foi estendida a classe Informacao com um atributo especie da classe Especie; além disso, foi implementado um novo método Definir_Especie(), semelhante aos métodos já existentes: Definir_Parametro(), Definir_Metodo(), etc. $O$ método Definir_Especie () define uma nova espécie, quando essa espécie não existir. A Figura 5.7 apresenta o diagrama de classes para o framework resultante da composição.

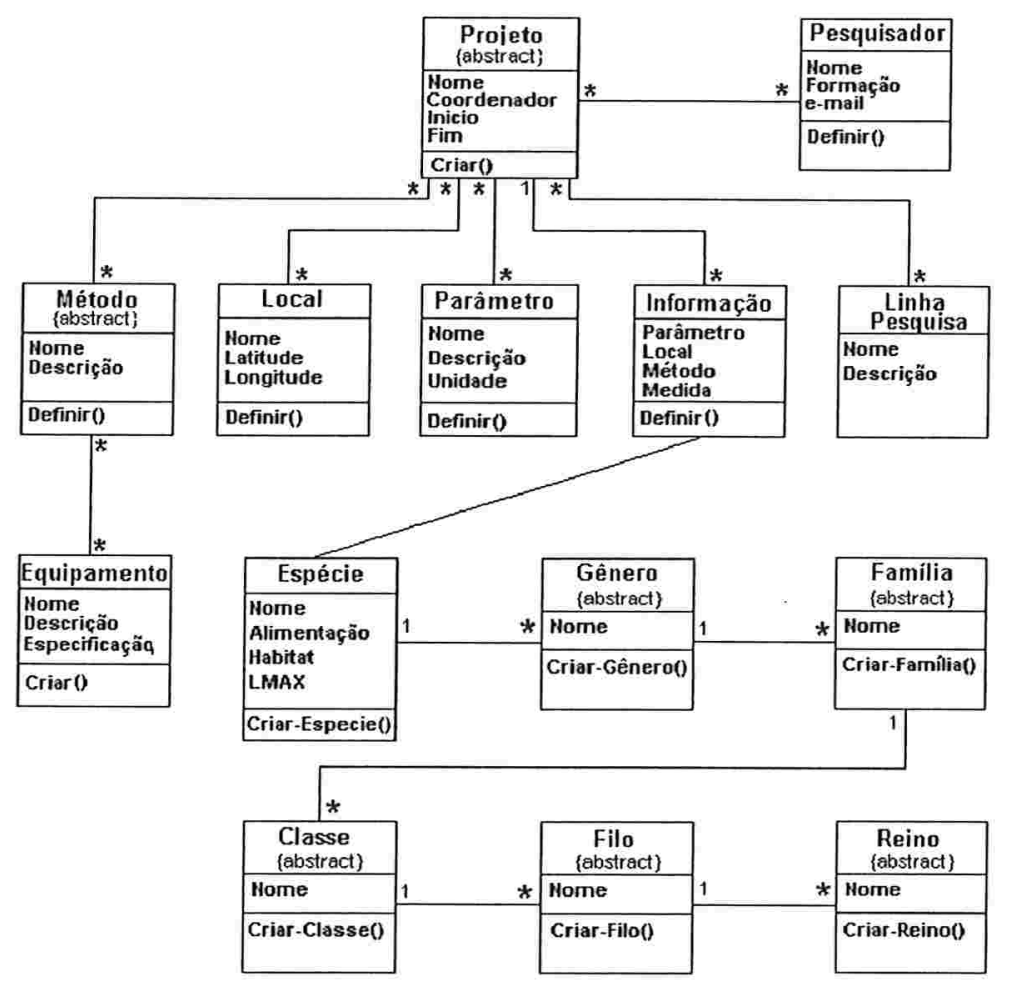

Figura 5.7: Diagrama de Classes para a Composição Projeto + Espécie

A troca de mensagem foi realizada em um método já definido no fluxo de controle, por isso, é necessário estender a classe que o método foi definido (extensão para modificação) e depois estender o fluxo de controle do framework Projeto. No método escolhido para realizar a chamada (Criar_Projeto()) houve apenas o acréscimo de uma chamada para o método Definir_Especie(), pertencente ao framework Espécie. No novo fluxo de controle ambos os frameworks podem estar ativos ao mesmo tempo. $\mathrm{O}$ número de espécies necessárias na definição de projetos será o número de chamadas realizadas.

Depois de terminada a execução do fluxo de controle do framework Espécie, o controle voltará ao framework Projeto. O novo fluxo de controle é implementado pela chamada do método que inicia o fluxo de 
controle do framework Projeto, sendo que o fluxo de controle do framework Projeto chama o fluxo de controle do framework Espécie, através do método Definir_Especie(). A implementação no novo fluxo de controle é feita pela criação de uma thread para cada método que inicia o fluxo de controle, seguido da ativação das duas threads. A Figura 5.8 apresenta o fluxo de controle para o framework composto.

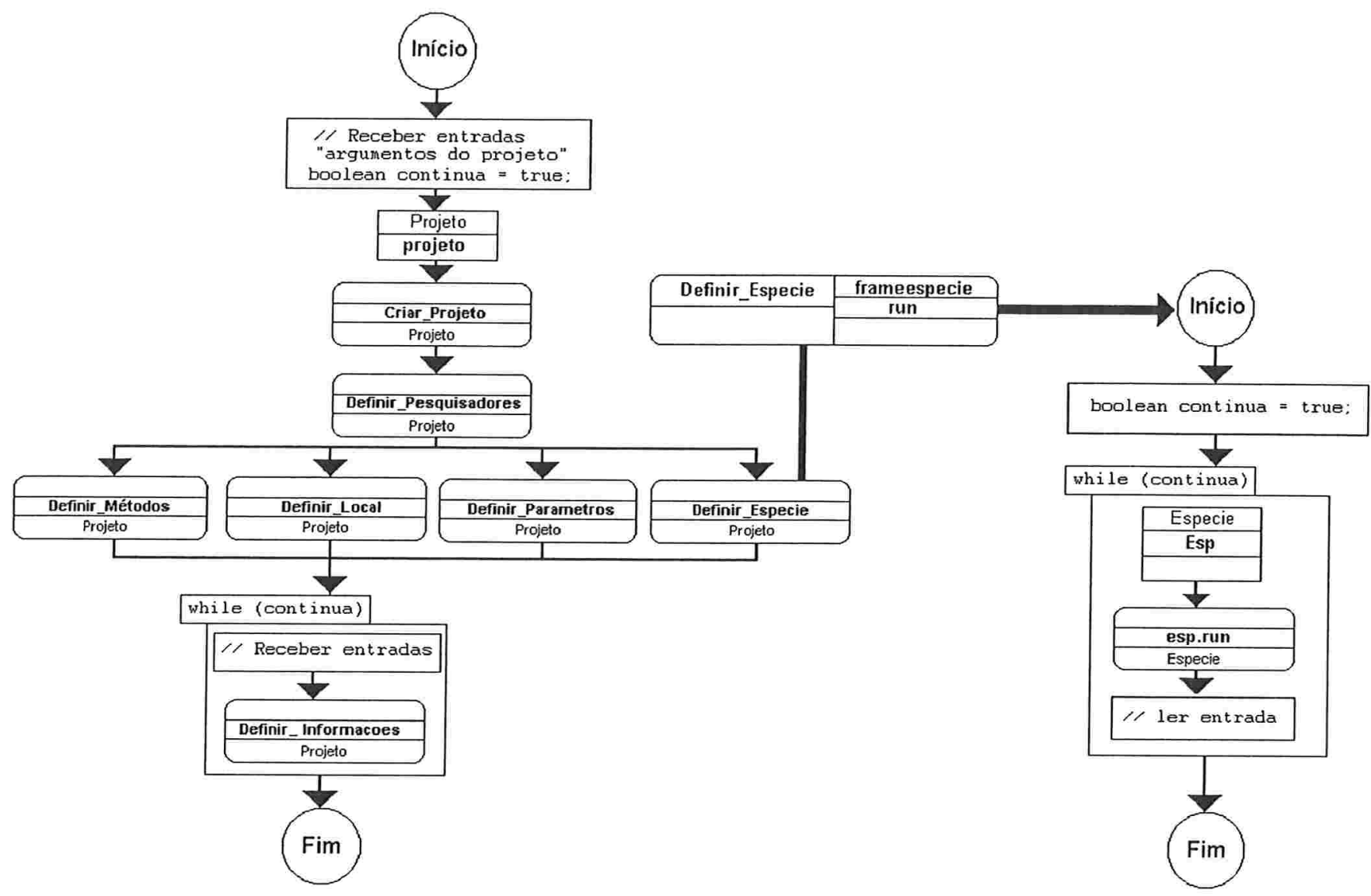

Figura 5.8: Fluxo de Controle para a Composição Projeto + Espécie

\subsubsection{4 - Bidirecional}

A composição bidirecional é a mais complexa de todas. Nela os dois frameworks mandam e recebem mensagens. Nesse caso, pode acontecer uma grande quantidade de troca de mensagens entre os frameworks. O novo fluxo de controle é a execução dos dois fluxos de controle dos frameworks, sendo que os frameworks trocam mensagens entre si em vários pontos. A implementação no novo fluxo de controle é semelhante ao caso da composição unidirecional. 
Como exemplo de composição bidirecional temos a composição do framework Espécie (Seção 3.4.2) com Publicação (Seção 3.4.3). O novo framework deve tratar de publicações que têm como palavra-chave alguma espécie. Além disso, um novo atributo para uma espécie é saber quando ela foi referenciada pela primeira vez na literatura. Para isso foram adicionados dois novos campos: especie à classe Palavra_chave e publicacao à classe Especie. A Figura 5.9 mostra como ficou a parte estática do novo framework.

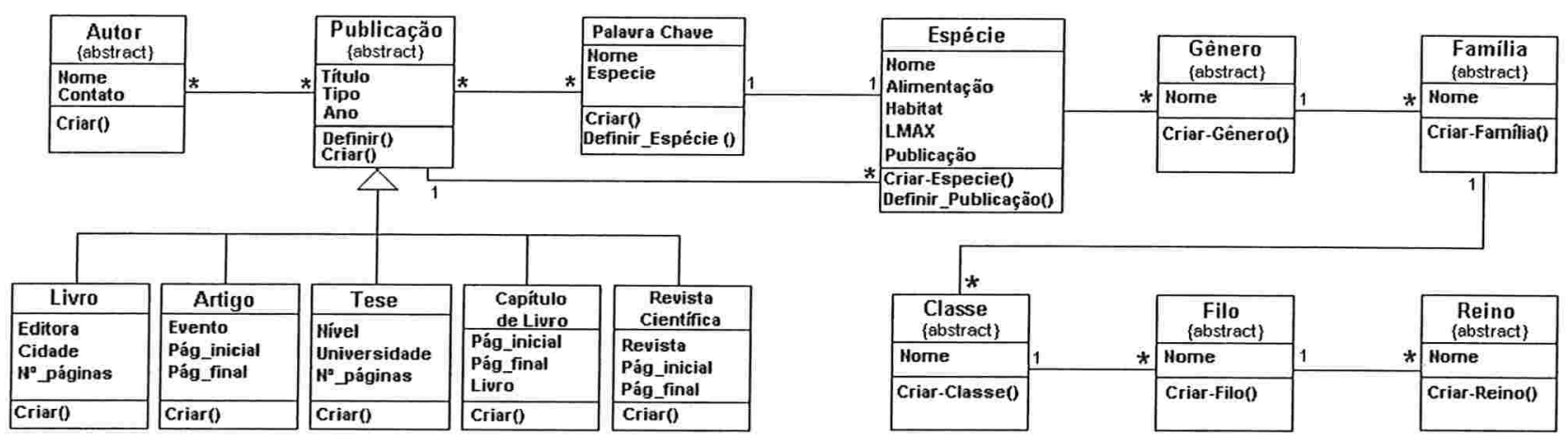

Figura 5.9: Diagrama de Classes para a Composição Publicação + Espécie

Existem duas trocas de mensagens, sendo que cada framework realiza uma. Para realizar a troca de mensagem foram criados dois métodos: Definir_Publicacao()na classe Especie e Definir_Especie() na classe Palavra_chave. O método Definir_Publicacao() faz uma chamada para o método criar_publicacao () no framework Publicação. Tal método inicia a definição de uma nova publicação, quando a publicação referenciada por uma espécie não existir. A outra troca de mensagem parte do método Definir_Especie (), tal método faz uma chamada para o método run () do framework Espécie, ou seja, ele define uma nova espécie, quando essa não existir. O novo fluxo de controle é apresentado na Figura 5.10. 


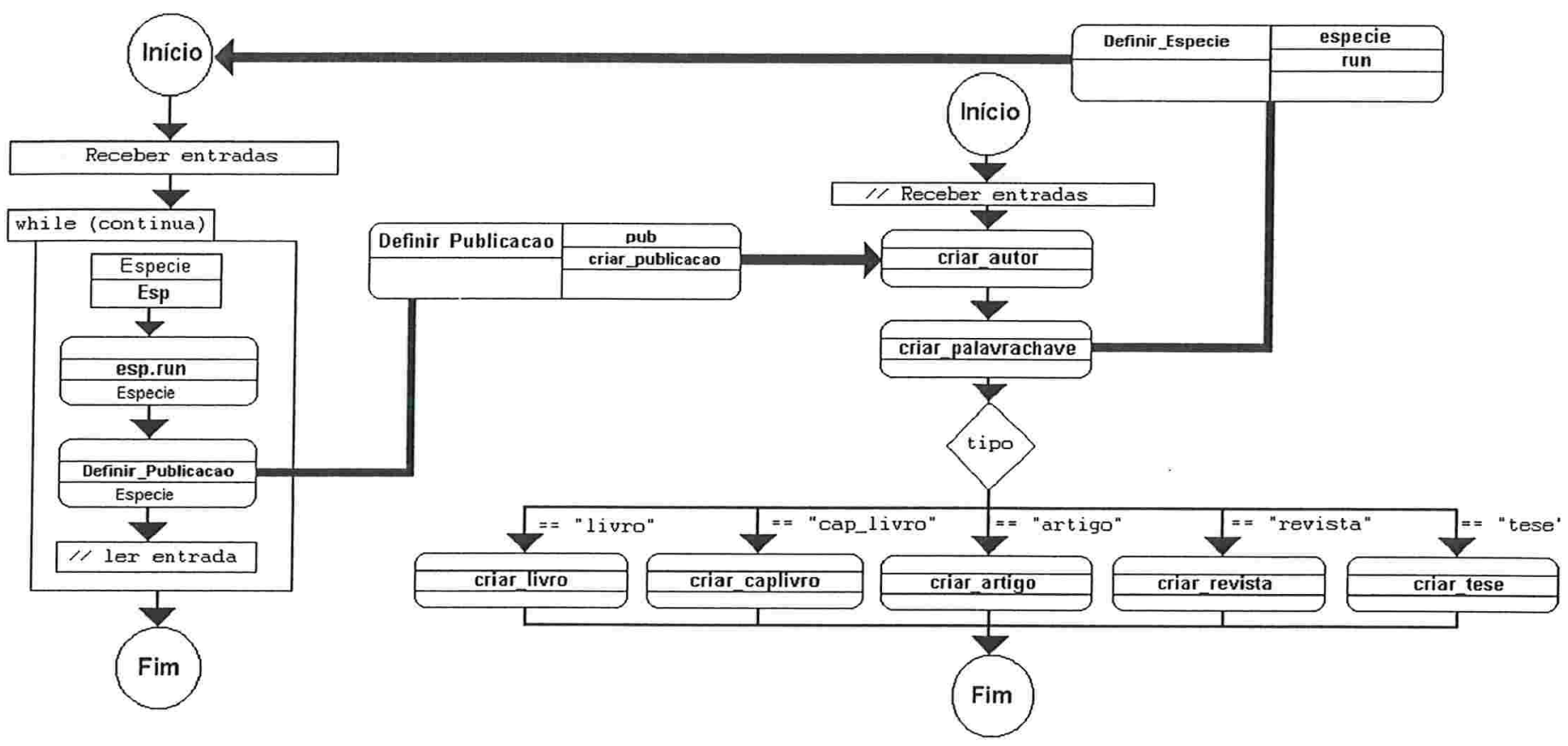

Figura 5.10: Fluxo de Controle para a Composição Publicação + Espécie

A implementação do novo fluxo de controle é feita pela criação de uma thread dos métodos que iniciam os fluxos de controle dos dois frameworks, sendo que ambos os fluxos de controle devem ser estendidos para serem capazes de fazer a chamada para os novos métodos.

\section{4 - Problemas Potenciais na Composição de Fluxos de Controle}

Nessa seção serão descritos os problemas potenciais que podem acontecer em uma composição de fluxos de controle de frameworks. O levantamento dos problemas foi feito para a composição de fluxos de controle que se comunicam apenas por troca de mensagens. Tais frameworks devem satisfazer às seguintes restrições apresentadas na Seção 5.1: tratamento apenas da composição de fluxo de controle; frameworks "que chamam"; frameworks devem possuir fluxo de controle isolado; não há memória compartilhada entre os frameworks; falta de suporte a eventos compartilhados; acesso ao código fonte; frameworks corretos e não serão alterados. 
Tais limitações são necessárias para podermos identificar apenas os problemas envolvidos com troca de mensagens. O levantamento de problemas será feito para as quatro formas de composição descritas anteriormente: sem comunicação; seqüencial; unidirecional e bidirecional.

Para cada forma de composição foi analisado o nó (objeto/método) que faz a chamada e o nó que recebe a chamada. Para o nó que faz a chamada temos: nó inicial; nó intermediário (seqüencial, condicional e paralelo) e nó final. Para o nó que recebe a chamada temos: nó inicial; nó intermediário (seqüencial, condicional e paralelo); nó final e nó que não pertence ao fluxo de controle. Essa descrição foi utilizada didaticamente para realizar o levantamento de problemas. Os tipos de nós analisados para cada forma de composição foram:

- Sem comunicação: como não há troca de mensagem, nenhum tipo de nó foi analisado.

- Seqüencial: foi realizado para o nó que chama final e nó chamado inicial ou nó que não pertence ao fluxo e chamadas sem retorno. Isso será feito pela própria definição da composição seqüencial, ou seja, um framework inicia outro framework e termina a sua execução.

- Unidirecional: foi realizado para todos os tipos de nós, tanto nó que chama quanto nó chamado, sendo que as chamadas podem ser com argumentos e sem argumentos e com ou sem retorno.

- Bidirecional: foi realizado para todos os nós (semelhante ao unidirecional) e também foram analisadas todas as combinações possíveis entre os nós (pares de nós).

\subsection{1 - Descrição dos Problemas Potenciais}

De acordo com a forma do levantamento de problemas descrita na seção anterior, foram encontrados os seguintes problemas: (i) chamada de um método com argumento inválido; (ii) retorno inválido da chamada de um método; (iii) interferência, (iv) chamada de um método que ainda não deveria ser executado (précondições do fluxo de controle); e (v) deadlock. Nessa seção faremos uma descrição desses problemas e mostramos as conseqüências para a composição de fluxo de controle. 


\subsubsection{1 - Chamada de um método com argumento inválido}

Quando um framework manda uma mensagem para o outro framework ele pode passar alguns argumentos (parâmetros) junto com a mensagem. Mas, algumas vezes, o framework que recebe a mensagem pode não trabalhar corretamente com os valores passados como argumento. Isso acontece porque o framework que recebe a chamada pode limitar os argumentos que ele trata, e o framework chamado pode não limitar ou não tem conhecimento que o método não está habilitado a trabalhar com determinados valores passados como argumento. Por exemplo, um método pode trabalhar apenas com valores inteiros entre $1 \mathrm{e}$ 100 , ou um objeto que tenha um campo chamado "nome" que não pode ser nulo. Problemas surgem quando o framework que faz a chamada passa uma mensagem e o argumento dessa mensagem não satisfaz às restrições do método implementado no outro framework. Neste exemplo, o framework poderia passar uma mensagem com um inteiro valendo 110 ou um objeto com o campo "nome" nulo.

Existem duas formas de se tratar argumentos de métodos: direta ou indiretamente. Na verificação direta existe um pedaço de código escrito somente para isso, por exemplo:

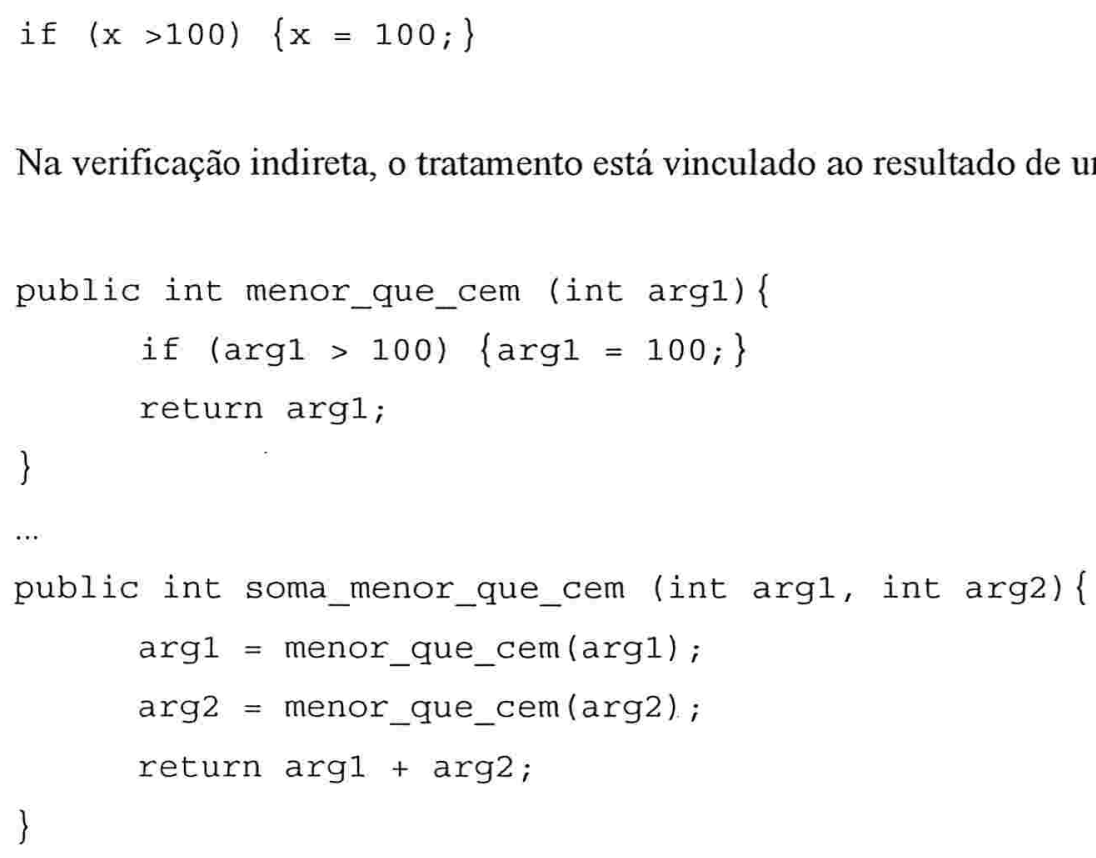

Nesse caso, temos que o tratamento está sendo feito em um método definido anteriormente. Esse problema tem duas variantes, dependendo do tipo de chamada: (i) se a chamada não esperar resposta, apenas o framework que recebe a chamada pode executar incorretamente; e (ii) se o framework que faz a chamada 
esperar uma resposta, essa será devolvida, dependendo da aplicação, com uma mensagem de erro (exceção), ou com uma resposta incorreta.

Um ponto importante é se o método que recebe a chamada tem tratamento de exceção padrão de Java para os argumentos que ele recebe. Nesse caso, quando um argumento inválido é recebido uma exceção pode ser lançada, mas não necessariamente tratada.

- Conseqüências: caso o método que receba a chamada com argumento inválido implemente o tratamento direto, não haverá problema, uma vez que ele consegue tratar situações anormais. Caso não tenha, o problema pode acontecer. As conseqüências de uma chamada inválida são duas: (i) o método que recebeu a mensagem pode trabalhar assim mesmo e retornar um resultado sintaticamente correto (por exemplo, inteiro), mas semanticamente errado; ou (ii) execução inesperada, com erros ou até mesmo parada de execução (quando um erro acontece e o método não consegue tratar).

Um outro problema acontece quando o objeto no qual a chamada está sendo feita estiver ativo no framework que recebe a chamada, quando algum erro acontece com ele, esse erro pode ser propagado para outros métodos que acessam o objeto, causando problemas de execução nos dois frameworks. Esse caso pode causar erros inesperados ou a parada de execução do framework.

\subsubsection{2 - Retorno inválido da chamada de um método}

Semelhante ao caso acima, só que agora a resposta pode vir errada. Ela pode vir na forma de uma exceção lançada pelo método ou uma variável incorreta, causando com isso erros de execução no framework que fez a chamada. Uma outra forma de retorno inválido seria o mesmo caso acima, quando a variável de retorno fica fora de um limite estabelecido. Nesse caso também temos o tratamento direto ou indireto, que é definido de maneira semelhante ao anterior.

- Conseqüências: problemas de execução do framework que fez a chamada, tais como: parada de execução; execução com valores incorretos ou erros inesperados. Aqui também existe diferença entre o tipo de objeto que está sendo utilizado, quando o objeto for definido no framework que fez a chamada, o erro fica interno a ele. Mas quando o objeto pertencer ao outro framework, ambos os frameworks podem ter problemas na execução. 


\subsubsection{3 - Interferência}

A interferência acontece quando métodos executando em paralelo tentam acessar a mesma variável, causando modificações indevidas ou valores inconsistentes devido à falta de sincronização. A causa desse problema é a execução em paralelo de dois fluxos de controle que não foram projetados para isso. Esses fluxos de controle compartilham memória e ambos podem modificá-las sem problemas, uma vez que os métodos pertencem ao mesmo framework. Os fluxos de controle que executam em paralelo são: o fluxo de controle normal do framework e o fluxo de controle criado pela troca de mensagem.

A interferência pode acontecer nas variáveis privadas da classe do objeto que recebe a chamada e nas variáveis de classes públicas de qualquer classe do framework que recebe a chamada. Além disso, quando o objeto que recebe a chamada já estiver definido no framework, o(s) método(s) também podem alterar seu estado (variáveis de instância), dessa forma, as interferências podem acontecer também nas variáveis de instância desse objeto.

Existem duas formas de interferências: (i) interferência direta: fica localizada no método que recebe a chamada e (ii) interferência indireta: o método que recebe a chamada chama outros métodos que podem causar interferências.

- Conseqüências: acesso, ao mesmo tempo, às variáveis de classes (classe que o objeto sobre o qual a chamada está sendo feita é derivado) e às variáveis de classes públicas de todas as classes do framework. Como isso não foi inicialmente previsto no fluxo de controle, pode causar problemas de sincronização entre eles, gerando valores inconsistentes para uma mesma variável. Outro problema acontece quando a chamada é feita para um objeto já definido, como o método da troca de mensagem pode alterar seu estado, pode causar também problemas de sincronização com outros métodos que já estavam executando no fluxo de controle que recebe a chamada.

\subsubsection{4 - Chamada de um Método que Ainda não Deveria ser Executado (pré-condições do fluxo de controle)}

Nesse trabalho consideramos como pré-condições de fluxo de controle o seguinte caso: um método que para executar corretamente precisa de serviços de outros métodos. O problema acontece quando um método chamado precisa de um serviço fornecido por outro método que ainda não foi executado, ou seja, um 
método é chamado e esse método pode não executar corretamente porque precisa de resultados de um outro método do fluxo de controle. Como conseqüência o método pode não executar ou executar de maneira indevida, uma vez que ele não tem todos os argumentos necessários para sua perfeita execução, gerando erros nos dois frameworks.

- Conseqüências: a principal conseqüência é execução incorreta. Uma vez que o método precisa de um método que ainda não foi executado.

\subsubsection{5 - Deadlock}

Tanenbaum [54] define deadlock da seguinte forma: "um conjunto de processos está em uma situação de deadlock, se cada processo do conjunto estiver esperando por um evento que somente outro processo pertencente ao conjunto pode oferecer. Como todos os processos estão esperando (bloqueados), nenhum deles poderá fazer acontecer qualquer um dos eventos que podem vir a ativar um dos demais membros do conjunto".

Para o caso de composição através de troca de mensagens, um processo será um método no fluxo de controle e um evento será o retorno de um método. O deadlock acontece quando algum método do fluxo de controle faz uma chamada para o outro framework, que durante a execução faz uma outra chamada para o framework que fez a primeira chamada, mas esse framework está parado esperando a resposta da primeira troca de mensagem. Dessa forma, os dois fluxos de controle estão parados, esperando respostas um do outro, caracterizando uma situação de deadlock. Esse problema pode acontecer entre qualquer par de mensagens entre os frameworks.

- Conseqüências: a principal conseqüência é a parada parcial ou total dos dois fluxos de controle. A parte do fluxo de controle parada será aquela que fez a chamada.

O levantamento de problemas foi realizado para cada forma de composição descritas anteriormente. A Tabela 5.1 apresenta os problemas encontrados e o relacionamento com as formas de composição. 


\begin{tabular}{||c|c|c|c|c||}
\hline \hline $\begin{array}{c}\text { Chamada de um método com } \\
\text { argumento inválido }\end{array}$ & $\begin{array}{c}\text { Seqüencial } \\
\text { Composição }\end{array}$ & Unidirecional & Bidirecional \\
\hline $\begin{array}{c}\text { Retorno inválido de uma chamada } \\
\text { de método }\end{array}$ & & $\mathrm{X}$ & $\mathrm{X}$ & $\mathrm{X}$ \\
\hline $\begin{array}{c}\text { Interferência } \\
\text { Pré-condições de fluxo }\end{array}$ & & $\mathrm{X}$ & $\mathrm{X}$ & $\mathrm{X}$ \\
\hline Deadlock & & & $\mathrm{X}$ & $\mathrm{X}$ \\
\hline
\end{tabular}

Tabela 5.1: Problemas e Formas de Comunicação

\section{5 - Considerações Finais}

Este capítulo apresentou como dois fluxos de controle de frameworks Java podem ser compostos através de troca de mensagens e descreveu o resultado de um levantamento dos problemas que podem acontecer durante tal composição. Sendo que os frameworks envolvidos na composição não têm memória compartilhada, os conjuntos de eventos que eles conseguem manipular são disjuntos e ambos os fluxos de controle são reutilizados.

Os problemas encontrados acontecem porque a maioria dos frameworks não é projetada para ser composta com outros frameworks, os problemas encontrados foram: (i) chamada de um método com argumento inválido; (ii) retorno inválido da chamada de um método; (iii) interferência; (iv) chamada de um método que ainda não deveria ser executado (pré-condições do fluxo de controle) e (v) deadlock.

Na Seção 4.3 foram apresentadas as conseqüências para o fluxo de controle quando dois frameworks não são adequadamente compostos:

- Colisão de laços (overlap): acontece dois laços de controle tentam gerenciar o mesmo recurso (evento ou memória), nesse caso não temos nem eventos nem memória compartilhados. Os laços 
de eventos são compostos através de um adaptador de eventos. Devido ao escopo da composição apresentada, esse problema não acontece.

- Falta de controle (gap): um novo elemento é adicionado ao framework e nenhum dos frameworks é capaz de gerenciar esse elemento. Esse problema pode acontecer na forma de composição descrita acima, quando um novo elemento é adicionado ao framework composto (classes, interfaces ou eventos), sendo assim o projetista deve estender algum fluxo de controle para gerenciar um novo elemento ou o novo fluxo de controle deve gerenciar esse novo elemento.

- Interferência: acontece quando um framework interfere na execução do outro através da troca de mensagens entre eles.

- Execução incorreta: qualquer um dos frameworks pode executar incorretamente, isso pode acontecer devido a: argumentos inválidos; interferências e pré-condições do fluxo de controle.

- Parada na execução: um ou ambos os frameworks podem parar devido a erros de execução, que podem acontecer por causa de: argumentos inválidos; interferências; pré-condições do fluxo de controle e deadlock.

Além do levantamento de problemas, foram apresentados alguns exemplos de composição de frameworks Java, tais exemplos são didáticos e não foram construídos utilizando um extenso estudo de domínio (como todo o framework deve ser construído). A maior dificuldade para a realização das composições descritas acima foi o entendimento dos fluxos de controle existentes, mesmo eles estando isolados em uma entidade separada. Para isso foi importante o acesso ao código fonte, uma vez que sem esse, o entendimento do fluxo de controle ficaria muito prejudicado.

As composições descritas nesse capítulo apresentam alguns aspectos em comum que são válidos para a maioria das composições de fluxo de controle baseada em troca de mensagem em Java:

a) Definição de novos elementos: primeiramente deve-se definir os novos elementos do framework: classes, interfaces e eventos. As classes podem ser definidas de três formas: novas classes; extensão de classe para modificação e composição de classes. As interfaces podem ser definidas baseadas em interfaces existentes ou independentes. Os eventos podem ser adicionados normalmente, desde que apenas um framework responda a eles (domínio de eventos disjuntos). Quando se definem os novos elementos deve-se estender o fluxo de controle de um dos frameworks ou adicionar ao novo fluxo de controle código para controlar esses novos elementos, evitando dessa forma a falta de controle (gap). 
b) Trocas de mensagens: devem ser definidas tendo como base os fluxos de controle dos dois frameworks. Definidos os locais e o meio de comunicação das chamadas, deve-se estender o fluxo de controle do framework que faz a chamada para que possa incorporar a troca de mensagem.

c) Novo fluxo de controle: o novo fluxo de controle depende: da forma de composição; das trocas de mensagens entre os frameworks e do meio de comunicação. O novo fluxo de controle consiste na chamada dos fluxos de controle dos dois frameworks mais a chamada do adaptador de eventos que controla os eventos gerenciados pelos dois frameworks mais os novos eventos definidos para a composição.

d) Implementação do fluxo de controle: depende de algumas variáveis como: forma de composição; meio de comunicação e trocas de mensagens. Quando os fluxos de controle precisam executar em paralelo deve-se criar uma thread do fluxo de controle. Mas, quando os fluxos executarem seqüencialmente pode-se fazer uma chamada para os métodos que iniciam o fluxo de controle, criar uma thread do fluxo de controle ou copiar e colar.

e) Problemas: os problemas citados podem acontecer na maioria das composições. Eles acontecem porque os frameworks não foram projetados para ser utilizados para composição. O projetista deve verificar que tipos de problemas e aonde esses problemas acontecem em uma composição. Quando algum problema existe, o novo framework pode não executar corretamente.

No próximo capítulo é apresentada uma ferramenta que foi desenvolvida a partir do levantamento de problemas descrito nesse capitulo, ela tem como entrada dois frameworks e como é realizada a composição entre eles, tendo como saída alguns problemas que podem acontecer durante a composição e algumas sugestões de como contornar os problemas encontrados. 


\section{Capítulo 6 - Ferramenta para Composição de Fluxos de Controle de Frameworks Java}

Este capítulo apresenta uma ferramenta desenvolvida para auxiliar a composição de fluxos de controle de dois frameworks Java. Tal ferramenta tem como entrada os frameworks e a forma de composição entre eles, baseada nessa definição a ferramenta detecta que problemas acontecem nessa composição, tais problemas foram apresentados no Capítulo 5 e podem ser detectados de maneira estática e parcial. A ferramenta é descrita através da sua representação, uso e alguns exemplos.

\section{1 - Introdução}

Baseado no levantamento de problemas e na composição apresentados no capítulo anterior, foi construída uma ferramenta para auxiliar o projetista durante a composição de fluxos de controle de dois frameworks Java. A ferramenta faz um diagnóstico, verificando os problemas que podem acontecer durante a composição. E, de acordo com os problemas encontrados, algumas sugestões podem ser oferecidas, ficando a cargo do projetista a implementação ou não da sugestão.

A ferramenta tem como entrada dois frameworks e as definições da composição: os novos elementos, as trocas de mensagens e o novo fluxo de controle, Tendo, como saída, os tipos de problemas que podem acontecer mediante a composição, onde eles acontecem (objeto/método/variável), ou podem acontecer, e sugestões para contornar os problemas encontrados. A ferramenta indica ao usuário que problemas potenciais podem acontecer na composição que ele apresenta como entrada, e apresenta algumas restrições:

- Número de frameworks: ela está implementada para trabalhar apenas com a composição de dois frameworks, caso o usuário precise compor mais de dois frameworks ele deve fazer composições incrementais (pares de frameworks) até obter o framework desejado.

- Somente deteç̧ão estática e parcial: somente podem ser detectados os problemas estaticamente e de maneira parcial. Os problemas que podem ser detectados dinamicamente não são cobertos pela ferramenta. 


\section{2 - Representação}

A representação deve cobrir todas as informações relevantes para a composição de fluxos de controle. A descrição da representação foi dividida em três partes: framework; fluxo de controle e composição. Nessa seção serão apresentados apenas como os elementos envolvidos na composição de frameworks são representados. A forma como eles são usados na ferramenta será apresentado na Seção 6.4.

\subsection{1 - Framework}

Para cada framework devemos ter informações sobre seus elementos (classes, interfaces, objetos, eventos e fluxo de controle). Abaixo, são descritos todos os componentes e as informações necessárias para a sua descrição:

- Frameworks: nome; descrição; conjunto de classes; conjunto de interfaces; conjunto de eventos e uma classe controladora.

- Classes: nome; superclasse; modificadores (abstract, final, etc); visibilidade (public, private ou protected); interfaces que implementa; variáveis de classes; variáveis de instância e métodos.

- Interfaces: nome; métodos; variáveis e interfaces que estende.

- Variáveis: nome da variável; classe ou interface a que pertence; visibilidade; tipo (int, String, boolean, etc) e se a variável é de classe ou instância.

- Métodos: nome do método; visibilidade; classe ou interface a que pertence; argumentos de entrada; argumento de retorno; variáveis que lê; variáveis que altera; métodos que chama; fluxo de controle; objetos criados pelo método e pré-condições (métodos que devem ser executados antes para o perfeito funcionamento do mesmo).

- Eventos: nome do evento; fonte do evento; interface listener associada e métodos que chama.

- Classe controladora: nome de classe; nome do método que implementa o fluxo de controle e o nome do método que implementa as inicializações de variáveis, de acordo com o modelo de framework apresentado na Seção 2.2.4.

- Objetos: nome do objeto; classe a que pertence e visibilidade.

Para representar um framework, devemos primeiro obter informações sobre as classes, interfaces e eventos. Baseado nessas informações, pode-se descrever adequadamente o fluxo de controle, através da 
construção de objetos e chamadas de métodos. Todas as informações descritas acima são extraídas do código fonte do framework de maneira automática, dessa forma deve-se ter acesso ao código fonte dos frameworks. A Figura 6.1 apresenta os relacionamentos entre os elementos do framework.

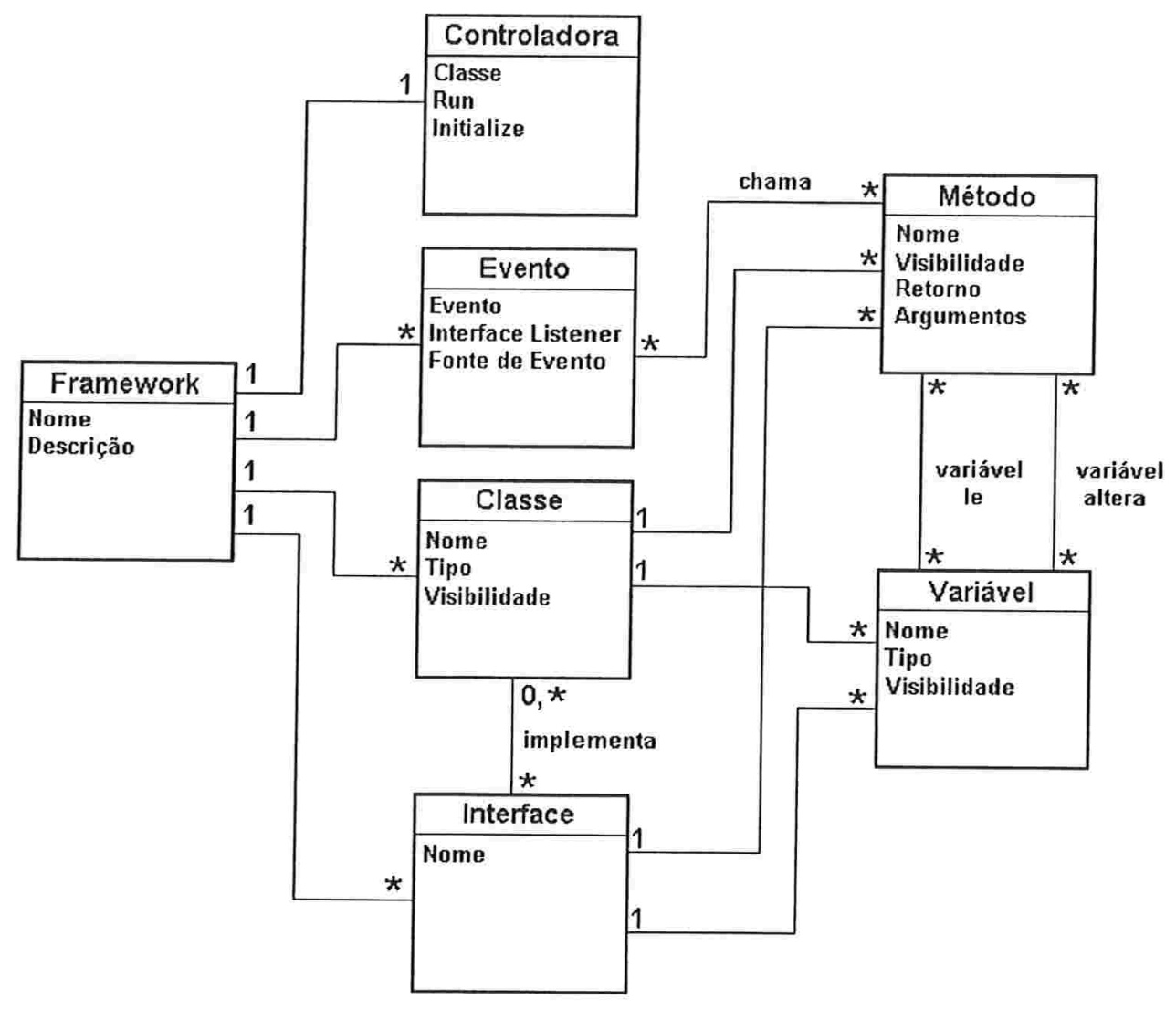

Figura 6.1: Diagrama de classes para a ferramenta

\subsection{2 - Fluxo de Controle}

É representado como um conjunto de nós (um par objeto/método), sendo que existe um nó especial (inicial) que inicia a execução do fluxo de controle. Um nó é representado como uma chamada de método feita sobre objeto, ou seja, um nó é constituído por: um método; um objeto sobre o qual a chamada é feita e o tipo de execução (paralelo, seqüencial ou condicional). Cada nó pode chamar vários outros nós, do mesmo modo que um método pode chamar vários métodos, e cada nó também tem informações sobre os nós que ele chama (nós filho). O fluxo de controle é representado por um grafo, sendo que os métodos que fazem as chamadas são os nós pai e os nós que recebem a chamada são os nós filho. Cada conjunto objeto/método 
aparece somente uma vez no grafo de fluxo de controle, caso contrário o grafo poderia ser infinito; por exemplo, quando existir uma recursão.

A partir da descrição do fluxo de controle e da descrição dos componentes contidos no framework, chega-se a uma representação completa do fluxo de controle. Baseado nessa representação, mais as informações sobre a composição, a ferramenta pode realizar o diagnóstico dos problemas para cada composição específica.

\subsection{3 - Composição}

Além da representação dos frameworks, deve-se definir como será feita sua composição. Para representar a composição temos que ter: os dois frameworks envolvidos; os novos elementos do framework composto; as comunicações entre eles e a forma de implementação do novo fluxo de controle.

Primeiro deve-se definir os novos elementos: classes e interfaces, como apresentados na Seção 5.3. $\mathrm{Na}$ definição das novas classes, as comunicações devem ser implementadas. As comunicações são representadas como: sentido (de qual framework parte a chamada); objeto que recebe a chamada; método que faz a chamada; método que recebe a chamada e tipo de execução (paralelo, seqüencial ou condicional). A comunicação pode partir de qualquer nó de um framework para qualquer nó do outro framework, incluindo várias comunicações entre os frameworks. As comunicações devem ser implementadas nas classes criadas para a composição. Definidas as trocas de mensagens, o usuário deve estender o fluxo de controle do framework que faz a chamada, para que as trocas de mensagens possam fazer parte do novo fluxo de controle.

O novo fluxo de controle deve ser implementado indicando a ordem de chamadas dos fluxos de controle, paralelo ou seqüencial e como implementar os fluxos de controle (chamada simples, threads, ou copiar e colar). Além disso, devem ser modificados os fluxos de controle dos frameworks para que os métodos que contêm a(s) troca(s) de mensagem(ns) possam fazer parte dele. Para isso o projetista tem as três opções citadas na Seção 5.3.2: substituição de um objeto em um nó existente; substituição de um método em um nó existente ou novo nó. 


\section{3 - Detecções}

Baseada na definição dos frameworks e na composição, a ferramenta pode realizar a verificação dos problemas potenciais que podem acontecer durante a composição de fluxo de controle. Os problemas que podem ser detectados foram descritos na Seção 5.4. A deteç̧ão realizada pela ferramenta pode ser feita apenas de maneira estática e de maneira parcial para alguns casos. A ferramenta consegue detectar os problemas da seguinte forma:

a) Argumento inválido: toda chamada de método corre o risco de passar um argumento inválido em tempo de execução. A verificação deste tipo de erro depende da forma de tratamento implementada. Quando ela é direta e existe tratamento de erros padrão de Java é possível realizar a detecção. Caso o tratamento seja indireto, ou não existir tratamento de erros, a detecção não pode ser realizada. A ferramenta consegue detectar apenas se o método que recebe a chamada tem tratamento de erros padrão de Java para os argumentos recebidos como entrada, caso o método não tenha esse tratamento o usuário é avisado.

b) Retorno inválido: é semelhante ao caso anterior. Aqui a resposta tem um retorno não esperado pelo método que fez a chamada. A ferramenta consegue verificar se o método que recebe a chamada tem tratamento de erros padrão de Java para o argumento que retorna da troca de mensagem, caso não exista, o usuário é avisado.

c) Interferência: deve-se verificar as variáveis de classe alteradas pelo método que recebe a chamada. Se tais variáveis coincidirem com as variáveis que o fluxo de controle que está em execução altera ou lê (incluindo os métodos chamados por todos os eventos, uma vez que não se sabe a hora que cada evento vai acontecer), então o problema de interferência pode acontecer. Não se pode detectar com certeza se a interferência acontece, pode-se apenas detectar a possibilidade dela acontecer, uma vez que os métodos que vão estar executando ao mesmo tempo dependem do fluxo de execução do framework (que normalmente é diferente para cada execução). A ferramenta consegue detectar a interferência direta nas variáveis de classes, e não consegue detectar as interferências que acontecem nos estados dos objetos e as interferências indiretas.

d) Pré-condições do fluxo: quando se faz a composição, pode-se fazer a chamada para um método que depende de outros. Antes de a chamada ser feita efetivamente, deve-se verificar se as condições (outros métodos) para que o método execute corretamente serão executadas. A ferramenta consegue detectar se um método que tem pré-condições do fluxo de controle foi chamado sem que o(s) método (s) que fazem parte da sua pré-condição tenha sido previamente chamado. 
e) Deadlock: alguns casos de deadlock podem ser identificados de maneira estática, outros de maneira dinâmica. Estaticamente pode-se detectar ciclos dentro dos dois fluxos de controle. Quando ciclos são encontrados, podemos ter certeza que o deadlock vai acontecer, mas deadlock não acontece apenas quando se têm ciclos, outras situações configuram deadlock, mas só podem ser detectadas dinamicamente. A ferramenta consegue detectar apenas ciclos no fluxo de controle, configurando uma situação de deadlock. Para detectar ciclos na composição entre fluxos de controle, podemos utilizar o grafo gerado pela representação do fluxo de controle composto. A verificação é feita da seguinte forma: quando uma chamada é feita basta verificar se durante a execução desse método ele faz uma chamada para algum método no outro framework (que fez a chamada primeiro), se na segunda chamada o nó que recebe a chamada estiver na mesma árvore do nó que fez a primeira chamada o deadlock acontece.

Caso encontre algum problema, a ferramenta avisa ao usuário que tipo de problema pode acontecer e onde (objeto/método/variável) o problema pode acontecer. Depois que todos os métodos são executados para todas as comunicações, a ferramenta apresenta em um formulário os problemas e algumas sugestões para ele.

\section{$6.4-$ Uso}

O uso da ferramenta pode ser descrito em três passos: (i) definição dos frameworks; (ii) definição da composição e (iii) detecção e sugestões.

\subsection{1 - Definição dos Frameworks}

Para definir um novo framework o usuário deve abrir o formulário Novo Framework. Nesse formulário, o usuário deve informar o nome do framework e uma pequena descrição do que ele faz. Depois de inseridas essas informações, um formulário de definição de framework é apresentado, no qual o usuário define todos os elementos do framework: classes; interfaces e a classe que implementa o fluxo de controle do framework (Controladora). 
Para inserir um novo componente no framework, o usuário precisa apertar no botão adicionar embaixo da lista de componentes já definidos. A Figura 6.2 apresenta o formulário de definição de frameworks.

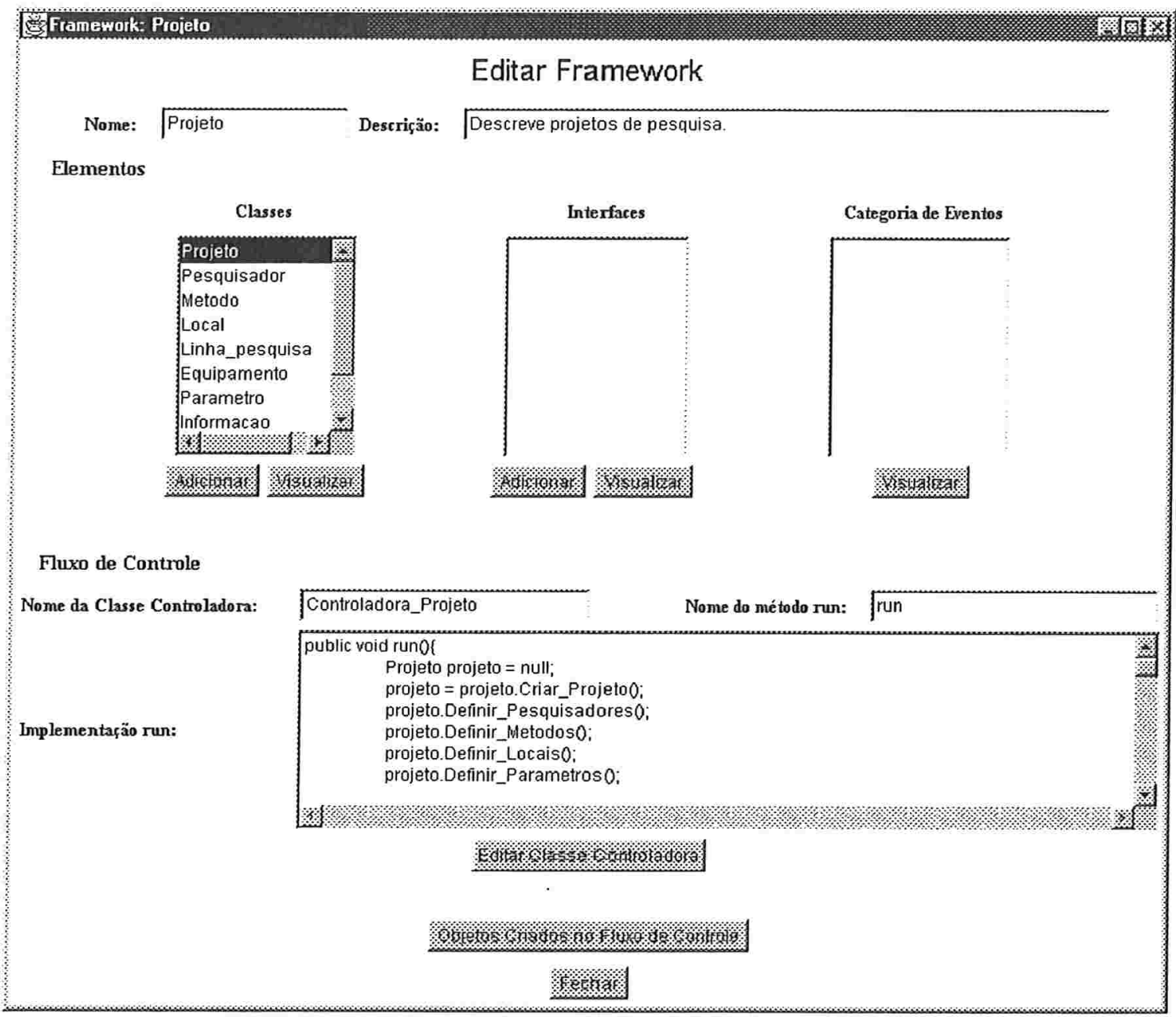

Figura 6.2: Formulário de definição do framework Projeto.

Para definir a classe Controladora, o usuário deve primeiro adicionar uma classe normalmente, para em seguida definir a classe Controladora. Para fazer isso, ele deve escolher o nome da classe, o nome do método que implementa o fluxo de controle $(r u n()$ ) e o nome do método que passa ao framework os argumentos da aplicação (initialize()). A ferramenta auxilia esta tarefa apresentando o nome de todas as classes pertencentes ao framework, junto com seus respectivos métodos. A Figura 6.3 apresenta o formulário de definição da classe Controladora para o framework Projeto. 


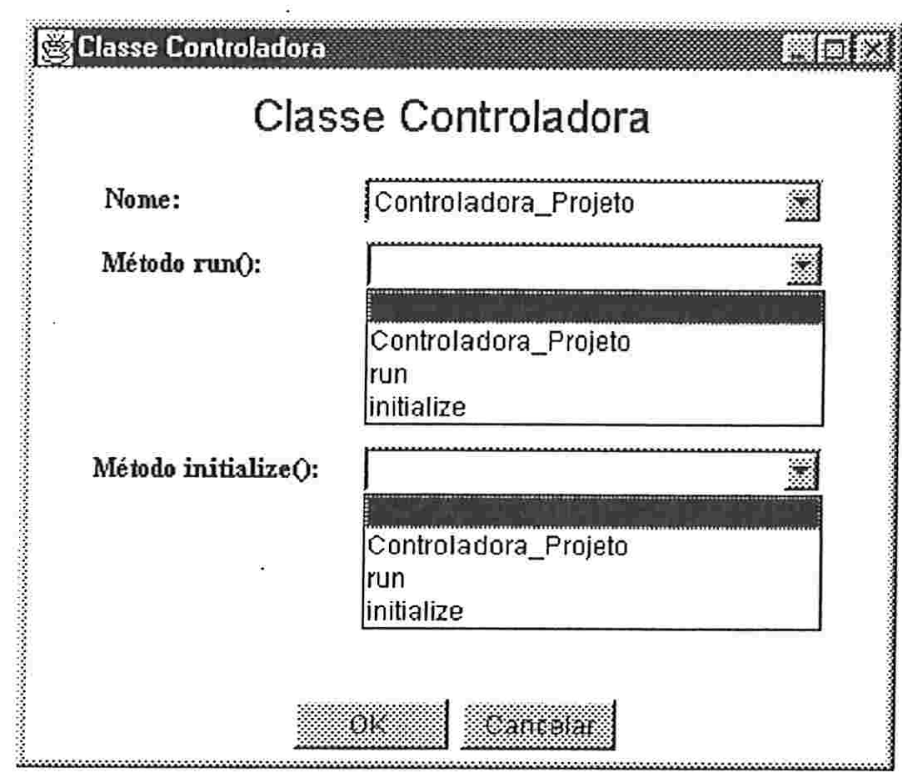

Figura 6.3: Formulário de definição da Classe Controladora para o framework Projeto.

\subsubsection{1 - Exemplos}

A definição de frameworks é feita de maneira bem simples, basta que o usuário entre com as informações do framework: nome e descrição, quando um novo framework é criado através do formulário Novo Framework. Em seguida é necessário adicionar os elementos do framework: classes e interfaces. Para isso, basta apertar no botão adicionar embaixo da lista do elemento que se deseja adicionar. Feito isso, é apresentado um formulário que solicita ao usuário o endereço do arquivo fonte (.java) do elemento que se deseja adicionar, a partir daí a ferramenta extrai de maneira automática os atributos descritos na Seção 6.2.1. Sendo que em cada arquivo fonte deve ser definida apenas uma classe. As classes definidas para cada um dos framework são:

a) Projeto: Equipamento; Local; Metodo; Linha_Pesquisa; Parametro; Pesquisador; Informacao; Projeto e Controladora_Projeto, sendo a última a classe que inicia o fluxo de controle do framework através da chamada do método run ( ) .

b) Espécie: Especie; Genero; Familia; Classe; Filo; Reino e Controladora_Especie (inicia o fluxo de controle do framework). 
c) Publicação: Autor; Palavra_chave; Publicacao; Livro; Tese; Revista_cientifica; Artigo_anais; Capitulo_livro e Controladora_Publicacao.

d) Financiamento: Pesquisa; Orgao_financiamento; Financiamento; Bolsista; Bolsa e Controladora_Financiamento.

\subsection{2 - Definição da Composição}

Depois de definidos os frameworks, o usuário pode realizar a composição entre eles. Para isso, ele deve abrir o formulário Nova Composição. Nesse formulário o usuário deve informar: o nome da composição, uma descrição e os dois frameworks envolvidos. Definidos os argumentos iniciais da composição, a ferramenta apresenta o formulário para realizar a composição (Figura 6.4). Para uma melhor visualização dos componentes dos frameworks, a ferramenta apresenta as classes, métodos e fluxo de controle dos frameworks envolvidos na composição.

Para a definição da composição, o usuário deve definir os novos elementos do framework: classes e interfaces, da mesma maneira que é definido nos frameworks. As novas classes podem ser definidas de três formas: (i) compor classes dos dois frameworks; (ii) extensão para modificação de uma classe de um dos frameworks e (iii) criar novas classes adicionadas à hierarquia de classes dos frameworks ou independentes. Essas definições são feitas a partir do formulário Adicionar extensão, cada forma de definição tem um formulário específico. A adição de novos elementos é semelhante à definição de classes e interfaces no framework. Junto com as definições de novas classes, devem ser implementadas as comunicações entre os frameworks. 


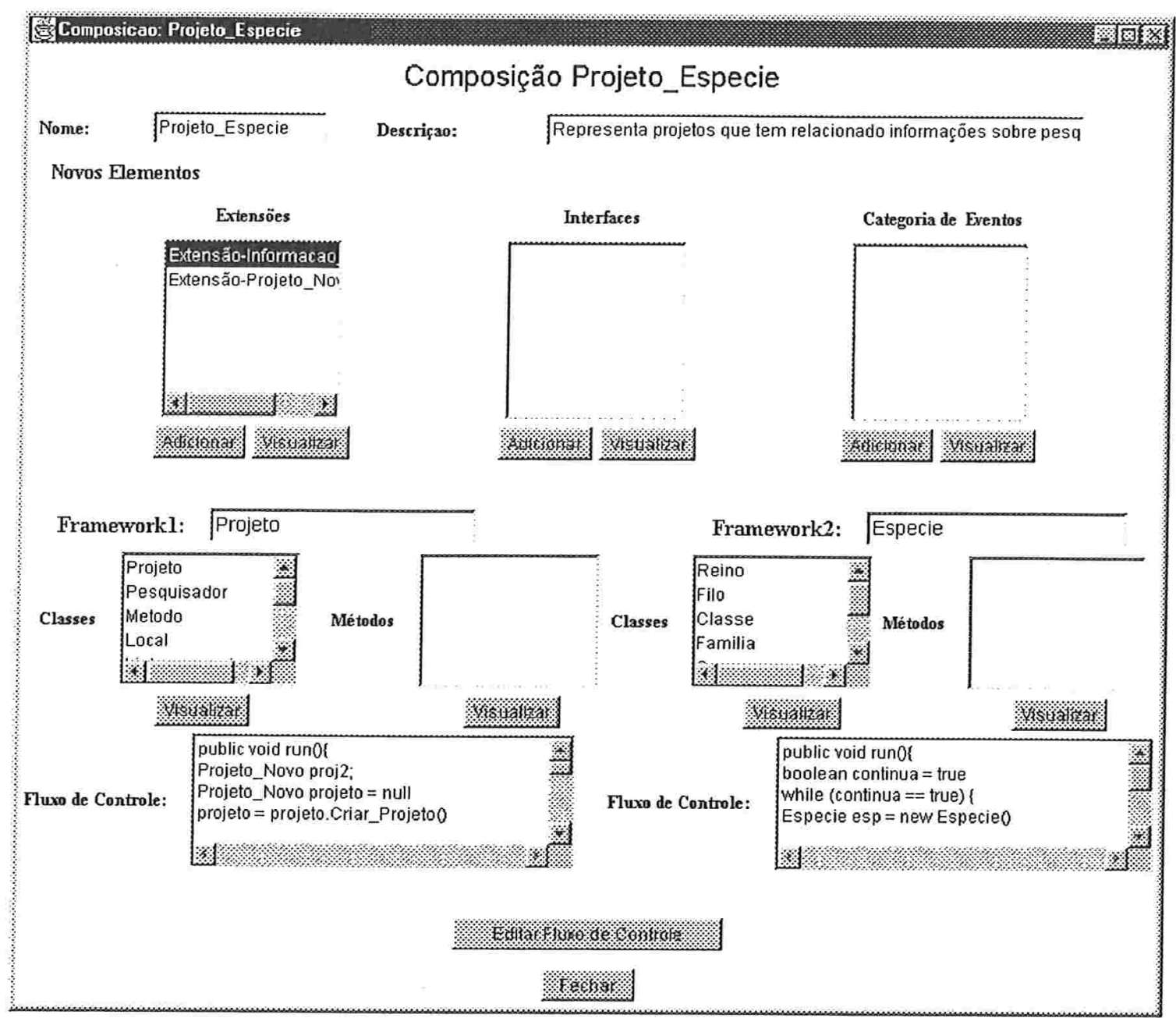

Figura 6.4: Formulário de definição da composição

O novo fluxo de controle é definido no formulário Novo fluxo de controle. O usuário deve seguir dois passos para criar o novo fluxo de controle: extensão do fluxo de controle e implementação do fluxo de controle.

Passo - 1: Extensão do fluxo de controle: definidas as comunicações, o usuário deve estender o fluxo de controle do framework que faz a chamada, essa extensão é necessária para que as comunicações implementadas possam fazer parte do fluxo de controle. A Figura 6.5 apresenta o formulário de extensão do fluxo de controle para a composição dos frameworks Projeto e Espécie. O formulário apresenta todos os nós e objetos pertencentes ao método que inicia o fluxo de controle. 


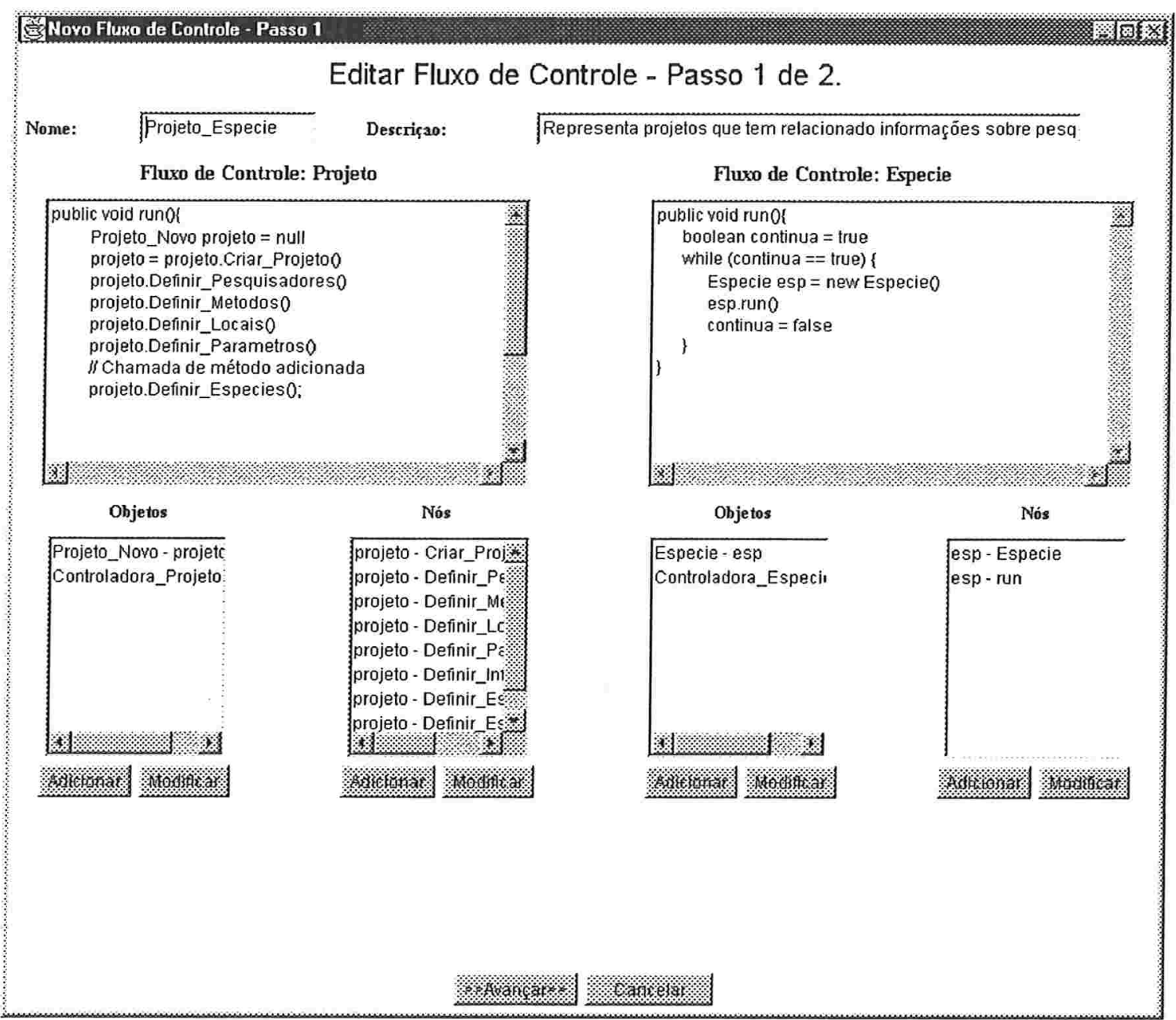

Figura 6.5: Formulário de definição do novo fluxo de controle - Passo 1.

O usuário tem três opções para fazer a extensão do fluxo de controle:

(i) Novo nó: deve-se definir um novo objeto ou utilizar um objeto existente e fazer a chamada para esse objeto. Na ferramenta o usuário deve apertar o botão adicionar nó (Figura 6.6 - C) e preencher as informações do nó (framework base, objeto, método e forma de execução) e indicar o local onde o novo nó será adicionado. Além disso, pode ser necessário criar um novo objeto no fluxo de controle, para isso o usuário deve apertar o botão adicionar objeto (Figura 6.6 - A) e adicionar o nome do objeto e o seu tipo.

(ii) Modificação de um objeto: aqui, apenas o tipo de um objeto é modificado. Para modificar um objeto o usuário deve pressionar o botão modificar objeto (Figura 6.6-B). A ferramenta apresenta todas as extensões realizadas sobre a classe base do objeto que será modificado. 
(iii) Modificação de um nó: um nó já existente é utilizado, bastando para isso modificar o método que está sendo chamado ou o objeto no qual a chamada está sendo feita. Na ferramenta deve-se escolher a opção modificar nó (Figura 6.6 - D).

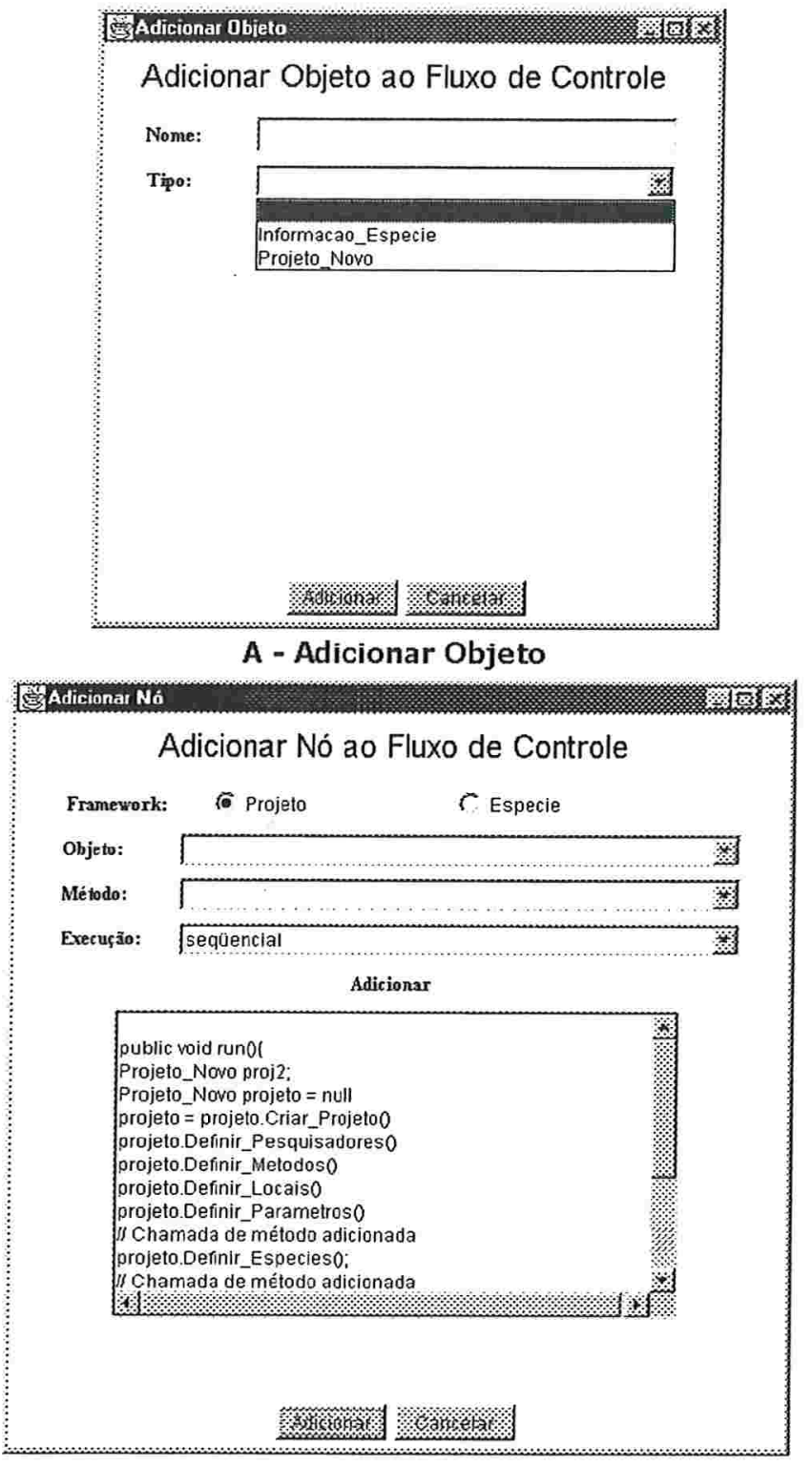

\section{C - Adicionar Nó}

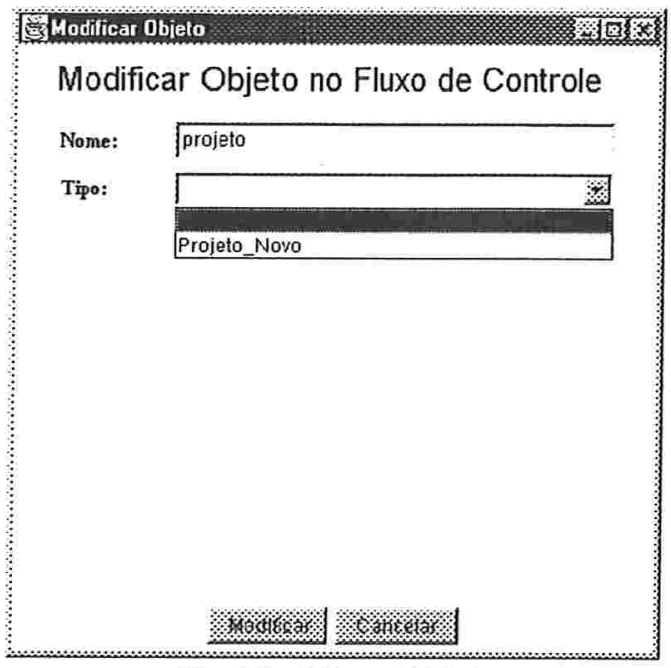

B - Modificar Objeto

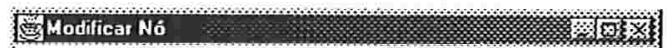

Modificar Nó no Fluxo de Controle

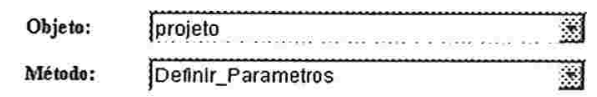

Figura 6.6: Formulários de Extensões do fluxo de controle

Definidas as extensões, o usuário pode ir para o passo 2 e define como será a implementação do fluxo de controle. 
Passo - 2: Implementação do novo fluxo de controle: deve-se definir três informações sobre a forma de implementação do novo fluxo de controle: ativação dos frameworks; implementação do fluxo de controle e implementação do método main. A Figura 6.7 apresenta o formulário para definir tais informações.

(i) Ativação dos frameworks: aqui o usuário define qual framework deve ser ativado primeiro, essa opção é importante quando a implementação do fluxo de controle for por chamada de método ou copiar e colar, uma vez que quando for utilizada uma thread os dois fluxos de controle vão executar em paralelo

(ii) Implementação do fluxo de controle: deve-se indicar a forma de implementação dos dois fluxos de controle: chamada do método que inicia o fluxo de controle; criação de uma thread ou copiar e colar.

(iii) Implementação do método main: o usuário escolhe se existirá um método main definido na classe.

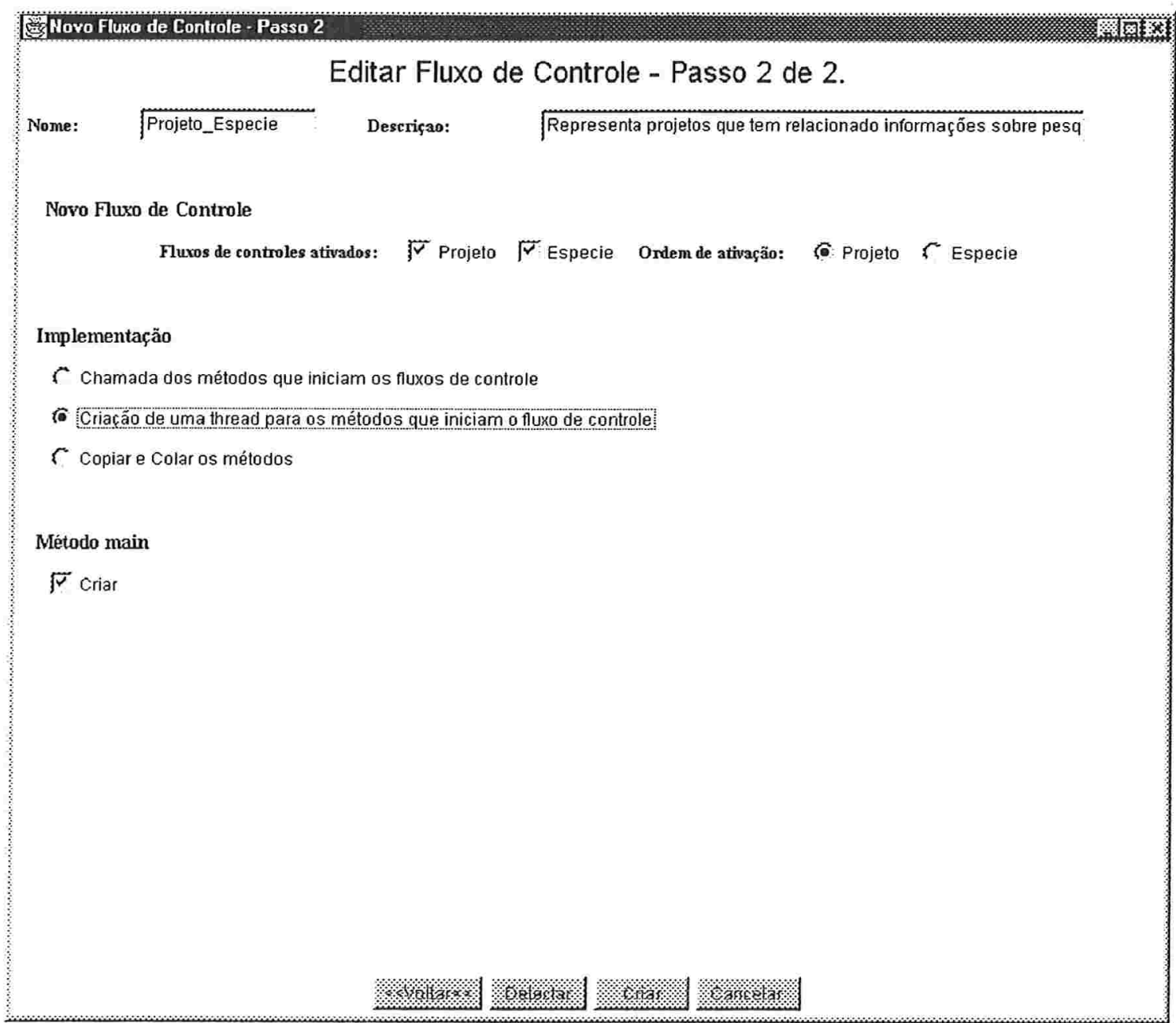

Figura 6.7: Formulário de definição do novo fluxo de controle - Passo 2. 
Definido o novo fluxo de controle o usuário pode apertar no botão Criar, esse botão cria um arquivo Java com o novo fluxo de controle baseado nas opções apresentadas.

\subsubsection{1 - Exemplos}

Nessa seção são apresentados exemplos de composição de frameworks utilizados no presente trabalho, uma descrição mais detalhada da composição é apresentada no apêndice A. Para exemplificar as composições vamos descrever os passos envolvidos na definição do novo fluxo de controle apresentado na Seção 6.4.2.

a) Projeto e Financiamento: nenhum dos dois frameworks foi modificado e o novo fluxo de controle é implementado pela criação de uma thread para cada classe que implementa o fluxo de controle e a chamada das threads. Os passos seguidos para a composição do fluxo de controle foram:

- Passo1 - Extensão do fluxo de controle: como não há comunicação entre os frameworks não são necessárias extensões no fluxo de controle.

- Passo2 - Implementação do novo fluxo de controle: os fluxos de controle são implementados através da criação de uma thread, de forma que eles possam executar em paralelo.

b) Projeto e Publicação: a classe Projeto foi estendida para uma classe Projeto_publicacao. Tal classe contém referências para as publicações de determinado projeto através de uma variável de instância chamada publicação. Além disso, foi criado um método Definir_publicacao(), o qual inicia o fluxo de controle do framework Publicação e define as publicações para um determinado projeto. É nesse método que a troca de mensagem é implementada. Os passos seguidos para a implementação do fluxo de controle foram:

- Passo1 - Extensão do fluxo de controle: o objeto projeto derivado da classe Projeto foi modificado para ser derivado da classe Projeto_Publicacao. Além disso, foi adicionado um nó para realizar a troca de mensagem, esse nó é a chamada do método Definir_Publicacao() sobre o objeto projeto. 
- Passo2 - Implementação do novo fluxo de controle: como a composição é seqüencial apenas o fluxo de controle do framework Projeto é ativado através da chamada do método que inicia o fluxo de controle do framework.

c) Projeto e Espécie: foi criada uma nova classe chamada Projeto_novo estendida da classe Projeto, para adicionar o método Definir_espécie () (em tal método é realizada a troca de mensagem). A classe Informacao foi estendida para uma nova classe Informação_especie que contém agora uma nova variável de instância denominada especie. A definição do fluxo de controle foi realizada da seguinte forma:

- Passo1 - Extensão do fluxo de controle: o objeto projeto derivado da classe Projeto foi modificado para ser derivado da classe Projeto_Novo. Além disso, foi adicionado um nó para realizar a troca de mensagem no fluxo de controle, esse nó é a chamada do método Definir_Especie() sobre o objeto projeto.

- Passo2 - Implementação do novo fluxo de controle: os fluxos de controle são implementados através da criação de uma thread.

d) Publicação e Espécie: nesse exemplo ambos os frameworks precisaram ser modificados. No framework Projeto a classe Palavra_chave foi estendida para uma classe denominada Palavra_chave_N. Tal classe contém uma variável de instância especie do tipo Especie_N que indica que aquela palavra-chave referencia uma espécie. Além disso, foi criado um método Definir_especie(), que inicia a definição de uma nova espécie quando uma nova palavra-chave é criada através do método Nova_Palavra_Chave_N().

No framework Espécie a classe Especie foi estendida para uma classe Especie_N. Tal classe tem agora uma variável de instância chamada publicacao e um novo método Definir_publicacao(), onde a troca de mensagem é realizada.

Os passos para a implementação do novo fluxo de controle foram os seguintes:

- Passo1 - Extensão do fluxo de controle: o framework Publicação foi estendido através da modificação do objeto palavra derivado da classe Palavra_chave para ser derivado da classe Palavra_chave_N. O framework Espécie foi estendido pela modificação do objeto 
especie derivado da classe Especie para ser derivado da classe Especie_N. Além disso, foi adicionado um nó para realizar a troca de mensagem no fluxo de controle, esse nó é a chamada do método Definir_Publicacao () sobre o objeto especie.

- Passo2 - Implementação do novo fluxo de controle: os fluxos de controle são implementados através da criação de uma thread.

\subsection{3 - Detecção e Sugestões}

Definidos os frameworks e a composição, o usuário pode realizar a detecção dos possíveis problemas para aquela composição. Para isso, basta apertar o botão Detectar no formulário de definicão do fluxo de controle (Figura 6.7). Quando o botão é pressionado, as detecções são realizadas e um formulário é apresentado com uma lista dos problemas encontrados e algumas sugestões para solucioná-los. O formulário que lista os problemas para cada comunicação é apresentado na Figura 6.8 .

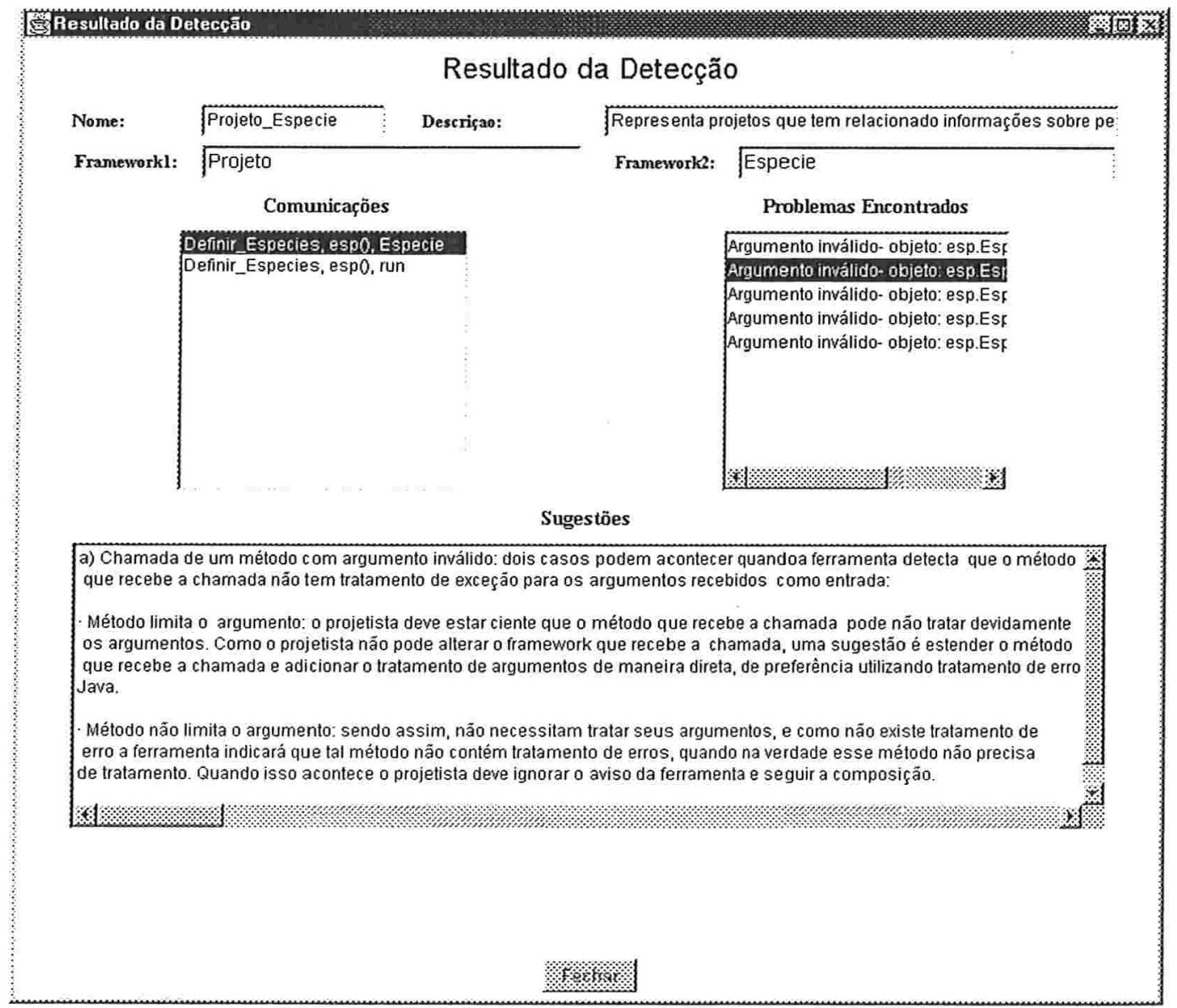

Figura 6.8: Formulário dos problemas encontrados e sugestões 
Mesmo tendo como objetivo apenas a detecção dos problemas, algumas sugestões podem ser oferecidas ao usuário. Tais sugestões servem para o usuário contornar os problemas. Abaixo segue um resumo das principais sugestões da ferramenta.

a) Chamada de um método com argumento inválido: dois casos podem acontecer quando a ferramenta detecta que o método que recebe a chamada não tem tratamento de exceção para os argumentos recebidos como entrada:

- Método limita o argumento: o projetista deve estar ciente que o método que recebe a chamada pode não tratar devidamente os argumentos. Como o projetista não pode alterar o framework que recebe a chamada, uma sugestão é estender o método que recebe a chamada e adicionar o tratamento de argumentos de maneira direta, de preferência utilizando tratamento de erros padrão de Java.

- Método não limita o argumento: sendo assim, não necessitam tratar seus argumentos, e como não existe tratamento de erro a ferramenta indicará que tal método não contém tratamento de erros, quando na verdade esse método não precisa de tratamento. Quando isso acontece o projetista deve ignorar o aviso da ferramenta e seguir a composição.

b) Retorno inválido da chamada de um método: pode ser desde um valor que o método que fez a chamada não sabe como tratar, até uma mensagem de erro padrão de Java. Nos dois casos devem ser feitos tratamentos para evitar que o framework que fez a chamada tenha problemas de execução. $\mathrm{O}$ tratamento deve ser feito dentro da classe que fez a chamada, esse tratamento é de responsabilidade do projetista da aplicação. $\mathrm{O}$ tratamento deve consistir de evitar que valores inválidos sejam retornados ao método que fez a chamada. Um outro ponto importante é quando se retorna uma mensagem de exceção padrão de Java. Neste caso, deve-se verificar se o método que fez a chamada é capaz de tratar essa mensagem. Caso não seja, o projetista deve implementar um comportamento padrão quando uma mensagem de erro é retornada. Geralmente esse tratamento deve ser implementado, uma vez que, durante o desenvolvimento original do framework não existia essa troca de mensagem.

c) Interferência: uma sugestão seria acrescentar código de sincronização nos métodos identificados com possíveis problemas de interferência nas variáveis de classe, a ferramenta diz em que métodos as interferências nas variáveis de classes podem acontecer, o projetista pode estender esses métodos com código de sincronização. Além disso, quando a chamada for feita sobre um objeto já definido, deve-se adicionar código de sincronização em todos os métodos executados sobre esse objeto. 
d) Chamada de um método que ainda não deveria ser executado (pré-condições no fluxo de controle): sempre que uma troca de mensagens for feita, deve ser verificado se as pré-condições daquela chamada são verdadeiras; caso não sejam, o método pode não executar corretamente. Nesse caso, o projetista tem duas opções: (i) refazer a chamada de forma que satisfaça os pré-requisitos; ou (ii) realizar a chamada sabendo que podem acontecer erros.

e) Deadlock: quando o deadlock ocorre, parte dos dois fluxos de controle fica parada, esperando resposta um do outro e podendo causar uma parada total dos frameworks. Podemos verificar a existência de ciclos entre os frameworks envolvidos na composição. Quando ciclos são encontrados as trocas de mensagens não podem acontecer nos pontos determinados, deve-se modificar uma ou as duas trocas de mensagens e a deteç̧ão deve ser feita novamente para verificar a existência de novos erros.

\subsubsection{1 -Exemplos}

Os exemplos de composição utilizados foram descritos na Seção 6.4.2.1. E uma descrição mais completa dos composições é apresentada no apêndice A.

a) Projeto e Financiamento: como não há troca de mensagem, não existe problemas que possam ser detectados pela ferramenta.

b) Projeto e Espécie: essa composição tem os seguintes problemas:

1. Argumento inválido na chamada de método: durante a execução do método Definir_especie(), ele pode passar argumentos inválidos para o método Nova_especie () do framework Espécie.

2. Retorno inválido para a chamada de método: o método Nova_especie() (método chamado pela comunicação) pode ter retorno inválido. Por exemplo, uma espécie com um valor nulo.

3. Interferência: durante a execução do método Definir_especie() do framework Projeto, pode haver interferência na variável Nespecie definida na classe Especie.

c) Projeto e Publicação: os problemas detectados pela ferramenta foram: 
1. Argumento inválido na chamada de método: durante a chamada (método Definir_publicacao()) podem ser passados argumentos inválidos.

2. Interferência: o método Definir_publicacao() faz uma chamada ao método Nova_Publicacao () do framework Publicação que modifica a variável Npubli cacao da classe Publicacao.

d) Publicação e Espécie: os problemas detectados pela ferramenta foram:

1. Argumento inválido na chamada de método: durante as chamadas (método Definir_publicacao() e método Definir_Especie()) podem ser passados argumentos inválidos.

2. Retorno inválido para a chamada de método: os métodos Definir_publicacao()) e Definir_especie() podem ter retornos inválidos.

3. Interferência: o método Definir_publicação() pode interferir na variável Npublicacao da clssse Publicacao, e Definir_especie() pode interferir na variável Nespecie da classe Especie.

\section{5 - Considerações Finais}

Este capítulo apresentou uma ferramenta para detectar que problemas podem acontecer quando se compõem fluxos de controle de frameworks Java. Tais problemas podem ser detectados apenas estática e parcialmente. Abaixo segue em resumo dos problemas e como a ferramenta trata cada um deles.

a) Chamada de um método com argumento inválido: consegue detectar se existe tratamento de erros padrão de Java, caso exista o usuário recebe um aviso. Apenas tratamento direto e com tratamento de erros padrão de Java são detectados.

b) Chamada de um método como retorno inválido: também consegue detectar se existe tratamento de erros para o retorno do método, nesse caso é bom o projetista implementar sempre um tratamento de erros, já que esse método foi criado ou estendido para fazer a chamada. 
c) Interferência: a maioria das chamadas implementada nos exemplos causou interferência na execução do fluxo de controle que recebeu a chamada. Isso acontece porque o método disparado pela execução da chamada e o fluxo de controle existente compartilham as variáveis de classes do framework. Em Java, o problema de interferência pode ser corrigido com os mecanismos de sincronização da própria linguagem. A ferramenta consegue detectar quais métodos necessitam de sincronização. Isso é importante, uma vez que evita colocar sincronização em métodos desnecessariamente, melhorando o desempenho do framework.

d) Pré-condições do fluxo: quando um método é chamado e tal método necessita de algumas pré-condições para executar, o usuário deve estar ciente dessas pré-condições e se ela está prevista para ocorrer. A ferramenta faz exatamente isso, avisa ao usuário que um determinado método necessita de algumas précondições e quais são.

e) Deadlock: consegue detectar ciclos no grafo do novo fluxo de controle; quando um ciclo é encontrado significa que existe um deadlock. Quando isso acontece, a composição não pode ser realizada dessa maneira, o usuário deve mudar uma ou ambas as chamadas, uma vez que, quando acontece o deadlock, os dois frameworks executam de maneira incorreta, podendo até ter parada de execução.

A ferramenta é atualmente apenas um protótipo, algumas possíveis extensões são:

a) Visualização gráfica do framework: a partir da representação textual pode ser obtida uma representação gráfica das classes, objetos, métodos e fluxo de controle. Permitindo uma melhor compreensão do fluxo de controle e da composição.

b) Composição de mais de dois frameworks: a ferramenta dá suporte à composição de pares de frameworks, composição de mais frameworks ao mesmo tempo é útil e diminui o esforço durante a composição.

c) Soluções implementadas: quando um problema detectado pela ferramenta for solucionado de uma forma diferente daquela sugerida pela ferramenta, o usuário deve ser capaz de fazer uma descrição textual daquela solução. E da próxima vez que esse problema for detectado (para uma outra composição) a ferramenta pode também sugerir essa outra solução. 


\section{Capítulo 7 - Conclusões}

Framework é hoje uma das abordagens mais utilizadas para reutilizar design OO. Composição é um tópico importante em reutilização de frameworks, uma vez que hoje muitas aplicações são construídas a partir de frameworks, através da composição com outros componentes (frameworks, bibliotecas de classes, design patterns, etc). Contudo, compor frameworks com outros componentes não é ainda uma questão resolvida por completo. Dessa forma, faz-se necessário o desenvolvimento de técnicas que auxiliem o projetista durante a composição de frameworks.

Durante a composição de frameworks, surge a necessidade de compor os seus fluxos de controle. Este trabalho apresentou como compor fluxos de controle em frameworks desenvolvidos em Java. Composição de fluxos de controle de frameworks não é uma tarefa trivial, uma vez que o fluxo de controle pode ser grande e complexo, dificultando seu entendimento. Além disso, frameworks não são projetados para ser compostos. Existe uma série de problemas que podem acontecer durante a composição de fluxo de controle. Esse trabalho fez o levantamento de tais problemas e implementou uma ferramenta para verificar quando esses problemas acontecem na composição de fluxo de controle.

\section{1 - Contribuições}

As contribuições desse trabalho são:

a) Forma de composição de fluxo de controle: apresenta uma forma de compor fluxos de controle em frameworks Java baseada em troca de mensagem, sem precisar de nenhuma técnica adicional além da compreensão de conceitos de orientação a objetos, da linguagem Java e de desenvolvimento de frameworks.

b) Levantamento de problemas: foi realizado um levantamento de problemas para a composição de frameworks que se comunicam através de trocas de mensagens. Esse levantamento foi realizado para as quatro formas de composição: sem composição; seqüencial; unidirecional e bidirecional. Os problemas encontrados durante o levantamento de problemas foram: 
- Chamada de um método com argumento inválido.

- Retorno inválido da chamada de um método.

- Interferência.

- Chamada de um método que ainda não deveria ser executado (pré-condições do fluxo de controle)

- Deadlock.

c) Desenvolvimento de uma ferramenta: para fazer um diagnóstico da composição de fluxo de controle baseado nos problemas levantados, a ferramenta verifica os problemas que podem ser encontrados em uma dada composição de fluxos de controle de framework. A ferramenta detecta os problemas apenas de maneira estática e parcialmente.

d) Algumas sugestões propostas: baseado no levantamento de problemas, foram propostas algumas sugestões para os problemas encontrados, as sugestões não são completas, mas procuram diminuir o impacto dos problemas na composição de fluxos de controle.

\section{2 - Comparação com outras Abordagens}

Nessa seção serão apresentadas as comparações com outros trabalhos que resolveram o problema de composição de fluxo de controle. As soluções apresentam alguma semelhança com o presente trabalho são: concorrência; wrapping; remover e reescrever; frameworks menores e integração de laços de eventos.

a) Concorrência [1 e 42]: é uma boa opção, quando não há comunicação entre os frameworks, ou seja, cada framework tem o seu próprio fluxo de controle. A forma de composição apresentada no presente trabalho também usa essa abordagem quando não há troca de mensagens entre os frameworks.

b) Wrapping [1]: uma boa prática para implementar as comunicações, uma vez que isola todas as comunicações entre os frameworks, mas deve-se ter acesso ao código fonte e o código adicional diminui o desempenho do framework. O presente trabalho não utiliza essa forma de composição. 
c) Remover e reescrever [1]: quando a forma de comunicação desejada causar muitos problemas, pode ser a melhor forma de se implementar o novo fluxo de controle, uma vez que ele será completamente reescrito. Quando a fọma de composição desejada apresentar muitos problemas, desenvolver um novo fluxo de controle pode ser a única solução viável. No presente trabalho essa abordagem também pode ser utilizada quando a composição desejada apresentar vários problemas.

d) Frameworks menores [13 e 42]: tal solução é útil e tem bons resultados para composição de frameworks, mas aumenta substancialmente o trabalho do projetista, uma vez que ele tem que dividir os frameworks em vários frameworks menores e sem fluxo de controle (framelets) para depois fazer a composição entre eles, que por sua vez, não tem problemas de composição de fluxos de controle já que os frameworks menores são "chamados".

e) Integração de laços de eventos [52]: é apresentado um design pattern REACTOR [53] que fornece um mecanismo para integrar eventos de múltiplos frameworks, tal mecanismo se interpõe entre a fonte e o recebimento de eventos. Esse design pattern é semelhante ao adaptador de eventos utilizado no presente trabalho, mas o REACTOR pode manipular eventos compartilhados entre os frameworks, caso que não foi tratado no presente trabalho.

f) Abstract Design View (ADV) e Abstract Design Object (ADO) [51]: apresenta como compor frameworks Java para plataforma Web utilizando ADVs/ADOs que serviu como base para a criação da WebCompose; uma linguagem que permite a composição de frameworks como um conjunto de serviços que permitem colaboração entre si e composição por meio de papéis (roles). O presente trabalho apresenta composição de frameworks gerais desenvolvidos em Java (que satisfaça algumas restrições), não apenas limitados à plataforma Web.

\subsection{1 - Considerações}

O objetivo do trabalho difere um pouco dos trabalhos acima. Em [1] são apresentadas soluções gerais para frameworks existentes, não importando a forma de comunicação e a linguagem utilizada para o desenvolvimento do framework. Os trabalhos [13 e 42] apresentam soluções semelhantes, dividindo o framework em frameworks menores e sem fluxo de controle embutido, essa abordagem tem bons resultados, mas é muito trabalhosa, uma vez que um novo fluxo de controle deve ser construído. Finalmente em [51] foi 
apresentada a composição de Webframeworks (a maioria desenvolvida em Java), mas foi apresentada uma nova teoria para resolver o problema.

O trabalho apresentou composição de frameworks enfatizando a composição de fluxo de controle para frameworks Java que se comunicam apenas por troca de mensagens, mostrando os problemas que podem acontecer e algumas sugestões para contornar tais problemas. Além disso, foi desenvolvida uma ferramenta que auxilia o projetista durante a composição, detectando que problemas podem acontecer e aonde tais problemas acontecem.

\section{3 - Trabalhos Futuros}

Como trabalho futuro é possível investigar os seguintes temas:

a) Estudar problemas de composição de eventos: o trabalho estudou apenas os problemas com composição baseada em fluxo de controle. Os problemas de composição baseados em eventos poderiam ser estudados e verificados: quais problemas são semelhantes, quais problemas não acontecem e quais problemas têm a mais.

b) Estudar outros problemas de composição: estudar os outros problemas de composição de frameworks: composição com sistemas legados, frameworks gap, sobreposição de entidades e composição de funcionalidade de entidade. Com comunicações baseadas tanto em troca de mensagens como em eventos.

c) Estudar os problemas de composição de frameworks para a criação de uma aplicação: estudar se os problemas encontrados para a construção de uma aplicação baseada em mais de um framework são os mesmos problemas encontrados para a criação de um novo framework.

d) Outras linguagens: estudar o problema de composição de fluxo de controle em frameworks desenvolvidos em outras linguagens orientadas a objeto: como $\mathrm{C}++$ ou Delphi, por exemplo. E verificar se os problemas e as soluções para Java são aplicáveis também a outras linguagens.

e) Evolução da ferramenta: implementar as extensões da ferramenta propostas na Seção 6.5. Um resumo das extensões é: (i) visualização gráfica do framework e (ii) disponibilizar soluções implementadas e (iii) composição de mais de dois frameworks. 


\section{Bibliografia}

[1] Michel Mattsson e Jan BOSCH. Framework Composition: Problems, Causes and Solutions. Proceedings TOOLS USA'97, 1997, pp.1-17.

[2] Ralph Jonhson e Vicent RUSSO, Vicent. Reusing Object Oriented Design, 1991, 34 pp.

[3] Mohamed Fayad e Douglas Schmidt. Object Oriented Application Frameworks, Communications of the $A C M, 40(10), 1997$, pp.32-38.

[4] Erich Gamma, et al. Design Patterns: Elements of Reusable Object-Oriented Software, AddisonWesley, Reading, MA, Dez, 1994.

[5] Ralph E. Johnson, Documenting Frameworks Using Patterns, Object-Oriented Programming Systems, Languages, and Applications - OOPSLA'92, 1992.

[6] Joseph W Yoder, Patterns for Developing Successful Object-Oriented Frameworks. Position Paper, Conference on Developing Successful Object Oriented Frameworks, 1997, pp.72-76.

[7] Ralph Jonhson. Components, Frameworks, Patterns, 1997, 23 pp.

[8] Hermann Huni, Ralph Jonhson e Robert Engel. A Framework for Network Protocol Software. $A C M, 1995,12 \mathrm{pp}$.

[9] Paul Dustin Keefer. An Object Oriented Framework for Accounting Systems. Master Thesis, University of Illinois at Urbana-Champaign, 1994, 86 pp.

[10] Peter Molin. Applying the Object-Oriented Framework Technique to a Family of Embedded Systems. Ronneby, Austria, Universidade de Karlskrons/Ronneby, 1997, 11 pp.

[11] Jan Bosch. An Object-Oriented Framework for Measurement Systems. Ronneby, Austria, Universidade de Karlskrons/Ronneby, 1996, 15 pp.

[12] Jan Bosch, Peter Molin, Michael Mattsson e PerOlof Bengtsson. Object-Oriented Frameworks Problems \& Experiences. Ronneby, Suécia, Universidade de Karlskrons/Ronneby, 1997, 18 pp.

[13] Wolfgang Pree e Kai Koskimies. Framelets-Small Is Beautiful. In: Building Application Frameworks: Object Oriented Foundations of Framework Design Eds: M. E. Fayad, D. C. Schmidt, R. E. Johnson, Wiley \& Sons, 1999. pp. 411.

[14] Peter Deutsch. Design and Reuse and Frameworks in the Smalltalk-80 System. Ted J. Biggerstaff e Alan J. Perlis, Software Reusability Volume II Applications and Experiences, ACM Press, 1989. pp. 57-71.

[15] Greg Butler, L Li. e TJANDRA, I. A. Tjandra. Reusable Object-Oriented Design, 1994, 25 pp. 
[16] Wolfgang Pree. Design Patterns for Object Oriented Software Development. Reading: AddisonWesley, 1995, pp. 268.

[17] Serge Demeyer, Theo Dirk Meijler, Oscar Niertrasz e Patrick Steyart. Design Guidelines for 'Tailorable' Frameworks. Communications of the ACM: 40(10), 1997, pp. 60-64.

[18] Garry Frohlich et. al. Using Object-Oriented Frameworks. 1998, 30 pp.

[19]] Ralph Jonhson e Brien Foore. Designing Reusable Classes. Journal of Object Oriented Programming. June/July, 1998.

[20] Rebecca J Wirfs Brock. e Ralph Jonhson. Current Research in Object-Oriented Design. Communications of the ACM: 33(9), 1990, pp. 104-124.

[21] Ricardo Pereira Silva. Avaliação de Metodologias de Análise e Projeto Orientadas a Objetos Voltadas ao Desenvolvimento de Aplicações, Sob a Ótica de Sua Utilização no Desenvolvimento de Frameworks Orientados a Objetos. Universidade Federal do Rio Grande do Sul, 1996, 125 pp.

[22] André Weinand, Erich Gamma e Rudolf Marty. Design and Implementation of ET++, a seamless Object Oriented Application Framework, 1989, 35 pp.

[23] Wai Ming Ho e Jean-Marc Jéséquel. Object-Oriented Frameworks for Distributed Systems: A Survey. INRIA, No 3590, 1998, 22 pp.

[24] Douglas C Schmidt. An Architectural Overview of the ACE Framework A Case study of Successful Cross-platform Systems Software Reuse. USENIX Login, 1998.

[25] SUN Microsystems. Java Commerce Framework Internationalization Specification, March, 1999, 5 pp.

[26] TALIGENT Software. Building Object Oriented Frameworks, 1995, 23 pp.

[27] Don Roberts e Ralph Johnson. 1997. Evolving Frameworks - A Pattern Language for Developing Object-Oriented Frameworks. In: RIEHLE, D.; BUSCHMANN, F. (eds) Patterns Language of Program Design 3. Addison-Wesley Reading, 1997.

[28] Ralph Johnson. How to Design Frameworks. Tutorial Notes, OOPSLA'93, 1993, 56 pp.

[29] Marcus Felipe Fontoura. A Systematic Approach to Framework Development. Pontificia Universidade Católica - Departamento de Informática - Tese de Doutorado, 1999. 165 pp.

[30] Garry Frohlich, et. al. Designing Object-Oriented Frameworks, 1998, 30 pp.

[31] Erich Gamma, André Weinand e Rudolf Marty. Integration of an Programming into ET++ a Case Study. ECOOP'89. 1989.

[32] SUN Microsystems. Input Method Framework. 1999. Disponível em http://www.javasoft.com/. 
[33] Neelan Soundarajan. Understanding Frameworks. Ohio State University, Computer and Information Science, 1997, 16 pp.

[34] Steve Sparks, Kevin Benner e Chris Faris. Managing Object-Oriented Framework Reuse. IEEE Computer, 1996, pp. 52-61.

[35] Michael Mattson. Evolution and Composition of Object-Oriented Frameworks, University of KarlsKrona/Ronneby, Department of Software Engineering and Computer Science. Ph.D. thesis. Sweden, 2000, 216 pp.

[36] PerOlof Bengtsson. Object Oriented Frameworks: Development issues. 1997, 23 pp.

[37] Antti Viljamaa. Tools Supporting the Use of Design Patterns in Frameworks. University of Helsinki, Department of Computer Sciences. C-1997-25, March, 1997, pp. 38 pp.

[38] Doug Lea. Concurrent Programming in Java Design Principles and Patterns. Addison-Wesley: Reading, Massachusetts, 1996, 339 pp.

[39] Doug Lea. Design for Open System in Java. 1997. 23 pp.

[40] SUN Microsystems. JavaBeans API specification. Sun White Paper. 1997, 114 pp.

[41] Grady Booch, James Rumbaught e Ivar Jacobson. UML Guia do Usuário. Editora Campus., 2000, $472 \mathrm{pp}$.

[42] Garry Frohlich et. al. Application Framework Issues when Evolving Business Applications for Electronic Commerce. 1998. 10pp.

[43] James Rumbaught et al. 1994. Modelagem e Projetos Baseados em Objetos. Rio de Janeiro: Editora Campus.

[44] SUN Microsystems. Java Media Framework API. 1999. Disponível em http://.javasoft.com/jmf.

[45] Ken Auer. Fundamental Elements of an Extendible Java Framework. 1998. 15 pp.

[46] Desmond D'Souza. Frameworks in Java and Catalysis. 1996. 8 pp.

[47] Juha Hautamaki. A Survey of Frameworks. 1997, 31 pp.

[48] Oscar Nierstrasz. Research Topics in Software Composition. Proceedings, Langueges et Modèles à Objects, 1995, pp. 193-204.

[49] Ivica Crnkovicet al. Object-Oriented Design Frameworks: Formal Specification and Some Implementation Issues. 2000, 15 pp.

[50] Michel Mattson. Framework Integration Problems, Causes, Solutions. Communications of the ACM: 42(10). 1999, pp. 80-87.

[51] Sérgio Pinto. Composição em WebFrameworks. Tese de Doutorado, Departamento de Informática, Pontificia Universidade Católica do Rio de Janeiro. 200, 216 pp. 
[52] Irfan Pyarali, Tim Harrison e Douglas C Schmidt e Thomas D Jordan. Design and Performance of an Object-Oriented Framework for High-Speed Electronic Medical Imaging. Computing Systems Journal, USENIX: 9(4). 1996.

[53] Douglas C Schmidt. Reactor: An Object Behavioral Patterns for Concurrent Event Demultiplexing and Event Handler Dispatching, in Patterns Language am Program Design, Reading, MA:AddisonWesley. 1996.

[54] Andrew S. Tanenbaum. Sistemas Operacionais Modernos, Prentice Hall do Brasil: Rio de Janeiro, 1995, pp. 493.

[55] He Zhu e Ian Watson. 1996. A Full Program Control Flow Representation for Real Programs. 1996, 4 pp.

[56] Michael Mattsson. 1996. Object-Oriented Framework - A survey of methodological issues. Lund University, 1996, $102 \mathrm{pp}$.

[57] Simon Moser e Oscar Nierstrasz. The Effect of Object-Oriented Framework on Developer Productivity. IEEE Computer, 1996, 45-51p.

[58] Deborah Adair. Building Object-Oriented Frameworks. AIXpert May, 1995, 20 pp.

[59] Paulo Alencar et al. Pragmatic Issues Behind Framework Design. 2000, 5 pp.

[60] Mehmet Askit. Composition and Separation of Concerns in the Object-Oriented Model. ACM Computing Surveys, 28(4), 1996.

[61] Grady Booch. Designing an Application Framework. Dr. Dobb's Journal: 19(2). 1994, pp24-32.

[62] Ruth Breu e Radu Grosu. Modeling the Dynamic Behavior of Objects On Events, Messages and Methods. Technische Universität München, Institut für Informatik. TUM-I9804, 1998, 15 pp.

[63] David Papurt e Pierre LeJacq. Design with Java: Resource Management. Journal of ObjectOriented Programming. 1997.

[64] Einar Dehli. Developing Successful OO Frameworks. Position Paper, Conference on Developing Successful Object Oriented Frameworks, 1997, pp 33-41.

[65] David Garlan, Robert Allen e John Ockerblomm. Architectural Mismatch or why it's hard to build systems out of existing parts. Proceedings of the Seventeenth International Conference on Software Engineering. 1995.

[66] Jilles van Gurp. Design Principles for Reusable, Composable and Extensible Frameworks. Dissertação de Mestrado, 1999, 103pp.

[67] Niklas Landin e Axel Niklasson. Development of Object-Oriented Framework. Lund University, Department of Communication Systems. Master thesis, 1995, 198 pp. 


\section{Apêndice A - Exemplos de Composição dos Frameworks Java}

Nesse apêndice são apresentados os exemplos de composição de frameworks desenvolvidos em Java. São apresentados os quatro exemplos de composição utilizados no presente trabalho: Projetos + Financiamento, Projetos + Publicação, Projeto + Espécies, Publicação + Espécie.

\section{A.1 - Projeto + Financiamento}

Essa composição é um exemplo de composição sem comunicação e deve ser usada para representar projetos e pesquisas juntamente com suas fontes de financiamento. Nenhuma alteração foi feita nas classes e interface dos frameworks e também nenhum outro elemento foi adicionado durante a composição. $\mathrm{O}$ diagrama de classes para tal composição é apresentado na Figura A.1.

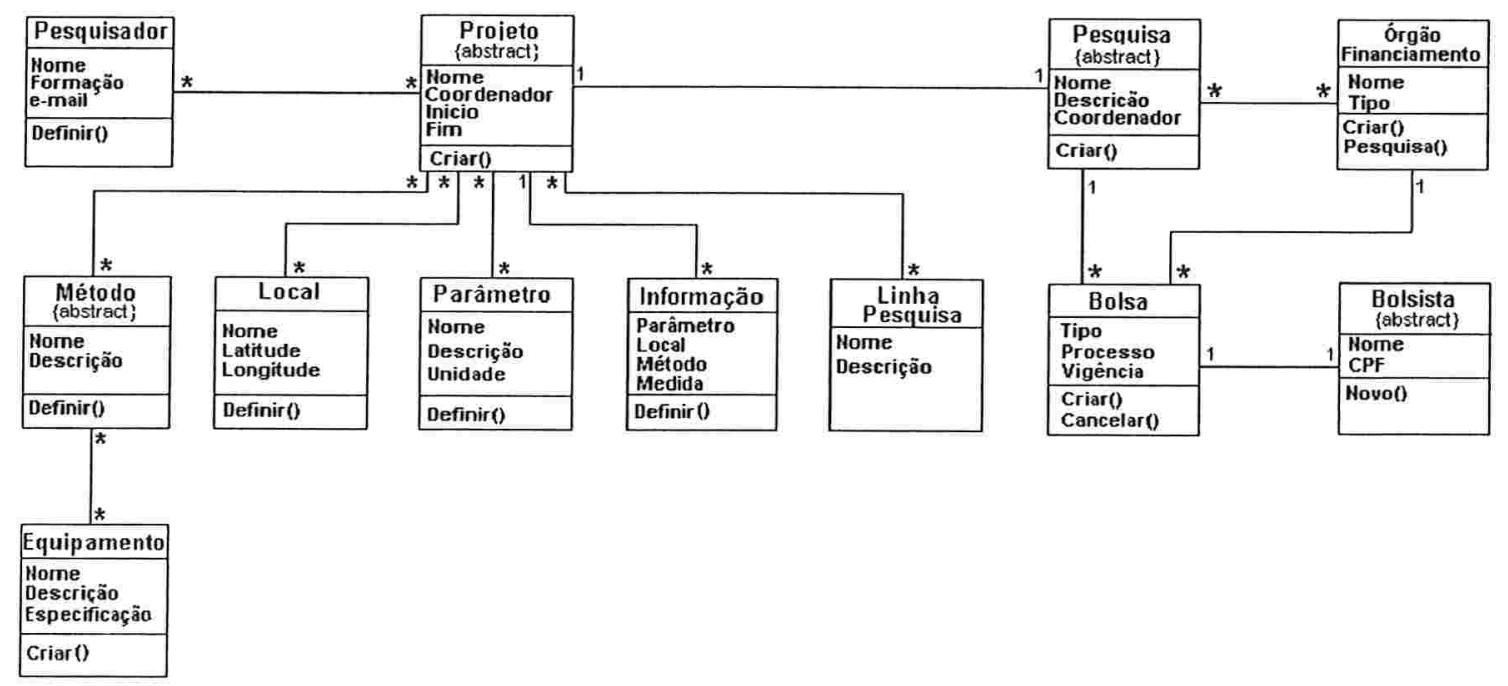

Figura A.1: Diagrama de Classes para a Composição Projeto + Financiamento 
O novo fluxo de controle é a execução dos dois fluxos de controle como mostrado na Figura A.2. Os passos utilizados para implementar o novo fluxo de controle são apresentados abaixo.

- Passo1 - Extensão do fluxo de controle: como não há comunicação entre os frameworks não são necessárias extensões no fluxo de controle.

- Passo2 - Implementação do novo fluxo de controle

2.1 - Ativação dos frameworks: como os dois são implementados através da criação de uma thread, a ordem de ativação não influenciará o resultado final.

2.2 - Implementação do fluxo de controle: os fluxos de controle são implementados através da criação de uma thread, de forma que eles possam executar em paralelo.

2.3 - Implementação do método ma in: um método main foi criado para a composição.
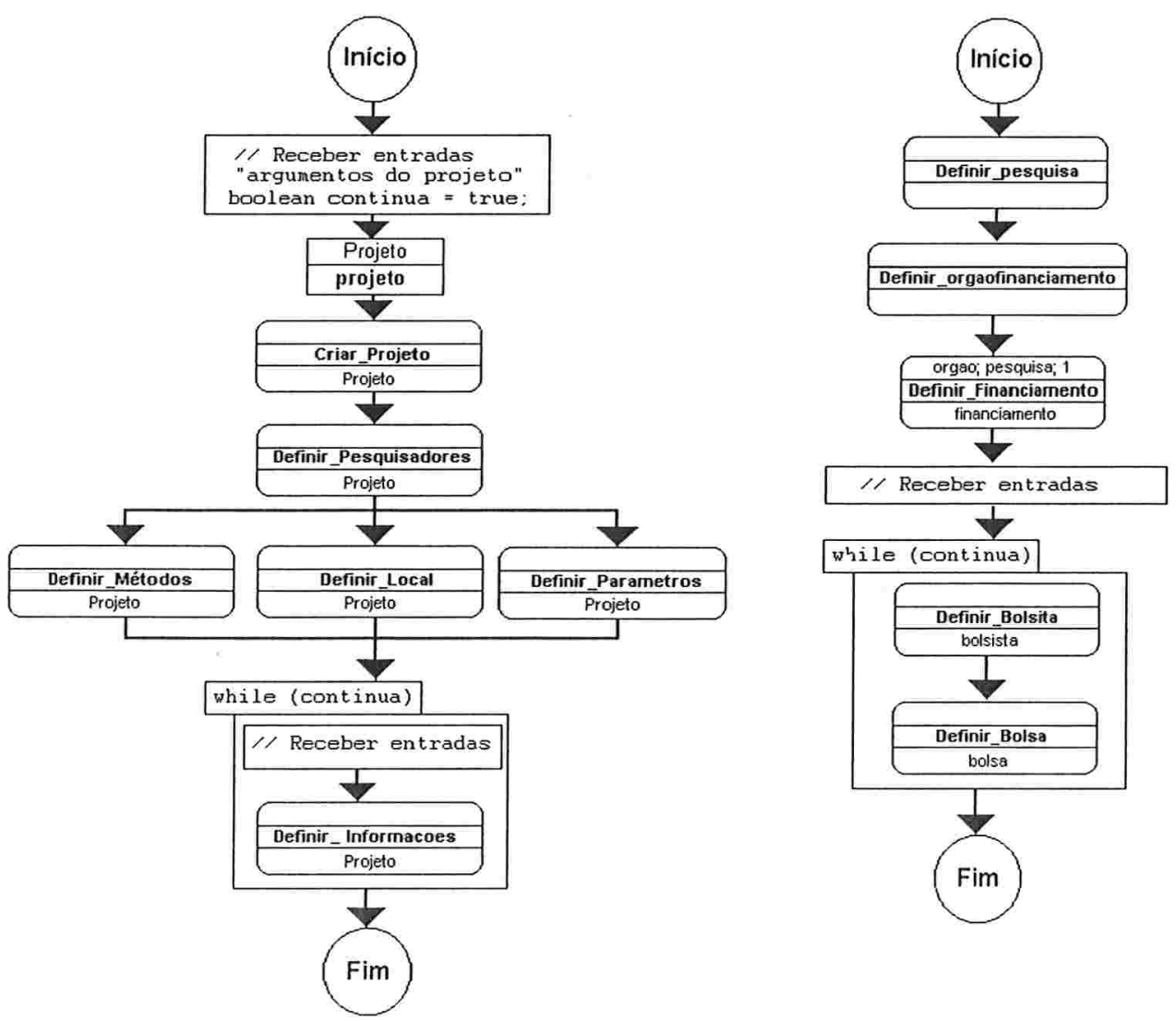

Figura A.2: Fluxo de Controle para a Composição Projeto + Financiamento 


\section{A. 2 - Projeto + Publicação}

A composição do framework Projeto com o framework Publicação é um exemplo de composição seqüencial. A composição foi realizada para o novo framework tratar de projetos mais as publicações realizadas durante a vigência do mesmo. A extensão realizada na parte estática do framework foi:

- Extensão para modificação: criação e uma classe Projeto_Publicacao estendida da classe Projeto do framework Projeto. A extensão representa agora as publicações realizadas dentro de um determinado projeto. Nessa classe é que se realiza a troca de mensagens implementada no método Definir_publicacao().

A Figura A.3 apresenta o diagrama de classes para a composição.

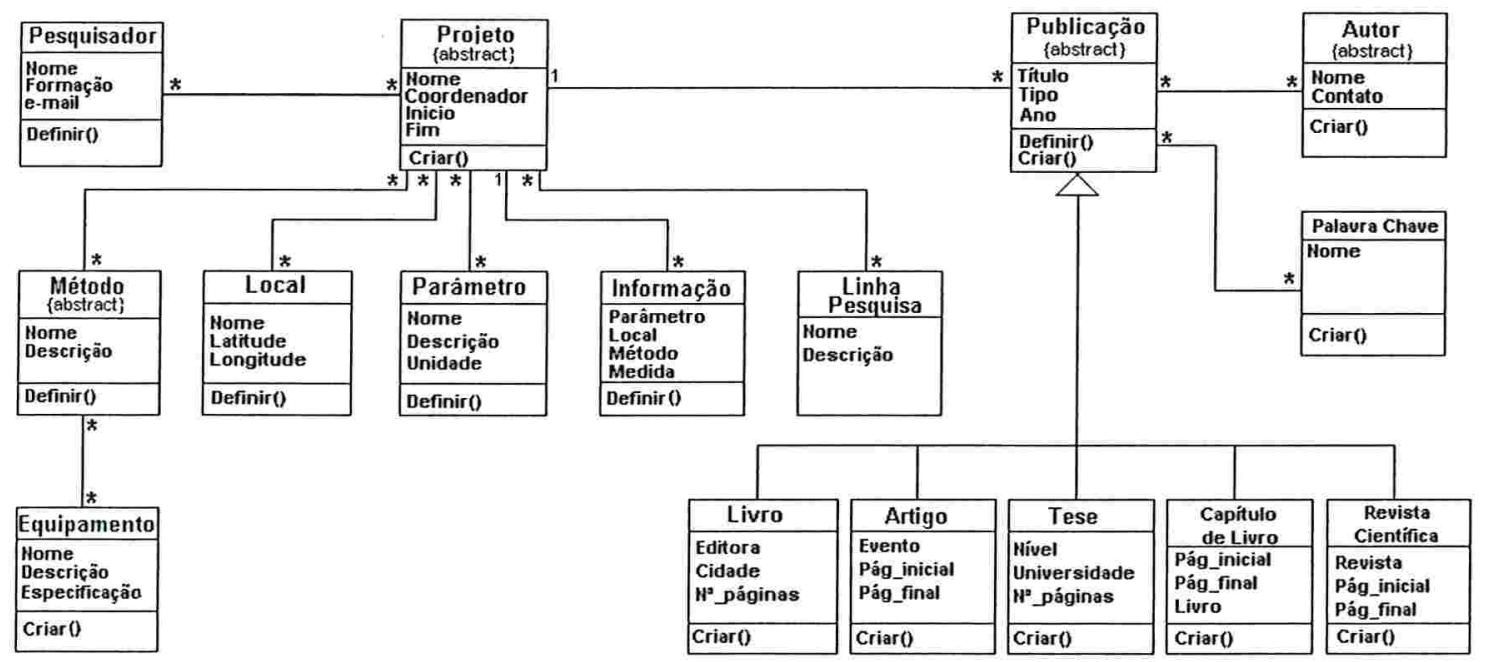

Figura A.3: Diagrama de Classes para a Composição Projeto + Publicação

O novo fluxo de controle é a execução seqüencial dos fluxos de controle, sendo que o fluxo de controle do framework Projeto executa primeiro e depois chama o fluxo de controle do framework Publicação. Os passos utilizados para realizar a composição do fluxo de controle são apresentados abaixo.

- Passo1 - Extensão do fluxo de controle: foram realizadas duas extensões do fluxo de controle do framework Projeto:

(i) modificar objeto: o objeto projeto derivado da classe Projeto foi modificado para ser derivado da classe Projeto_Publicacao. 
(ii) adicionar nó: foi adicionado para realizar a troca de mensagem no fluxo de controle, esse nó é a chamada do método Definir_Publicacao() sobre o objeto projeto.

- Passo2 - Implementação do novo fluxo de controle

2.1 - Ativação dos frameworks: como a composição é seqüencial apenas o fluxo de controle do framework Projeto é ativado.

2.2 - Implementação do fluxo de controle: os fluxos de controle são implementados através da chamada do método que inicia o fluxo de controle do framework Projeto.

2.3 - Implementação do método main: um método main foi criado para a composição.

O fluxo de controle para a composição é apresentado na Figura A.4 abaixo:

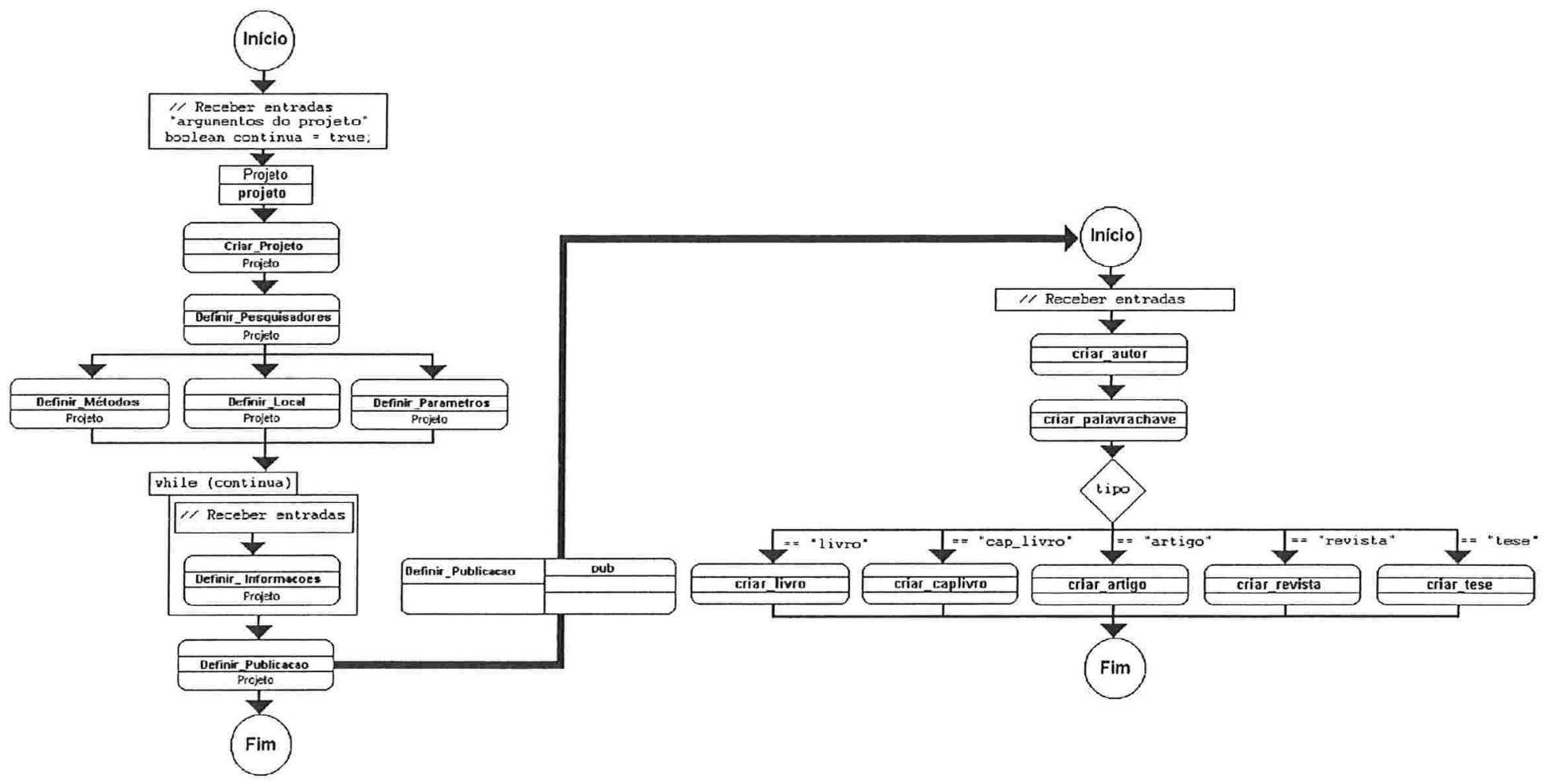

Figura A.4: Fluxo de Controle para a Composição Projeto + Publicação 


\section{A.3 - Projeto + Espécie}

A composição do framework Projeto com o framework Espécie é utilizada para representar informações de projetos, sendo que as informações geradas pelos projetos são relacionadas a alguma taxonomia de espécie. Ela é um exemplo de composição unidirecional, onde apenas um framework (Projeto) manda mensagens para o outro framework (Espécie). Para essa composição foram realizadas duas extensões para modificar classes existentes, ambas realizadas no framework Projeto:

- Informacao_Especie: estendida da classe Informacao, tal extensão serve para representar informações relacionadas a uma determinada espécie. A extensão foi realizada adicionando uma variável de instância especie do tipo Especie (classe do framework Espécie).

- Projeto_Novo: estendida da classe Projeto para representa projetos de pesquisa que tem informação relacionadas a espécies. Para isso foi adicionado um novo método Definir_Especie (), onde se realiza a troca de mensagem.

A Figura A.5 apresenta o diagrama de classes para o framework resultante da composição.

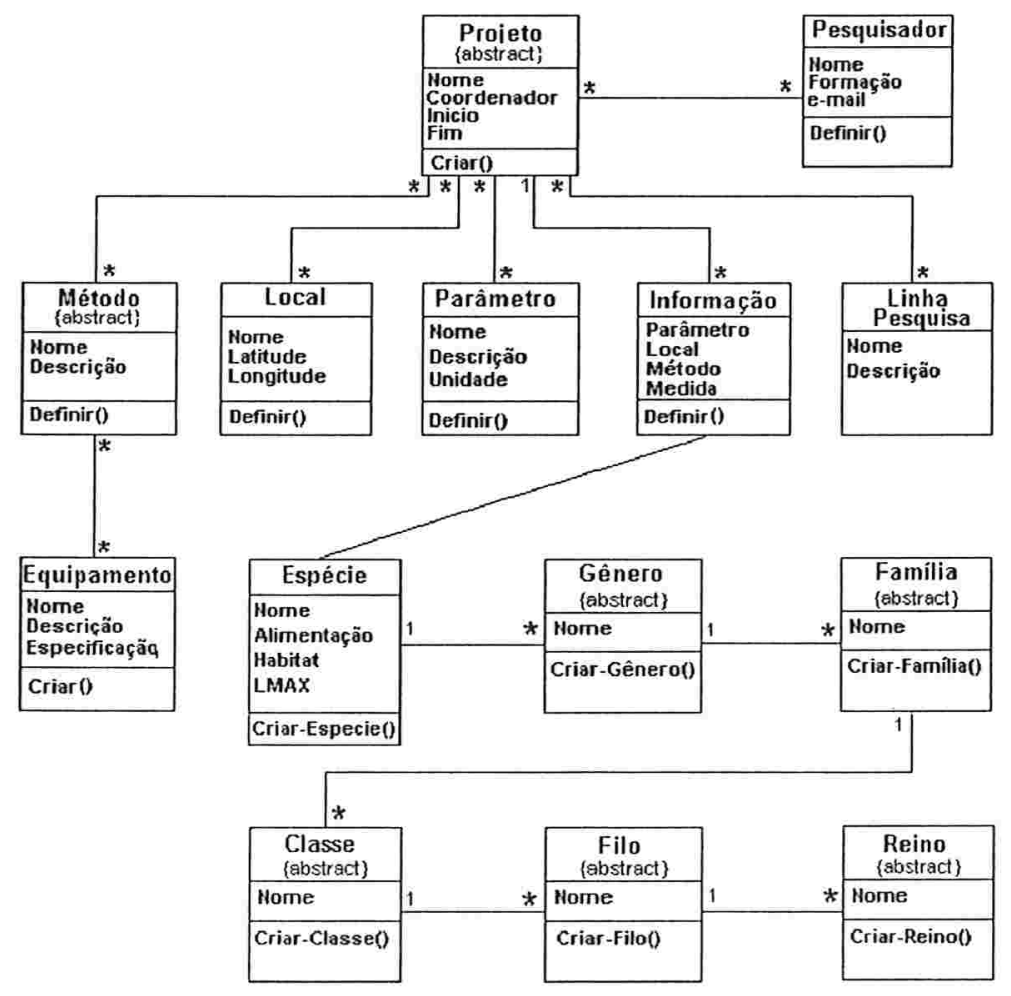

Figura A.5: Diagrama de Classes para a Composição Projeto + Espécie 
O novo fluxo de controle é a execução em paralelo dos fluxos de controle. E o framework Projeto manda algumas mensagens para o framework Espécie. Os passos utilizados para realizar tal composição são:

- Passo1 - Extensão do fluxo de controle: foram realizadas duas extensões do fluxo de controle do framework Projeto:

(i) modificar objeto: o objeto projeto derivado da classe Projeto foi modificado para ser derivado da classe Proj eto_Novo.

(ii) adicionar nó: foi adicionado para realizar a troca de mensagem no fluxo de controle, esse nó é a chamada do método Definir_Especie() sobre o objeto projeto.

- Passo2 - Implementação do novo fluxo de controle

2.1 - Ativação dos frameworks: como os dois são implementados através da criação de uma thread, a ordem de ativação não influenciará o resultado final.

2.2 - Implementação do fluxo de controle: os fluxos de controle são implementados através da criação de uma thread.

2.3 - Implementação do método ma in: um método main foi criado para a composição.

A Figura A.6 apresenta o fluxo de controle para a composição. 


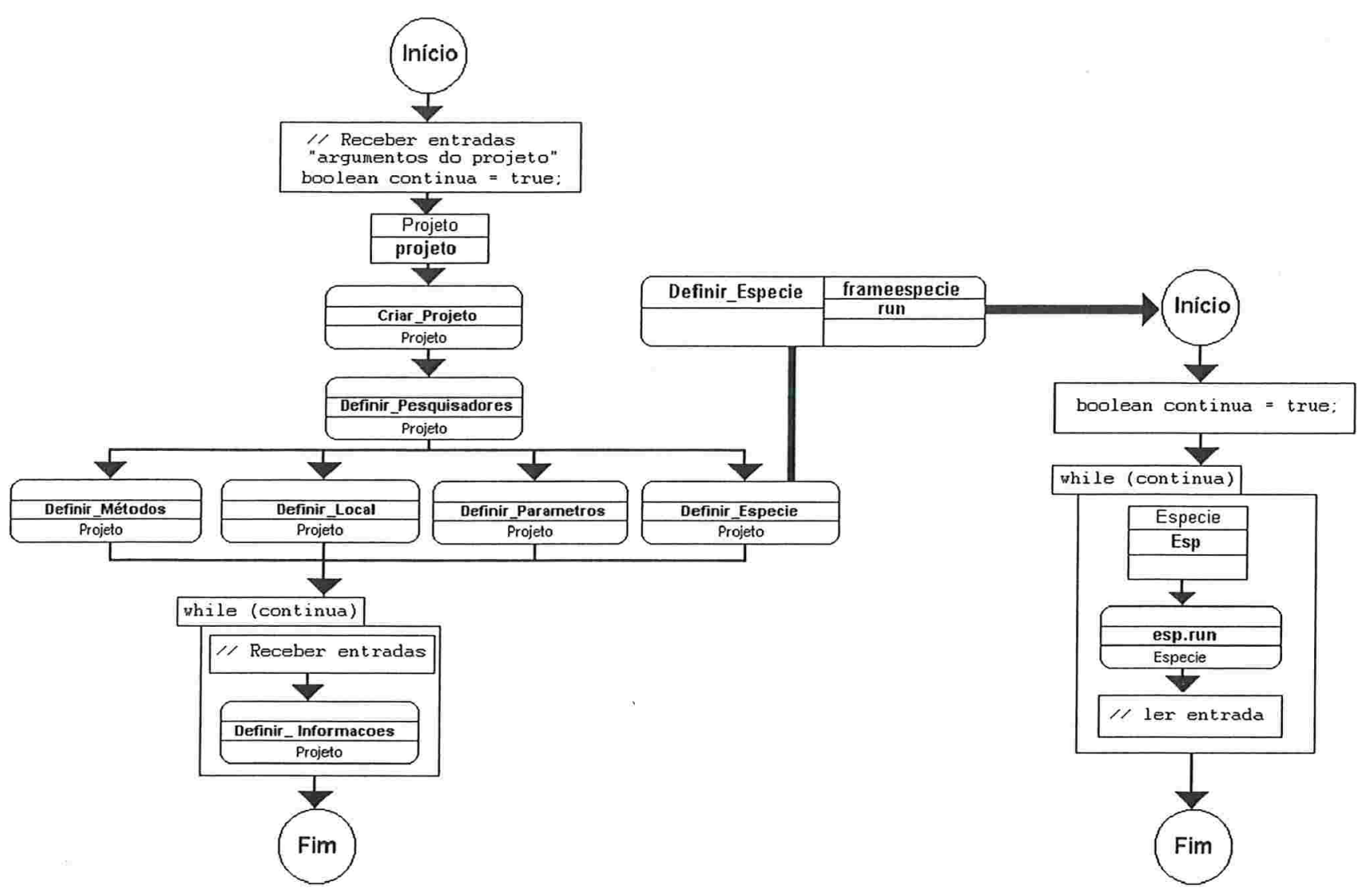

Figura A.6: Fluxo de Controle para a Composição Projeto + Espécie

\section{A.4 - Publicação+ Espécie}

A composição do framework Espécie com o framework Publicação é um exemplo de composição bidirecional. A composição deve tratar de publicações que têm como palavra-chave alguma espécie e saber quando uma determinada espécie foi citada pela primeira vez em uma publicação. Para isso foram feitas as seguintes extensões para modificações:

- Espécie_N: estendida da classe Especie do framework Espécie, tal extensão serve para representar quando uma determinada espécie foi citada na primeira vez na literatura, para isso foi adicionada uma variável de instância publicacao da classe Publicaćao. Nessa classe existe uma troca de mensagem implementada no método Definir_Publicacao().

- Palavra_chave_N: estendida da classe Palavra_chave do framework Publicacao para representa palavras-chaves que tem como nome uma determinada espécie. Para isso foi 
adicionada uma variável de instância especie da classe Especie e um novo método Definir_Especie (), onde se realiza a troca de mensagem do framework Publicação.

A Figura A.7 apresenta a parte estática do novo framework.

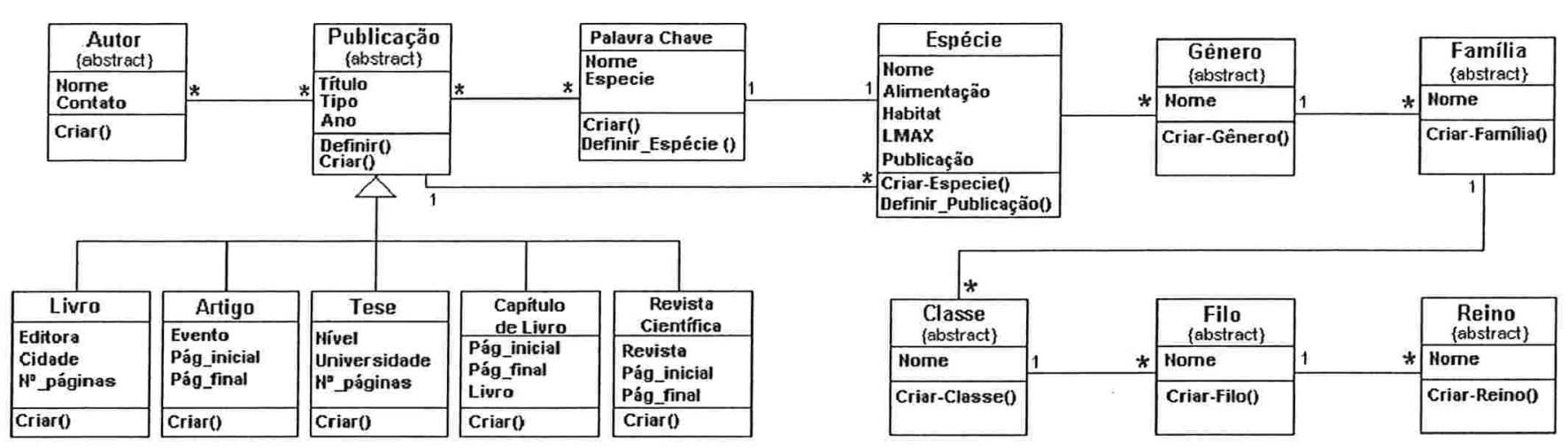

Figura A.7: Diagrama de Classes para a Composição Publicação + Espécie

O novo fluxo de controle é a execução em paralelo dos fluxos de controle. Nessa composição ambos os frameworks trocam mensagens. Os passos utilizados para realizar tal composição são:

- Passo1 - Extensão do fluxo de controle: foram realizadas três extensões do fluxo de controle, sendo que duas em cada framework. As extensões no framework Publicação foram:

(i) modificar objeto: o objeto palavra derivado da classe Palavra_chave foi modificado para ser derivado da classe Palavra_chave_N.

As extensões no framework Espécie foram:

(ii) modificar objeto: o objeto especie derivado da classe Especie foi modificado para ser derivado da classe Especie_N.

(iii) modificar nó: foi adicionado para realizar a troca de mensagem no fluxo de controle, esse nó é a chamada do método Definir_Publicacao() sobre o objeto especie.

- Passo2 - Implementação do novo fluxo de controle

2.1 - Ativação dos frameworks: como os dois são implementados através da criação de uma thread, a ordem de ativação não influenciará o resultado final. 
2.2 - Implementação do fluxo de controle: os fluxos de controle são implementados através da criação de uma thread.

2.3 - Implementação do método main: um método main foi criado para a composição.

O novo fluxo de controle é apresentado na Figura A.8.

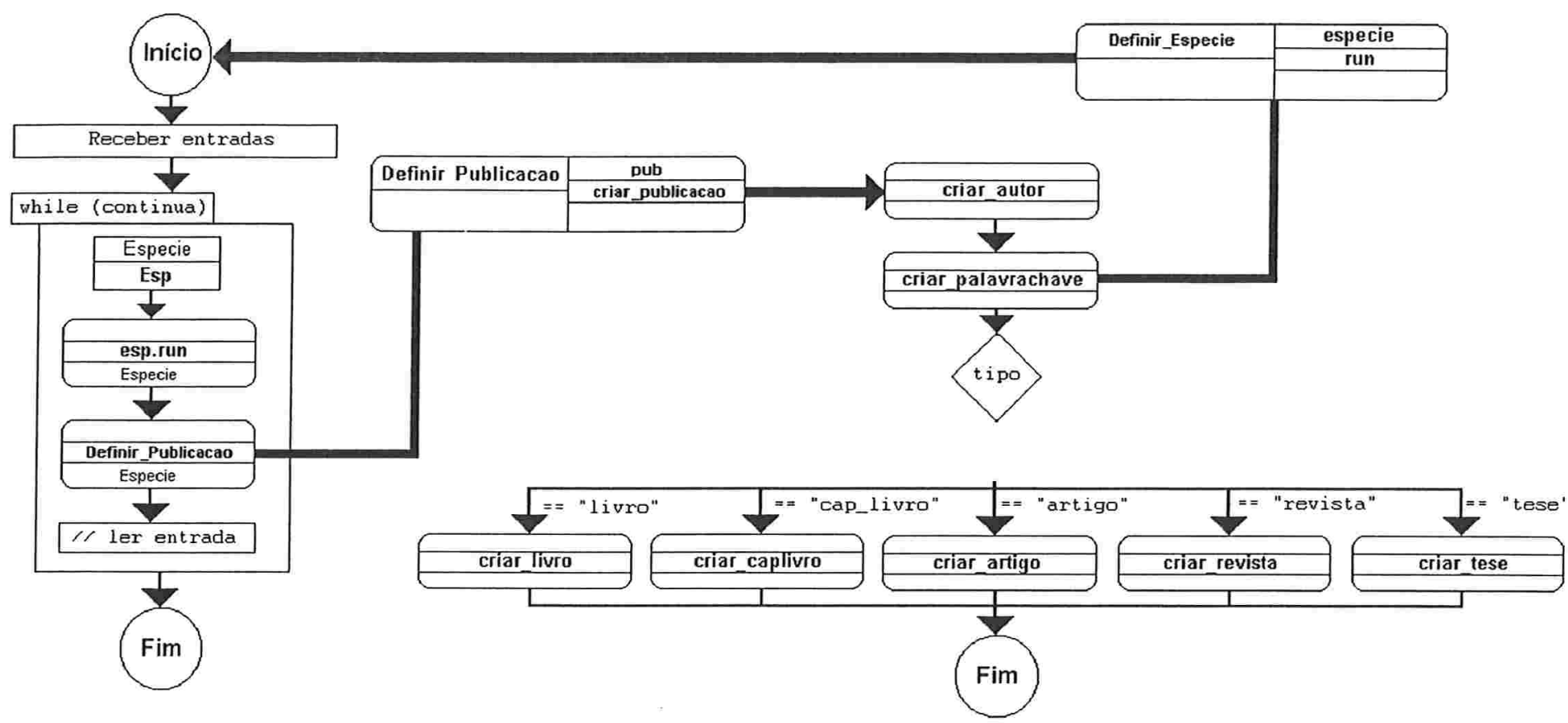

Figura A.8: Fluxo de Controle para a Composição Publicação + Espécie 